OECDpublishing

\title{
MISSION-ORIENTED INNOVATION POLICY IN NORWAY
}

CHALLENGES, OPPORTUNITIES AND FUTURE OPTIONS

OECD SCIENCE, TECHNOLOGY AND INDUSTRY POLICY PAPERS April 2021 No. 104 
This paper was approved and declassified by written procedure by the Committee for Scientific and Technological Policy (CSTP) on 4 March 2021 and prepared for publication by the OECD Secretariat.

Note to Delegations:

This document is also available on O.N.E. under the reference code:

DSTI/ STP(2020)27/FINAL

This document, as well as any data and any map included herein, are without prejudice to the status of or sovereignty over any territory, to the delimitation of international frontiers and boundaries and to the name of any territory, city or area

The statistical data for Israel are supplied by and under the responsibility of the relevant Israeli authorities. The use of such data by the OECD is without prejudice to the status of the Golan Heights, East Jerusalem and Israeli settlements in the West Bank under the terms of international law

Note by Turkey:

The information in this document with reference to "Cyprus" relates to the southern part of the Island. There is no single authority representing both Turkish and Greek Cypriot people on the Island. Turkey recognises the Turkish Republic of Northern Cyprus (TRNC). Until a lasting and equitable solution is found within the context of the United Nations, Turkey shall preserve its position concerning the "Cyprus issue".

Note by all the European Union Member States of the OECD and the European Union:

The Republic of Cyprus is recognised by all members of the United Nations with the exception of Turkey. The information in this document relates to the area under the effective control of the Government of the Republic of Cyprus.

COECD 2021

The use of this work, whether digital or print, is governed by the Terms and Conditions to be found at http://www.oecd.org/termsandconditions. 


\title{
Challenges and opportunities of mission-oriented innovation policy in Norway
}

\author{
By Philippe Larrue
}

(OECD Directorate for Science, Technology and Innovation)

\begin{abstract}
This report assesses the potential for mission-oriented innovation policies (MOIPs) to contribute to the sustainable transition in Norway, and examines the challenges and opportunities that MOIPs would present. As part of a series of MOIP national case studies, the report finds that MOIPs could contribute significantly to alleviating some of the long-standing limitations of Norway's innovation system, acknowledging the country's strong advantages for mission-orientation and its innovative policy experimentations, such as the Pilot-E scheme and the CLIMIT programme. It proposes two options for Norway's future MOIP approach, with corresponding recommendations. Under a 'scaling-up' option, Norway would develop a system to manage the implementation of cross-agency schemes in relevant challenge areas. A 'levelling-up' option would involve the programming of a pilot mission in the four-year investment plan of the next edition of Norway's Long Term Plan, with support from high-level policy and political actors.
\end{abstract}

Keywords: Science and technology, Innovation, societal challenges

JEL codes: O14, O25, O38, Q55 


\section{Acknowledgements}

This report has been prepared and drafted by Philippe Larrue, who is responsible within the OECD Secretariat for the project on the design and implementation of mission-oriented innovation policies to address societal challenges, conducted under the aegis of the OECD Committee for Scientific and Technological Policy (CSTP) during the biennium 2019-2020. The main results of the CSTP project are synthesised in the OECD Science Technology and Industry Policy Paper $\mathrm{N}^{\circ} 100$ (https://doi.org/10.1787/3f6c76a4-en).

We wish to acknowledge the essential contribution of Svend Otto Remøe, Special Adviser at the Research Council of Norway, to this case study. (RCN). We are also grateful to RCN management for their continuous support, in particular John-Arne Rottingen, Chief Executive at the time of this study, as well as Randi Søgnen, Chief of Staff; Fritjof Fossum Unander, Executive Director; and Rune Volla, Director of the Department for Energy.

Detailed information on the Pilot-E and CLIMIT initiatives are available on the MOIP Online Toolkit (https://stip.oecd.org/stip/moip), a comprehensive knowledge platform on mission-oriented innovation policies. The development of the MOIP Online Toolkit was funded from the European Union's Horizon 2020 research and innovation programme.

The document benefited from a review by Alessandra Colecchia, head of the Scientific and Technology Policy (STP) division and by the Science, Technology and Industry Director's Office. Blandine Serve provided valuable statistical support and Bora Kim careful proofreading (both from the Science and Technology Policy division, OECD).

Drafts of the case study report went through fact-checking coordinated by Svend Otto Remøe. The author would like to thank all those who provided comments and inputs during this process of validation.

This study also benefited from the discussions held in a workshop organised by the RCN International Advisory Board on 27 March 2020. The results of this study were presented at RCN's annual 'Knowledge base' conference on 25 November 2020, coordinated by Svein Olav Nås, Special Adviser at RCN.

Finally, the project has benefited from plenty of interactions with many policy makers, researchers and stakeholders during the on-site mission in Norway in January 2020.

This work received voluntary contribution funding from RCN. 


\section{Table of contents}

Challenges and opportunities of mission-oriented innovation policy in Norway......................................... 3

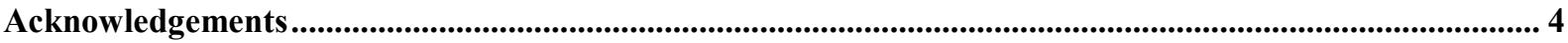

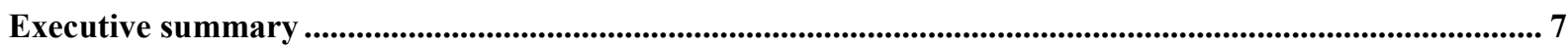

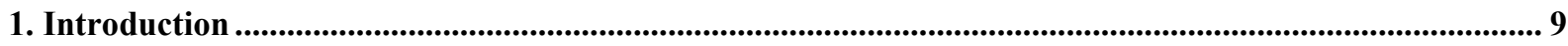

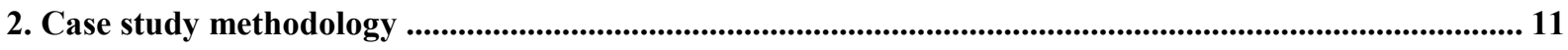

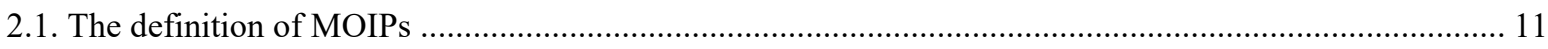

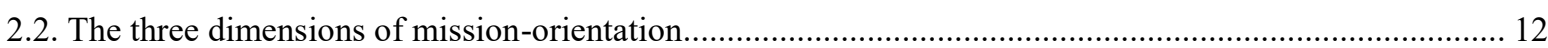

3. Framework conditions for mission-orientation in Norway ............................................................................ 13

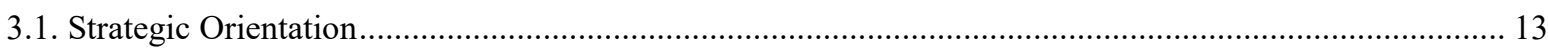

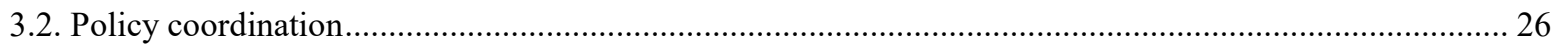

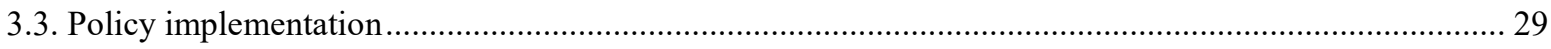

4. Mission-oriented policy initiatives in practice .....................................................................................................36

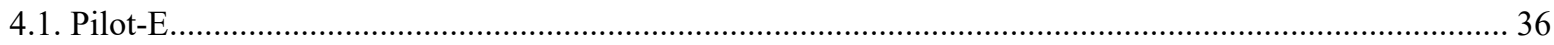

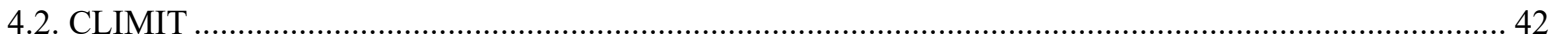

5. Conclusions and options for the future of the mission-oriented policy agenda in Norway ....................... 47

5.1. The Norwegian STI institutional setting is conducive to mission-orientation...................................... 47

5.2. Several well-established MOIP initiatives help raise awareness and learning on mission-orientation .... 50

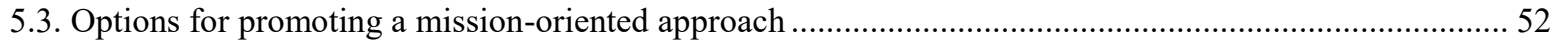

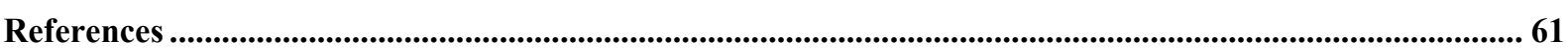

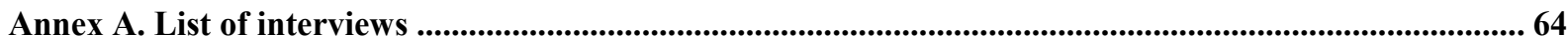

\section{FIGURES}

$\begin{array}{lr}\text { Figure 1. Structure of the case study report } & 10\end{array}$

Figure 2. The definition of MOIPs and the three MOIP dimensions 11

Figure 3. Government budget allocations to R\&D (GBARD), (2019 and 2013) 14

Figure 4. Gross domestic spending on R\&D (GERD) (2018 and 2013) 15 


\section{6 | MISSION-ORIENTED INNOVATION POLICY IN NORWAY}

Figure 5. GERD, financed by government (2013 and 2018 or latest) 15

Figure 6. Oriented and non-oriented government R\&D budget (2020 or latest year available) 16

Figure 7. Government R\&D budgets by SDG-related category, $2018 \quad 19$

Figure 8. Objectives of the revised Long-term plan for research and higher education 2019-2028 21

Figure 9. Direct government funding of business R\&D and tax incentives for R\&D, Norway, 2000-18 33

Figure 10. Direct and indirect government support to business R\&D, 2018 and $2006 \quad 34$

Figure 11. Percentages of institutional and project funding, year? 35

Figure 12. Synthesis of the process, governance and MOIP features of Pilot-E 38

Figure 13. Pilot-E as a fast-tracking scheme across sectors and stages of the innovation chain 41

Figure 14. Synthesis of the process, governance and MOIP features of CLIMIT $\quad 43$

Figure 15. CLIMIT and the exploration of different versions of the technology 46

Figure 16. Example of national mission proposal by RCN: Zero-emission maritime transport 57

\section{TABLES}

Table 1. The three dimensions of mission-orientation 12

Table 2. Norway's performance on the 17 SDGs according to the SDG index 17

Table 3. RCN's priorities and planned actions in its Strategy for Sustainability 2017-2020 18

Table 4. The MOIP features in the Revised Long-term plan for research and higher education 2019-2028 22

Table 5. Basic information on 21-Platforms 24

Table 6. The MOIP features in the 'Health\&Care21 Strategy' 25

Table 7. Performance goals by focus area $\quad 44$

Table 8. Main challenges and opportunities of innovation systems in Norway for adopting mission-oriented policies 49

Table 9. Basic characteristics of the two core types of MOIPs 51

Table 10. Main features of selected MOIP initiatives in Norway $\quad 52$

Table 11. Two strategies for pushing further a MOIP approach in Norway 53

\section{BOXES}

Box 1. The Norwegian Bioeconomy Strategy 26

Box 2. Energi21 recommendations for a cross-sectoral coordination of 21-platforms $\quad 29$

Box 3. Innovation Norway's Public-Private Innovation Partnership Procurement programme (PPIP). Programme 32

Box 4. The Green Platform Initiative $\quad 50$

Box 5. The German High Tech Strategy: from a technology-based to a mission-oriented strategy 55

Box 6. Japan's gradual building of a Cabinet Office-led mission-oriented policy 56

Box 7. Criteria and process to select challenges and missions 60 


\section{Executive summary}

Norway's system of research and innovation has gradually improved over decades, and significantly contributed to national economic and social development. Norwegian public authorities have used a variety of STI policy interventions and regulations to take advantage of natural opportunities (water, oil and gas, fish resources, etc.) and establish a virtuous circle between growth and innovation. It however still suffers from limitations that hinder its ability to contribute not only to feed into a continuous growth agenda but also to lead the transition towards a more sustainable development, less reliant on Oil and Gas.

This case study, undertaken as part of the OECD CSTP project on mission-oriented innovation policies (MOIPs), aims to assess the possible need for, as well as challenges and opportunities to, mission-orientation in Norway in order to contribute to its sustainable transition. On this basis, it seeks to provide inputs into the discussions on how Norwegian authorities could better promote a mission-oriented policy approach in order to effectively address societal challenges.

Is there a need for mission-oriented innovation policies in Norway?

Among the weaknesses of Norway's system of research and innovation highlighted in several reports are a lack of high level agenda-setting mechanism allowing for comprehensive and ambitious initiatives; weak holistic coordination due to a highly sectoral STI governance structure; a fragmented policy landscape, in particular with regards to business support policy instruments. MOIPs are designed to address these three limitations: they are cross-sectoral joined-up initiatives aimed at realising bold national priorities through consistent bundles of policy instruments. Adopting a MOIP approach in Norway would involve improvements along the three dimensions of strategic orientation, policy coordination and policy implementation.

However, it is clear that MOIPs are not the silver bullet that will solve economic and social issues and their trade-offs. It is relevant in specific conditions and for certain 'missions'. Furthermore, MOIPs are not meant to substitute for other types of more traditional policies. They build on other instruments and there is still a need for open, non-thematic, policy instruments in order to, for instance, provide generic scientific knowledge and raise the general level of business R\&D investment across the board.

Does Norway have specific features that are conducive to the design and implementation of missionoriented innovation policies?

Norway has some strong advantages for mission-orientation:

- It remains among countries who invest most intensively in research and innovation activities;

- Norway has strong ambitions with regards to addressing societal challenges;

- Although this might come at the expense of cross-ministerial action, several ministries are involved in research and innovation and are responsible for STI policy in their own 'sector';

- While Norway lacks strong business players in knowledge-intensive industries, it leads on significant portions of value chains, notably in aquaculture, maritime transport, energy generation, etc. These could form the basis of relevant missions;

- Some 'policy entrepreneurs', in particular in agencies, are strong advocates of missionoriented innovation policies and are keen to experiment and learn from new pilot schemes.

Does Norway implement mission-oriented innovation policies?

Norway has already seized these opportunities to implement several policies and programmes with strong mission-orientation features. Highly influenced by the specific national institutional setting in which they are embedded, Norwegian MOIPs are smaller-scale initiatives led by agencies, aiming 
for 'accelerator' missions rather than large and more disruptive/transformative national missions. Norway is therefore following a more bottom-up approach whereby agencies jointly play a key role in experimenting and implementing specific systemic policy initiatives.

Pilot-E is a cross-agency and challenge-oriented scheme launched in 2016 in the area of carbon-free transportation. It supports environmentally friendly transport and energy solutions from idea to market by combining financial schemes from different governmental bodies as a means of reducing emissions both in Norway and internationally. CLIMIT is a programme for research, development and demonstration of carbon capture and storage technologies (CCS) jointly initiated in 2005 by Gassnova (an agency under the Ministry of Petroleum and Energy) and RCN. Both cross-agency initiatives offer innovative ways to integrate instruments aiming to support the production and practical use of new knowledge to develop concrete solutions to societal challenges.

More recently, the national response to the COVID-19 pandemic shows that Norway can propose unified and novel approaches when there is a shared political understanding of the challenge to be solved. Although not covered in this study as it is too recent, the Green Platform Initiative jointly run by the Research Council, Innovation Norway and Siva could represent a significant MOIP initiative to support clean technology projects in a better targeted and coordinated way.

What could be next steps for mission-oriented innovation policies in Norway?

Two options for the future of Norway's mission-oriented policy approach are proposed in this study:

1. The 'scaling-up' option consists in expanding the range and scope of existing MOIP. This can be obtained mainly by: i) enlarging the existing MOIP schemes, for instance towards new group of options in the area of emission-free transportation; and ii) building on these experiences, mainstreaming the targeted inter-agency MOIP schemes. Agencies can jointly replicate such schemes in other areas, under a clear joint mandate from their principals which would allow for greater and better portfolio approaches.

2. The 'elevating' option consists in elevating the MOIP initiatives above the level of agencies, i.e. at the level of ministries and centre of government. This option is more challenging since it entails a strong direct involvement of higher-level public bodies in the strategic and coordination process. The next revision of the Long-Term Plan (LTP) for Research and Higher Education could represent an important opportunity if the relevant policy ministries agree on structuring the plan around (or include within it) some clear and selective missions.

The study makes two related recommendations: (1) develop a system to manage the setup of crossagency schemes in a few other relevant challenge areas; and (2) with support from high-level policy and political actors, designate one pilot mission to be programmed in the four-year investment plan of the next edition of the LTP. 


\section{Introduction}

The project on mission-oriented innovation policies (MOIP) was launched by the OECD Committee for Scientific and Technological Policy (CSTP) in 2019. It aims to provide a comprehensive understanding of how governments try to address societal challenges through various types of MOIPs in different national and thematic contexts. Using a dedicated methodological framework, the project consists of two main types of fieldwork:

1. Systematic investigations: identification and characterisation of MOIP initiatives in all OECD countries and beyond;

2. In-depth investigations: thorough analysis of mission-oriented policies in a sample of voluntary countries through case studies. To date, four countries have engaged in a partnership with OECD to conduct a 'MOIP case study': Austria, Japan, Korea and Norway. ${ }^{1}$

The results of the project were published in February 2021 (Larrue, 2021).

The present document sets out the draft results of the Norway MOIP case study. The main objective of this study is to identify the needs and opportunities for, and challenges to, mission-orientation in Norway. On this basis, it provides inputs into the discussions on how Norwegian authorities could, if needed and relevant, better promote a mission-oriented policy approach in order to effectively address societal challenges and meet national priorities.

The case study was undertaken with financial and technical support from the Research Council of Norway. An interview campaign took place in Oslo in January 2020 (see 0).

This draft document has five main sections (Figure 1). Following this introduction, the second one synthetises selected elements from the project methodological framework, in particular the definitions of the main concepts used to structure the analysis. The third section assesses the socalled MOIP framework conditions, i.e. the extent to which the institutional setting in Norway influences the ability of the government to design and implement MOIPs. This section is structured along the three dimensions of mission-orientation - strategic orientation, policy coordination and policy implementation - to address subsequently the following questions:

1. How Norway has currently and in the recent past set directions to achieve particular objectives of national importance, in particular those related to societal challenges;

2. How Norway coordinates STI policies across policy fields, communities and sectors;

3. How Norway implements specific STI policies and programmes that match to a greater or lesser extent the features of MOIPs as defined in this study.

The fourth section reviews two MOIPs that currently operates in Norway: Pilot-E in the area of environmentally friendly transport and energy solutions and CLIMIT in the area of Carbon Capture and Storage technologies (CCS). A last section recalls the main findings, concludes on opportunities and challenges of mission-orientation in Norway and proposes some options for the next steps. 


\section{0 | MISSION-ORIENTED INNOVATION POLICY IN NORWAY}

Figure 1. Structure of the case study report

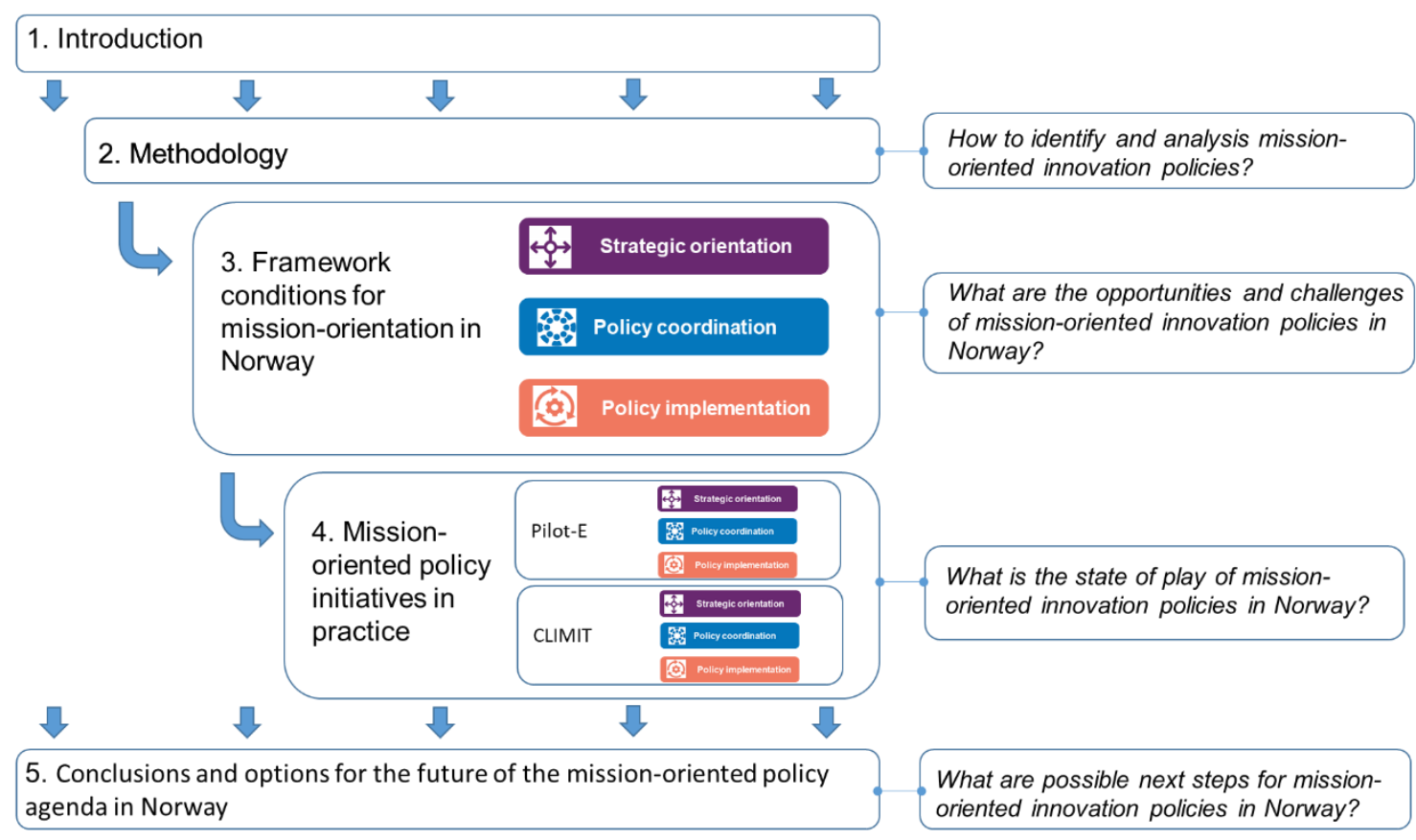




\section{Case study methodology}

The methodological framework developed in the context of the CSTP project on MOIPs is used to support and structure the case study.

\subsection{The definition of MOIPs}

The definition of MOIPs used in this project builds upon an extensive literature review and is consistent with the main research works conducted recently (European Commission, 2018a, 2018b, Mazzucato, 2018); A MOIP is defined as a co-ordinated package of policy and regulatory measures tailored specifically to mobilise science, technology and innovation in order to address well-defined objectives related to a societal challenge, in a defined timeframe. These measures possibly span different stages of the innovation cycle from research to demonstration and market deployment, mix supply-push and demand-pull instruments, and cut across various policy fields, sectors and disciplines (Larrue, 2021).

This definition can be broken down to isolate three main types of functions that MOIPs are expected to fulfil, along the three MOIP dimensions of Strategic orientation, Policy coordination and Policy implementation (see Figure 2).

Figure 2. The definition of MOIPs and the three MOIP dimensions

Coordinated package of research and innovation policy measures aiming to address societal challenges

C2 spanning several stages of the innovation cycle from research to demonstration and market launch

using various instruments (supply-side and demand-side; top-down and bottom-up)

웡 crossing various policy fields (interministerial, cross-agency, etc.)

(C) targeted towards ambitious and concrete goals

in a defined time-frame

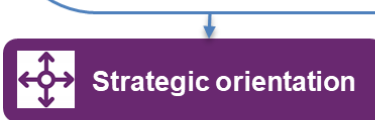

Orientate collective effort towards a well-defined challenge

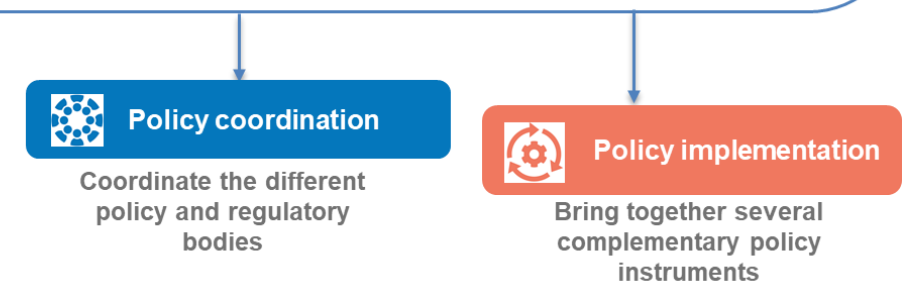




\subsection{The three dimensions of mission-orientation}

This definition encompasses the three main dimensions of mission-orientation (Table 1). These dimensions were used for fieldwork (design of templates and interview guidelines) and for analysis and delivery of results at national and initiative levels (structure of chapter 3 and 4).

\section{Table 1. The three dimensions of mission-orientation}

\begin{tabular}{l|l}
\hline Policy coordination & $\begin{array}{l}\text { The ability to engage a wide array of public and private } \\
\text { actors in the selection of well-informed societal } \\
\text { challenge(s) and the legitimation of focused policy } \\
\text { interventions towards these challenges. }\end{array}$ \\
\hline
\end{tabular}




\section{Framework conditions for mission-orientation in Norway}

The MOIP framework conditions systematically define the national factors that influence the ability of a country to design, fund and implement MOIPs. These national factors pertain to the three dimensions that lie at the core of MOIPs: strategic orientation, policy coordination and policy implementation. The main underpinning hypothesis is that the forms and types of MOIPs in a given country can only be understood within:

- the national institutional setting in which they are embedded and that determine to a great extent what is politically and socially feasible at one point in time. Countries differ for instance in their capabilities to steer, fund and implement complex policies (such as MOIPs);

- the policy trajectory that has gradually formed them, moving forward through experimentation, negotiation and learning. These trajectories are driven by a number of factors, among others the general policy stance toward state intervention, the respective choice of policy instruments (e.g. generic vs. specific measures).

The analysis shows that MOIPs can be beneficial to solve some of the current limitations of the Norwegian system, as revealed in the OECD Innovation Policy Review of Norway (OECD, 2017a): a lack of high level agenda-setting mechanism allowing for comprehensive and ambitious initiatives aiming to lead the transition process; weak holistic coordination due to a highly distributed governance of STI policies at the sectoral level. It also shows that Norway has some strong advantages that constitute a conducive ground for mission-orientation, which was useful to implement novel pilot MOIP initiatives.

\subsection{Strategic Orientation}

\subsubsection{Government $R \& D$ investment as a driver of national growth in Norway}

Norway is a resource-based economy and this favourable natural condition explains in part how it has transformed into one of the most highly developed and richest countries in the world. However, even more remarkable is how Norway has seized these opportunities and pursued an active industrial policy in the post-war era. Part of the revenues generated in sectors such as oil and gas (O\&G), shipbuilding and also fisheries and aquaculture were reinvested in initiatives to improve the competitiveness and added value of the corresponding products and services, including R\&D initiatives (OECD, 2017a]). This virtuous circle for building strong, interlinked research and innovation capabilities (together with the construction of strong public welfare schemes), became a driving force of a specific national model of economic and social development which draws significantly on two of the pillars of mission-orientation: innovation and collective action.

$R \& D$ has therefore become a higher national priority overtime, to the point that Norway allocates in 2019 more of its government resources to R\&D support than most OECD countries, after Korea and Germany (Figure 3). Norway had set the goal of having government allocations to R\&D (GBARD) account for $1 \%$ of GDP by 2019-2020, which was reached as early as 2016 (1.01 of GBARD in 2018). 


\section{4 | MISSION-ORIENTED INNOVATION POLICY IN NORWAY}

Figure 3. Government budget allocations to R\&D (GBARD), (2019 and 2013)

Percentage of general government expenditures

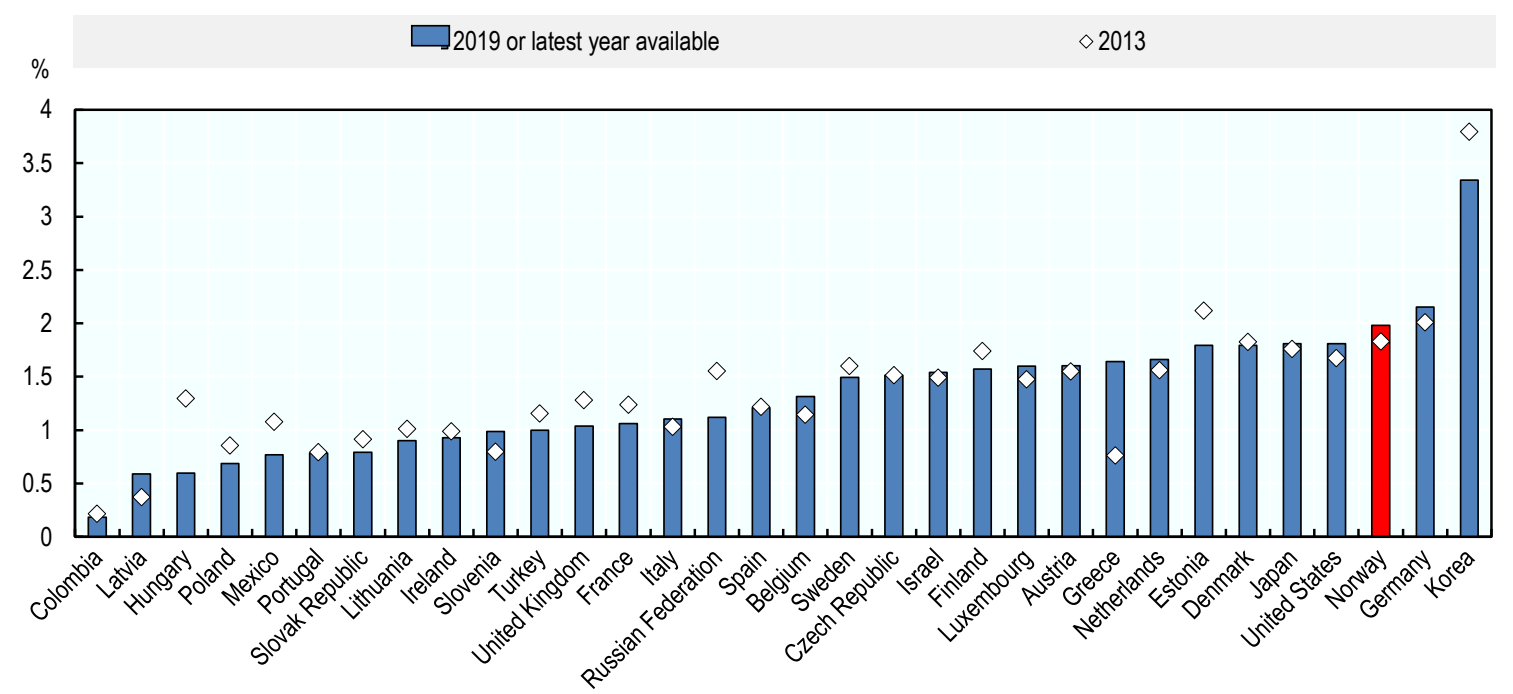

Source: "Calculations based on OECD, "Research and Development Statistics: Gross domestic expenditure on R-D by sector of performance and socio-economic objective", OECD Science, Technology and R\&D Statistics (database), https://doi.org/10.1787/data-00188-en and OECD, "'National Accounts Statistics, Government deficit/surplus, revenue, expenditure and main aggregates"' https://doi.org/10.1787/na-data-en (accessed on 25 January 2021)

Looking at R\&D expenditures all together, Norway is however not amongst the world's largest investors in science and innovation, spending 2.1\% of GDP on R\&D in 2018 (to be compared with an OECD average of 2.4\% and a R\&D intensity of 3.3\% in Sweden and 3.1\% in Austria). Norway's Business R\&D expenditure is affected by the composition of its industrial structure, which is skewed towards low R\&D intensity sectors. ${ }^{2}$ This characteristic makes the national R\&D intensity target of $3 \%$ of GDP (introduced in 2005) in 2030 very challenging to achieve. 
Figure 4. Gross domestic spending on R\&D (GERD) (2018 and 2013)

Percentage of GDP

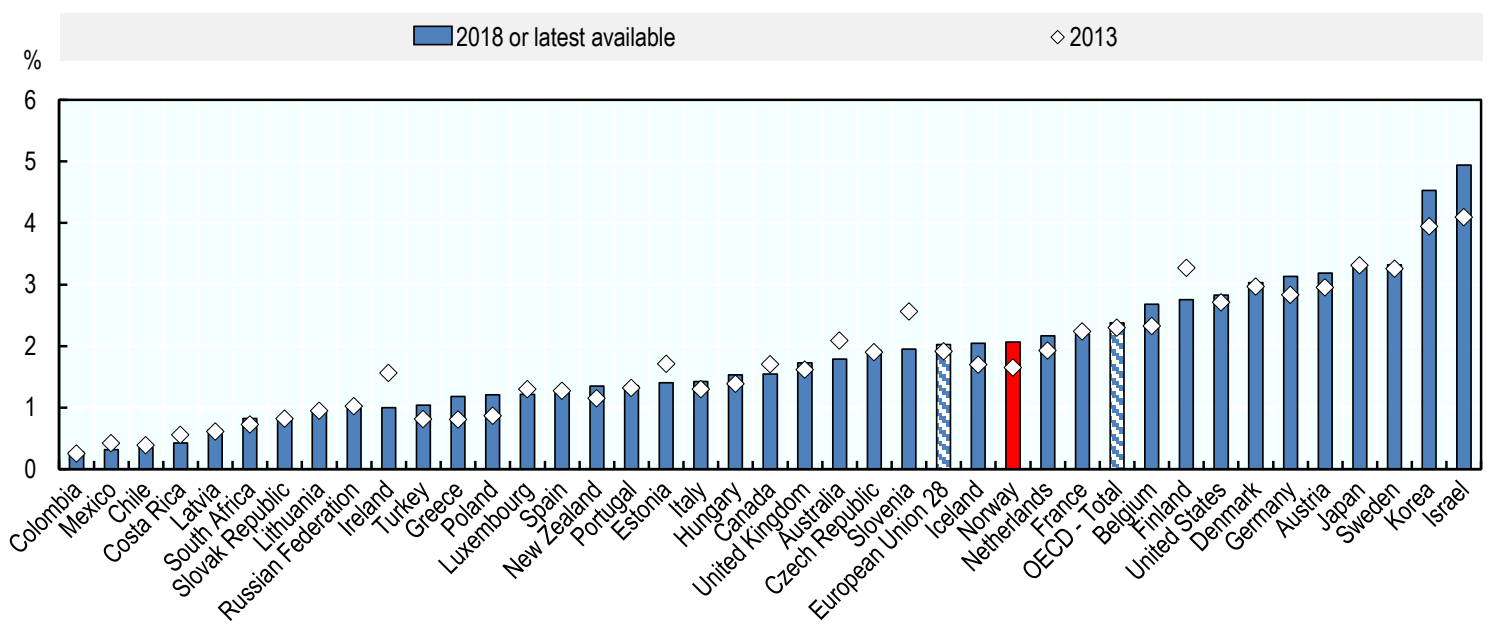

Source: OECD (2021), "Main Science and Technology Indicators", OECD Science, Technology and R\&D Statistics (database), https://doi.org/10.1787/data-00182-en (accessed on 25 January 2021).

Norway is also one of the countries where the share of the government in the funding of these expenditures is the highest, with a significant increase since $2013,{ }^{3}$ which confirms the higher priority put on research and innovation in Norway in the last decade ( Figure 5).

Figure 5. GERD, financed by government (2013 and 2018 or latest)

Percentage of GDP

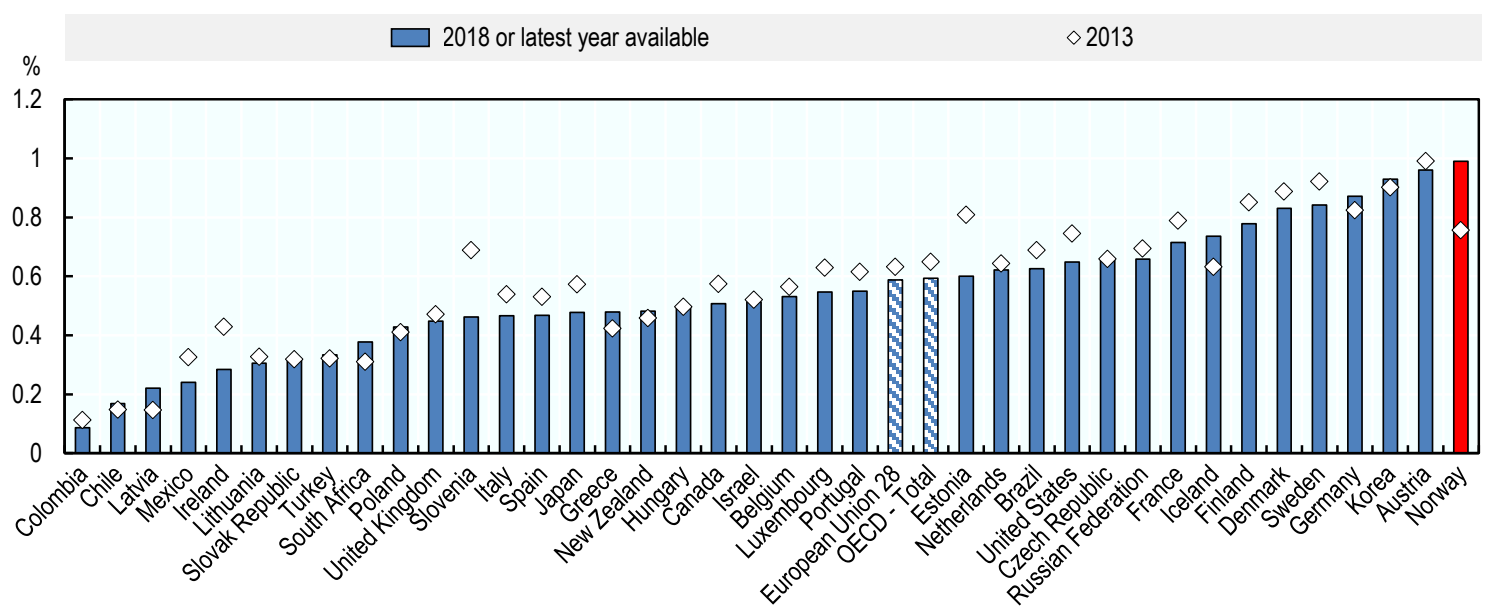

Source: OECD (2021), "Main Science and Technology Indicators", OECD Science, Technology and R\&D Statistics (database), https://doi.org/10.1787/data-00182-en (accessed on 25 January 2021).

What is more, a large portion of the government appropriations dedicated to R\&D in Norway is considered as thematically oriented (Figure 6). Non-oriented research includes both research for the general advancement of knowledge and institutional funding. Oriented research includes the research reported by national authorities as contributing to specific socio-economic objectives. In 
Norway, the public funds for oriented research account for $86 \%$ of the total (direct) fund for R\&D in 2019 (76\% in Korea, 78\% in Sweden, 87\% in Austria). ${ }^{4}$

Figure 6. Oriented and non-oriented government R\&D budget (2020 or latest year available) As a percentage of total GBARD

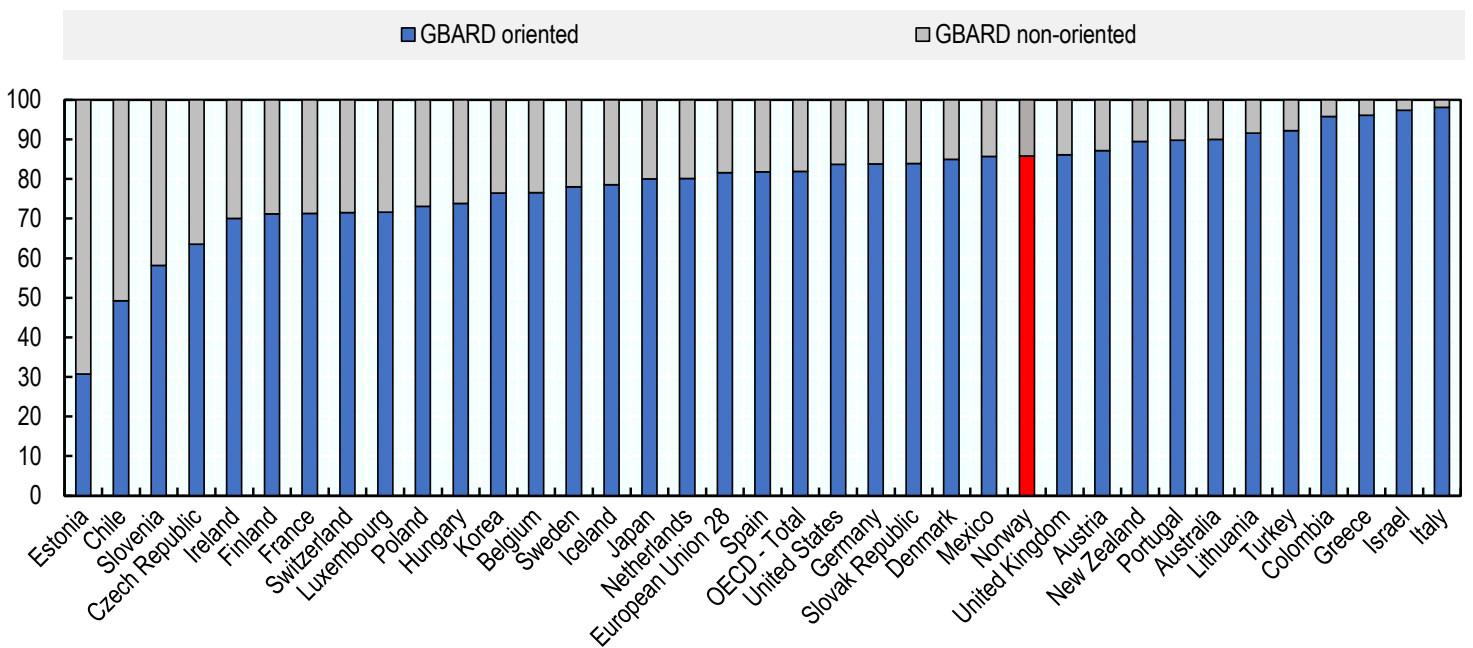

Source: OECD (2021), "Main Science and Technology Indicators", OECD Science, Technology and R\&D Statistics (database), https://doi.org/10.1787/data-00182-en (accessed on 18 March 2021).

\subsubsection{STI to address societal challenges}

In recent years, government efforts to support research and innovation have been increasingly directed towards the acknowledged need for the country to both diversify its economy away from oil and gas and solve pressing societal challenges. Norway fares very well in the SDG index that assesses countries' performance with regards to indicators associated to the 17 sustainable development goals (SDGs). It ranks at the $6^{\text {th }}$ position out of 193 countries - Sweden, Denmark and Finland reaching the 3 first ranks. Norway has already achieved some of the SDGs, far ahead of the 2030 deadline. Still, Norway is considered in a difficult situation on three SDGs, including the key one related to climate change, due to high $\mathrm{CO}_{2}$ emissions related to $\mathrm{O} \& \mathrm{G}$ production (Table 2). The OECD 'distance to SDG' report is more optimistic with regards to the 'climate action' SDG, however stressing some statistical data gaps that might affect results (OECD, 2019a). 
Table 2. Norway's performance on the 17 SDGs according to the SDG index

\begin{tabular}{ll}
\hline Status & SDGs \\
SDG achieved & SDG 1 No poverty \\
& SDG 3 Good health and well being \\
& SDG 5 Gender equality \\
& SDG 7 Affordable and clean energy \\
& SDG 10 Reduced inequalities \\
& SDG 17 Partnerships for the goals \\
& SDG 9 Industry, innovation and infrastructure \\
Challenges remain & SDG 11 Sustainable cities and communities \\
& SDG 14 Life below water \\
& SDG 16 Peace, justice and strong institutions \\
Significant challenges & SDG 4 Quality education \\
remain & SDG 6 Clean water and sanitation \\
& SDG 8 Decent work and economic growth \\
& SDG 15 Life on land \\
Major challenges remain & SDG 2 Zero hunger \\
& SDG 12 Responsible consumption and production \\
& SDG 13 Climate action \\
\hline
\end{tabular}

Source: SDG Index, consulted on February10, 2021, https://dashboards.sdgindex.org/profiles/NOR

While Norway is not accountable for the emissions resulting from the oil and gas it exports according to international laws and regulations (including the Paris Agreement), the extraction and transport of fossil fuels accounts for $15 \%$ of global energy-related emissions. This gives the oil and gas industry an important role to play to reduce greenhouse gas (GHG) emissions and achieve the goals of the Paris Agreement (IEA, 2020).

Contributing to fighting climate change is therefore a key priority in Norway. As part of the Paris Agreement, it has committed to a 40 percent reduction of greenhouse gas emissions in 2030 compared with the 1990 level and to become a low emission society by 2050 . Since the Paris Agreement Norway has become one of the very first country in the world to strengthen its goals to at least 50 per cent and up to 55 per cent of emission reduction compared with the 1990 level. Achieving these objectives in less than 10 years (the commitment period starts in 2021) is all the more challenging since Norway electricity production is nearly $100 \%$ produced from renewable (and $68 \%$ of its energy consumption). Therefore, to reduce its emissions, Norway cannot rely on wind power or solar energy. Meeting the international commitments will require significant changes in other sectors (e.g. transport and O\&G extraction notably).

This increasing priority on the promotion of STI activities that could contribute to alleviate societal challenges is clear in various strategic documents, at national and organisational level. The government released in 2016 the national Climate Strategy for 2030 titled a "transformational approach within a European cooperation framework" (Government of Norway, 2016). This strategy describes how the estimated emission gap can be closed by means of a broad range of domestic emission reductions measures by 2030. Its emphasises that the development and deployment of climate- and environmentally-friendly energy technologies will be an essential part of efforts to both address the challenge of climate change and substitute in part the decrease of revenues from petroleum-related activities by providing new market opportunities for the Norwegian business sector. The inventory of the measures currently in place covers the indirect/neutral measures (taxbased schemes), framework conditions measures but also the proactive interventions that aim to drive longer term market change (mainly mentioning the actions of the agency ENOVA ${ }^{5}$ ). The strategy also stresses that The Government will ensure that the public procurement should support the adoption and development of new environmentally friendly technologies and solutions.

In the STI policy field more specifically, societal challenges are prominent in the Long-Term Plan for Research and Higher Education 2015-2024 (LTP) and even more in its revision in 2018 (MER, 2014 and 2018). At about the same time as the launch of the first LTP, the government also released 
a White Paper presenting its vision for an "active industrial policy" that would result in a "greener, smarter and more innovative industry" (Ministry of Trade, Industry and Fisheries, 2016).

RCN's strategy for 2020-24 emphasises the need of research and innovation for tackling societal challenges. Sustainable development is one of the three overarching objectives of the strategy ${ }^{6}$ (RCN, 2020). The Strategy spells out the need to not only put more resources into research for sustainable development but also to rethink the agency's instrument. The complexity of the SDGs requires a systemic approach whereby a wide range of instruments mutually support one other, instead of isolated individual measures. The reference to MOIPs is explicitly made in this Strategy:

We must experiment more widely with research and innovation missions that have clearly defined goals and timeframes, and that incorporate broad-based involvement and employ a broad range of instruments. We need to provide greater latitude for trial initiatives, and for testing, learning and scaling up well-functioning solutions

(RCN, 2020a)

As a follow up action plan to its former strategy titled "Research for Innovation and Sustainability" covering the period 2015-20 (RCN, 2015), RCN released a few years later a specific "Strategy for Sustainability" covering the period 2017-2020 that sets out the actions that RCN will implement to contribute to achieving the SDGs (RCN, 2018). This strategy presents a very proactive framework that includes action principles. These principles echo some of the main features of missionorientation, such as a challenge-driven approach, the promotion of cooperation and integrated solutions, new market-led instruments (Table 3).

Table 3. RCN's priorities and planned actions in its Strategy for Sustainability 2017-2020

\begin{tabular}{|c|c|}
\hline Priority & Action principles \\
\hline $\begin{array}{l}\text { Give priority to } \\
\text { sustainability when } \\
\text { funding R\&D activities }\end{array}$ & $\begin{array}{l}\text { Include a focus on the sustainability dimension in its analyses, advisory services and guiding documents, } \\
\text { including work programmes. } \\
\text { Attach importance to including sustainability perspectives in calls for proposals where this is relevant. } \\
\text { Require grant applicants to describe how their projects will lead to sustainability gains when this is relevant. } \\
\text { Incorporate sustainability as an element of the assessment criteria for grant Proposals in relevant areas }\end{array}$ \\
\hline $\begin{array}{l}\text { Further develop funding } \\
\text { instruments targeted } \\
\text { towards sustainability } \\
\text { challenges }\end{array}$ & $\begin{array}{l}\text { Strengthen existing and test out new mechanisms for promoting cooperation and more integrated solutions to } \\
\text { sustainability- related challenges across research programmes and initiatives, subject fields, thematic areas } \\
\text { and sectors. } \\
\text { Further develop instruments that encourage rapid deployment to the private and public sectors of research } \\
\text { results that will enhance sustainability. } \\
\text { Further develop concepts for high-risk, breakthrough research in areas that are particularly critical to achieving } \\
\text { lasting sustainability gains. } \\
\text { Encourage relevant research on policy instruments that will promote markets for sustainable solutions, } \\
\text { including public procurements, regulatory activities and incentives }\end{array}$ \\
\hline $\begin{array}{l}\text { Strengthen sustainability } \\
\text { perspectives in } \\
\text { international R\&D } \\
\text { cooperation }\end{array}$ & $\begin{array}{l}\text { Emphasise sustainability perspectives in its strategic input to international } \\
\text { research arenas. } \\
\text { Give priority to international arenas that focus on global challenges and are oriented towards research that } \\
\text { fosters sustainability. } \\
\text { Ensure that international calls for proposals incorporate sustainability issues. } \\
\text { Prioritise research cooperation that includes developing countries in order } \\
\text { to promote capacity-building and technology transfer. }\end{array}$ \\
\hline
\end{tabular}

Source: RCN, 2018.

Societal challenges have also become increasingly prominent in Innovation Norway's strategy and interventions as well besides its historical focus on the support to growth and competitiveness. (Innovation Norway, 2019). More generally, all strategic and policy documents acknowledge the need for a transition from a resource-based economy to a sustainable (low-emission) knowledgebased economy. 
This priority is partly reflected in the allocation of $R \& D$ public funds among themes. Norway is one of the countries that allocate a higher share of Government R\&D budgets to projects and activities that are related to health and society issues (Figure 7). Norway is particularly active in the area of health research, which alone represents about $16 \%$ of its Government R\&D appropriations. One controversial report released in 2016 by the Productivity Commission claimed that the Norwegian research system remained "subject to extensive political skewing towards broad social objectives" (Productivity Commission, 2016).

\section{Figure 7. Government R\&D budgets by SDG-related category, 2018}

As a percentage of total GBARD

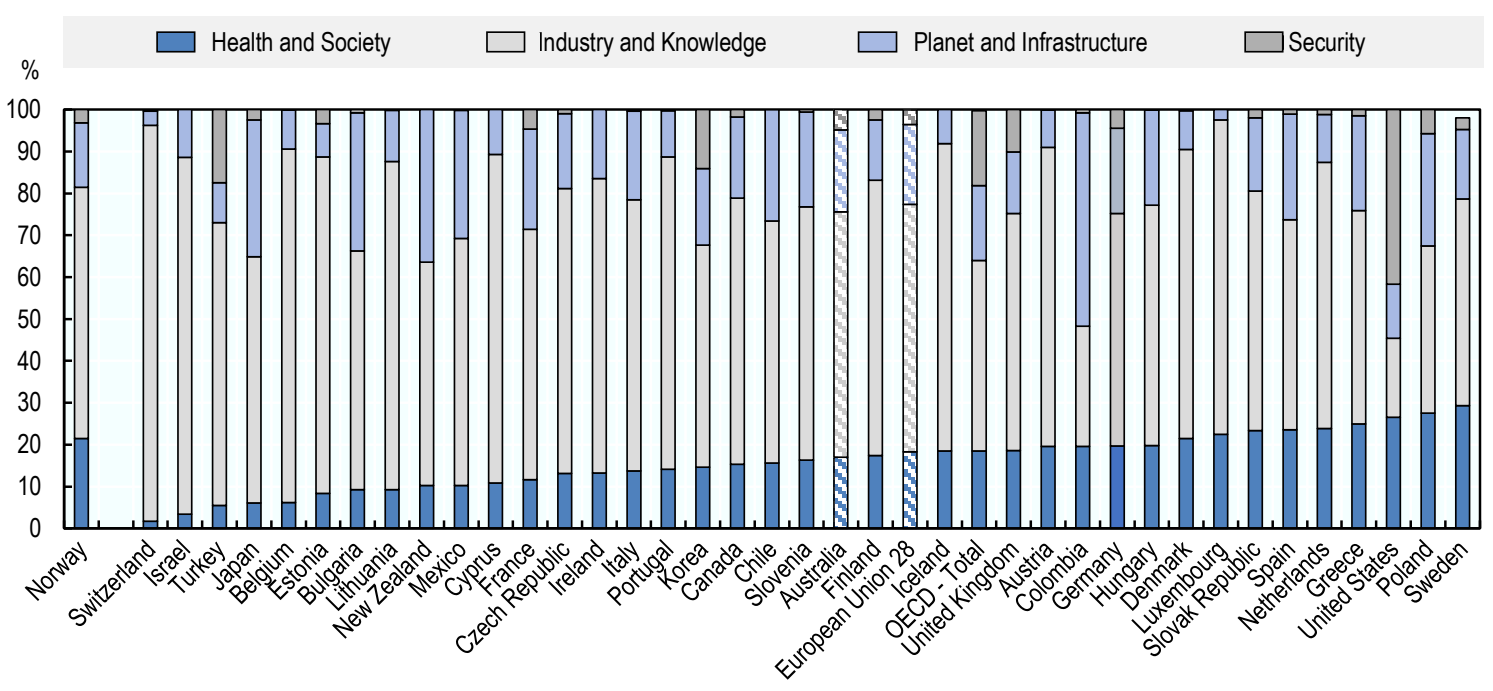

Source: OECD, Research and Development Statistics Database, http://oe.cd/rds, (access 25 January 2021).

Notes:

Note by Turkey: The information in this document with reference to "Cyprus" relates to the southern part of the Island. There is no single authority representing both Turkish and Greek Cypriot people on the Island. Turkey recognises the Turkish Republic of Northern Cyprus (TRNC). Until a lasting and equitable solution is found within the context of the United Nations, Turkey shall preserve its position concerning the "Cyprus issue".

Note by all the European Union Member States of the OECD and the European Union: The Republic of Cyprus is recognised by all members of the United Nations with the exception of Turkey. The information in this document relates to the area under the effective control of the Government of the Republic of Cyprus.

More precisely, climate research in Norway is mainly directed at climate and climate adaptation. Less research is undertaken on climate technology and other emissions reductions and $\mathrm{CO} 2$ management. Another key area of research with important potential impact SDGs is energy. Recent trends show an increase in research expenditures in renewable energy, energy efficiency and restructuring and a decrease in petroleum research (RCN, 2019a).

RCN has already increased its activities in this area and many of its programmes target specific societal challenges such as health, welfare, climate, environment, or promote generic efforts aimed at promoting responsible research and innovation or public sector renewal. For instance, in 2016, RCN allocated about $57 \%$ of its resources (not including research infrastructure and basic funding for research institutes, hence about NOK $1 \mathrm{bn}$ ) to environmentally-friendly energy. RCN's portfolio of R\&D for renewable energy, transport and low emission solutions accounted in 2019 for 984 mill NOK out of a total of 2000 mill NOK, hence about half of the total amount (including additional 
programmes such as infrastructure and institutional funding). R\&D for sustainable development also includes the portfolio of climate and polar research, which allocated some 4600 mill NOK in 2017 , and 484 mill NOK from the portfolio of marine related R\&D (including marine offshore technologies) of a total of 1000 mill NOK expenditures on ocean-related R\&D. ${ }^{7}$

A quick analysis of the number of projects in the area of climate research also shows a slow but continuous increase at least since 2011 (443 in 2018, 372 in 2011). ${ }^{8}$

$51 \%$ of all Innovation Norway grants in 2019 were allocated to projects that have a defined environmental impact, a share that is increasing from previous years. The funds allocated via some programmes like the Value Creation Program for Renewable Energy in Agriculture based Businesses are also increasing and reaching all-time high record. $7 \%$ of the funds distributed by Innovation Norway were allocated in the area of energy and environment (but other areas such as marine and agriculture also contributes to sustainability). As a matter of comparison, oil and gas represented about $3 \%$ of the funds allocated. ${ }^{9}$

\subsubsection{Overarching STI agenda-setting in Norway}

Contrary to other countries where the state has also played an important role in the national technological catch up to leadership in key areas, Norway has not established strong priority-setting body or process to guide research and innovation activities apart from the Government itself who regularly discusses priority setting notably as part of the annual budgetary process. There is no toplevel referee such as a national STI council at the highest government level for holistic orientation and coordination.

Acknowledging the need for stronger orientation and coordination to help the country achieve its transition, the Norwegian government launched in 2014 its first Long-Term Plan for Research and Higher Education 2015-2024 (LTP). This comprehensive strategic plan was led by the Ministry of research but developed collectively with several other public bodies and benefited from various stakeholders' inputs through different consultation channels. It is built around three overarching government objectives for science, technology and innovation (STI) policy: developing research communities of outstanding quality; enhanced competitiveness and innovation; and tackling major societal challenges. The LTP also includes five broad priority areas (for instance 'Seas and Oceans', 'Climate, environment and energy') as well as some specific actions with budget commitments for the first four years (Figure 8). These actions include a support to "technologies that will contribute to the green shift in the economy". Although the LTP has a ten-year perspective, it is revised every 4 years. The second edition covers the period 2019-2028. The revision process will start in 2021 and the third long-term plan will be presented in the fall of 2022. 
Figure 8. Objectives of the revised Long-term plan for research and higher education 2019-2028

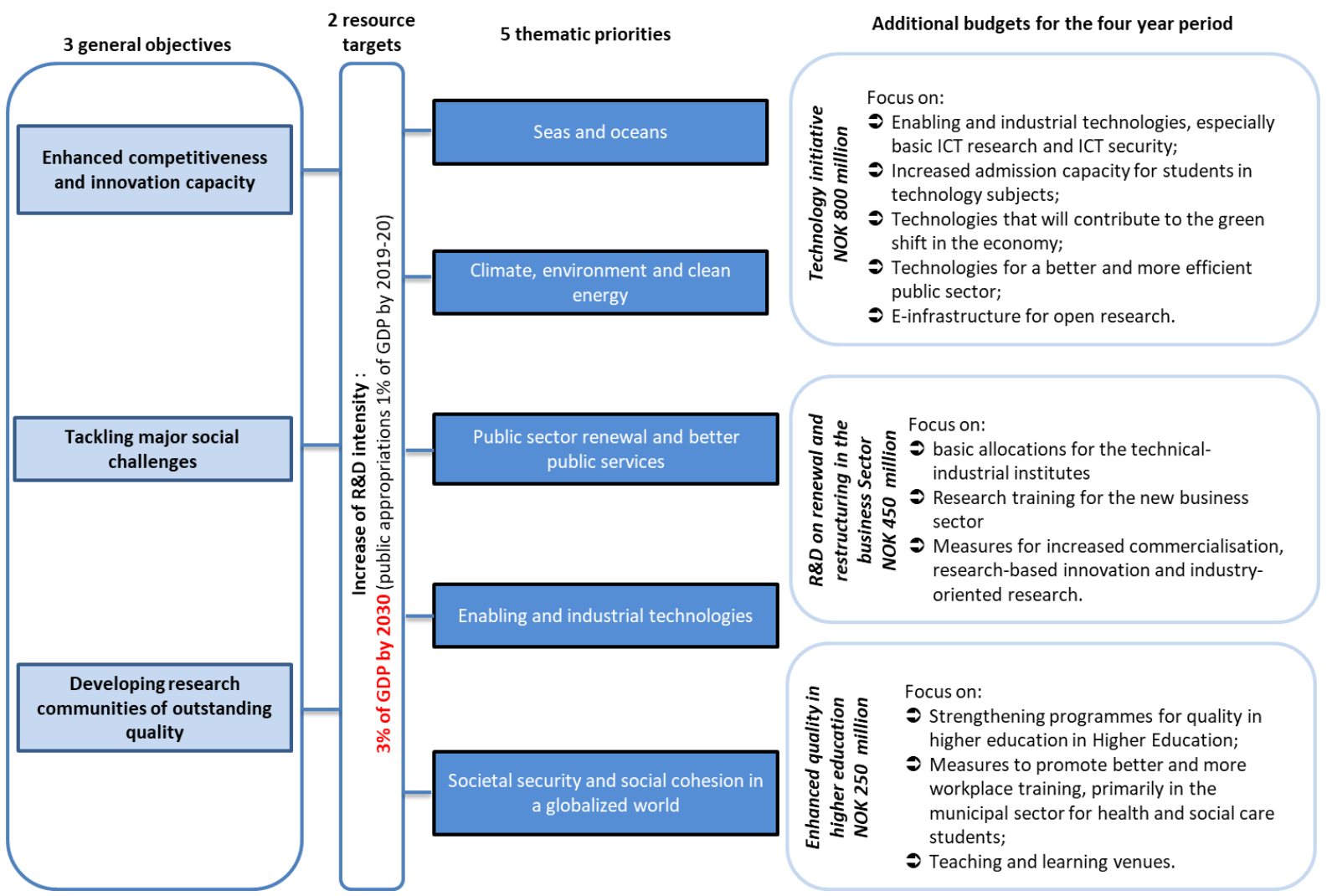

Source: based on MER (2018)

While the LTP clearly marks a significant first step to improve Norway's capacity for STI agendasetting, its priorities remain broad, leaving few policy fields excluded and adding little directionality to Norwegian STI policy. They are unsurprising as they correspond to areas of de facto national specialisation with little space for new emerging areas. While a number of studies have shown that new paradigms often emerge out a combination of previous knowledge, skills and institutions it is important to provide space and incentives for recombining and redirecting activities toward new exploratory options. Basic research, funded by RCN, provides such 'mechanism for surprise' but new opportunities can also arise from entrepreneurial activities or applied research and innovation activities.

The LTP is especially instrumental in providing a strategic framework for activities falling under the scope of the Ministry of Education and Research (MER) (which holds responsibilities for research and research-based innovation), and becomes less precise and more indicative when it addresses other policy mandates, not least business innovation and societal challenges. Furthermore, within each priority area the Plan often remains linear and rather science-push. Whereas it assigns a prominent place to societal challenges, its focus is on the development of the basic knowledge base underpinning societal challenges, rather than on the support to a more challenge-oriented and transformative agenda (OECD, 2017a).

The revised plan in 2018 has slightly changed the structure of its priorities, partly in response to the 2017 OECD Review. The new four-year investment plan that is embedded in the Plan is broader than its predecessor and includes funds from several ministries (it concerned only the MER in the first edition of the Plan). ${ }^{10}$

However, some of the limitations highlighted in this review are still valid. An analysis of the 2019 and 2020 budgets by NIFU shows a complex priority landscape characterised by a large number of 
individual intervention areas, which for the most part receive little funding. Furthermore, the distribution between the priority categories varies greatly between the two years, and there is little continuity in the initiatives (Kallerud and Sarpebakken, 2020).

Despite the limitations of this overall strategic plan, it succeeded in establishing a new approach that made agenda-setting politically more acceptable and increased commitment on some priorities across the government. Another intention was the need to overcome the perceived randomness of annual budgeting in an area in need of longer-term perspectives. It was - and still is - instrumental as an authoritative document for the key milestones of political process such as the bi-annual Budget conferences where various ministries have to agree on budget allocations.

Some organisations, such as RCN, and also a research institute like SINTEF have somewhat aligned their strategic framework to the LTP priorities, or are monitoring their activities and progress against these priorities.

Table 4 presents the main features of the LTP against the three MOIP dimensions.

Table 4. The MOIP features in the Revised Long-term plan for research and higher education 20192028

\begin{tabular}{|c|c|}
\hline Component & Main mission-orientation features \\
\hline Strategic orientation & $\begin{array}{l}\text { - Directionality - The Plan aims to coordinate STI activities of public and private actors around } \\
\text { priorities. It is structured around three overarching government objectives for (STI) policy: } \\
\text { developing research communities of outstanding quality; enhanced competitiveness and } \\
\text { innovation; and tackling major societal challenges. The LTP also includes five thematic priority } \\
\text { areas } \\
\text { - Directionality - The Plan assigns a prominent place to societal challenges, not only as one of the } \\
\text { three overarching priorities, but also in the five thematic priorities } \\
\text { - Flexibility - The strategy includes concrete investment plans with dedicated multi-year funding for } \\
\text { the upcoming four-year period } \\
\text { - Legitimacy - The thematic priorities and targets are developed every four years via various } \\
\text { consultation steps, including a call for input from various stakeholder and institutional actors, as } \\
\text { well as significant interactions between the Ministry of education and research and relevant } \\
\text { ministries in a number of working groups and other negotiations and hearings. }\end{array}$ \\
\hline Policy co-ordination & $\begin{array}{l}\text { - Horizontality - The LTP promotes a more strategic and co-ordinated policy approach in the STI } \\
\text { policy field, where co-ordination has been traditionally considered as 'weak', due to a high degree } \\
\text { of autonomy of individual Norwegian ministries in their respective fields (the so-called 'sector } \\
\text { principle' whereby sector ministries have R\&D policy responsibility in their areas) } \\
\text { - Horizontality - The LTP had concrete effects on horizontal co-ordination, notably through its role in } \\
\text { high-level 'LTP' meetings chaired by the prime minister and in Cabinet discussions on STI issues, } \\
\text { the establishment of some interdepartmental steering groups at administrative and political level } \\
\text { in the different priority areas to develop and monitor the strategy; and via alignment work in the } \\
\text { Research Council of Norway (RCN). } \\
\text { Intensity - The LTP is an authoritative strategic document, often referred by public and private STI } \\
\text { actors. It has concrete effects on horizontal co-ordination of policy actions of the different } \\
\text { ministries. }\end{array}$ \\
\hline Policy implementation & $\begin{array}{l}\text { - Policy mix diversity - The LTP is not only an aspirational long-term strategic document, it includes } \\
\text { concrete investment plans with dedicated funding from various ministries for the upcoming four } \\
\text { years (amounting to NOK1500 million, i.e. about } € 135 \text { million for the period 2019-2022) } \\
\text { Reflexivity - The LTP is conceived on a four-year rolling basis and is revised every four years, } \\
\text { which allows flexibility and reflexivity" }\end{array}$ \\
\hline
\end{tabular}

Source: based on OECD (2017a) and Schwaag Serger, Larrue and Smith (2017); Information provided by the MER

While it is clear that the LTP is in itself not a MOIP initiative, it provides insights into some essential mechanisms of orientation and coordination that would be instrumental in a national level missionoriented policy. The next revision of the LTP (to be launched in 2022) could be used to 'host' national missions. 


\subsubsection{Strategic orientation in key sectors}

Relying upon a strong tradition of consensus building, Norway has established numerous organisations to collectively drive some strategic orientations in some sectors. They also serve as 'voice of the industry' and act as channels for interaction with the public authorities.

With regards to research and innovation 10 so-called 21-platforms have been established (Table 5). These organisations are large platforms gathering public and private actors in order to advise ministries on how research and development can contribute to a certain thematic area, what the priorities should be and how initiatives can best be organised and supported. They fulfil these tasks principally by drawing up sectoral R\&D strategies ('21-Strategies', such as 'O\&G21 Strategy' or the "Health\&Care21 Strategy"). The 21-strategies are formulated by committees that serve as advisory bodies and stakeholder forums. The committees are appointed by the government ministries and with representatives from businesses, research institutions and public administrations. They also serve as stakeholder forums for strategic collaboration between various actors, including stakeholders. While most of 21-Forums are only active during the preparation or update of their ' 21 Strategy', some also function as permanent advisory bodies that advise the government on the implementation of the strategic recommendations and monitor related efforts and progress. 


\section{4 | MISSION-ORIENTED INNOVATION POLICY IN NORWAY}

\section{Table 5. Basic information on 21-Platforms}

\begin{tabular}{|c|c|c|c|}
\hline 21-Platform & Sector/area & Strategy & Governance \\
\hline OG-21 (2001) & Oil and Gas R\&D & $\begin{array}{l}\text { OG21 strategy revised } \\
\text { every } 5 \text { years. It was last } \\
\text { revised in } 2016\end{array}$ & $\begin{array}{l}\text { Board appointed by the Ministry of Petroleum } \\
\text { and Energy. } \\
\text { Consists of representatives from oil companies, } \\
\text { suppliers, research institutes, universities and } \\
\text { the authorities } \\
\text { Permanent secretariat }\end{array}$ \\
\hline Energi21 (2008) & $\begin{array}{l}\text { Renewable energy and } \\
\text { climate-friendly energy } \\
\text { technologies, including CCS } \\
\text { and energy to transport. }\end{array}$ & $\begin{array}{l}\text { Energi } 21 \text { strategy revised } \\
\text { every } 4 \text { years ( } 4 \text { strategies } \\
\text { to date) } \\
\text { The latest Energi21 } \\
\text { strategy is from } 2018 \text {. }\end{array}$ & $\begin{array}{l}\text { Board appointed by the Ministry of Petroleum } \\
\text { and Energy. } \\
\text { The board has representatives from energy and } \\
\text { supplier companies, research and education } \\
\text { environments and the authorities. } \\
\text { Permanent secretariat }\end{array}$ \\
\hline Klima21 (2009) & Climate and environment R\&D & Strategy launched in 2009 & $\begin{array}{l}\text { Strategy was developed by a committee } \\
\text { appointed by the government in December } \\
2008\end{array}$ \\
\hline Maritim21 (2010) & Maritime R\&D & $\begin{array}{l}1 \text { st strategy in } 2010 \\
\text { Revised in } 2016\end{array}$ & $\begin{array}{l}\text { Permanent secretariat since } 2018 \text { (at RCN) } \\
\text { Strategy Group (industry and research } \\
\text { communities) }\end{array}$ \\
\hline Hav21 (2013) & $\begin{array}{l}\text { Marine R\&D (resource } \\
\text { management, fisheries, } \\
\text { aquaculture and seafood }\end{array}$ & $1^{\text {st }}$ strategy in 2013 & $\begin{array}{l}\text { Strategy committee comprising both trade and } \\
\text { industry representatives, the public } \\
\text { administration and the knowledge community }\end{array}$ \\
\hline Skog22 (2014) & $\begin{array}{l}\text { Forest and timber industry } \\
\text { R\&D }\end{array}$ & $1^{\text {st }}$ strategy in 2014 & $\begin{array}{l}\text { Strategy committee comprising the entire value } \\
\text { chain }\end{array}$ \\
\hline $\begin{array}{l}\text { HelseOmsorg21 } \\
(2013)\end{array}$ & Health and care & $\begin{array}{l}1 \text { st strategy in } 2014 \\
\text { Government's action plan } \\
\text { for following up the } \\
\text { HelseOmsorg } 21 \text { strategy } \\
(2015-2018)\end{array}$ & $\begin{array}{l}\text { Council established in 2015, renewed in } 2019 \text {. } \\
\text { Comprises representatives of business, } \\
\text { hospitals, universities and colleges, research } \\
\text { institutes, public administration, the municipal } \\
\text { sector and user organizations }\end{array}$ \\
\hline Bygg21 (2013) & Construction & $1^{\text {st }}$ strategy in 2013 & $\begin{array}{l}\text { Board, strategic council, secretariat and } 6 \\
\text { working groups. }\end{array}$ \\
\hline Prosess21 (2018) & Process industry & $\begin{array}{l}\text { Recommendations } \\
\text { expected December } 2020\end{array}$ & $\begin{array}{l}\text { Steering group of industry } \\
\text { Secretariat led by the Research Council of } \\
\text { Norway with Gassnova, Innovation Norway, } \\
\text { Enova and the Norwegian Environment Agency } \\
\text { as members }\end{array}$ \\
\hline Digital21 & Digitalisation & $1^{\text {st }}$ strategy in 2018 & $\begin{array}{l}\text { Steering committee with representatives of } \\
\text { business, research institutes, universities } \\
6 \text { expert groups in } 6 \text { key strategic areas }\end{array}$ \\
\hline
\end{tabular}

Source: Various internet websites

These platforms are considered instrumental by the government for obtaining consensual recommendations on priorities. They are often referred to in government strategic or policy documents. Several of them however have not been revised for several years. While they cannot be considered as fully-fledged MOIP initiatives (several of them are just one-off initiatives and they remain in a purely advisory role), 21-platforms can be supportive in their respective sectoral scope of a mission-oriented approach. Their core characteristics are also those of mission-oriented policies albeit within sectoral boundaries.

In essence, 21-platforms:

- $\quad$ are directed towards challenges with important societal implications;

- are mandated to develop comprehensive national strategies for research and innovation, which will influence relevant policies, and enhance interactions between business, research, stakeholder groups and public authorities; 
- involve a broad community of actors in various events to design their strategy;

- have a dedicated governance structure to take decisions and, for some of them, an executive secretariat for communication and monitoring.

Table 6 presents the MOIP features of the 'Health\&Care21 Strategy'.

\section{Table 6. The MOIP features in the 'Health\&Care21 Strategy'}

Main mission-orientation features
Directionality - The 21-Forum in the health and care area produced the 'Health\&Care21 Strategy'
submitted to the government in June 2014. The three overall aims of the strategy were better public
health, breakthrough research at a high international level and national economic and business
development
Legitimacy - This strategy was developed by the Health\&Care21 Strategy Committee composed of
15 people appointed by the Ministry of Health and Care Services, representing industry, universities
and university colleges, hospitals, regional health authorities, user organisations, and government
agencies
Intentionality - The Strategy identified five main priority areas - knowledge mobilisation for the
municipalities, health and care as an industrial policy priority, easier access to and increased
utilisation of health data, an evidence-based health and care system, a stronger emphasis on
internationalisation of research
Horizontality: Meetings of the Health\&Care21 Strategy Committee are attended by different
ministries
Demand-articulation: In addition to the Health\&Care21 Strategy Committee, the Ministry also
established a 'Strategic Forum on Health and Care Research and Innovation (Chief Executives'
Forum)'
Policy mix diversity - Based on the strategy, the government drafted an 'Action Plan for
Implementation of the Health\&Care21 Strategy' in November 2015 in which it identified and
committed itself to carrying out a number of initiatives to implement the Health\&Care21 Strategy
Measurability and evaluability - A Health Care 21 Advisory Board, with a dedicated Secretariat,
funded by the Ministry of Health and Care Services and located at RCN, has an ongoing remit for
overseeing the implementation of all the recommendations in the original strategy. This high-level,
multi-stakeholder group, provides advice to Ministries and other users

Source: based on OECD $\left(2017_{[1]}\right)$ and Schwaag Serger, Larrue and Smith $\left(2017_{[2]}\right)$

Importantly, sustainability issues feature prominently in most of the 21-strategies, if not all. Several recommendations aim to reduce the environmental impact of these sectors.

Beside 21-platform strategies, there are other thematic strategies and plans that address societal challenges. For instance, the Bioeconomy Strategy developed in 2015 (Government of Norway, 2016) incorporates several dimensions that are key to a mission-oriented approach, notably a strong role of public authorities in facilitating greater collaboration within and between bio-based value chains as well as increased interdisciplinarity and societal dialogue (see Box 1). 


\section{Box 1. The Norwegian Bioeconomy Strategy}

The Bioeconomy Strategy was developed in 2015 through collaboration among the Ministries of Trade, Industry and Fisheries, Agriculture and Food, Climate and Environment, Education and Research, Local Government and Modernisation, Petroleum and Energy, Transport and Communications and Foreign Affairs.

Actions foreseen to improve cooperation across sectors, industries and thematic areas include:

- Coordinating project support along the whole value chain from R\&D to innovation and market introduction. This includes notably the development and strengthening of the links between the relevant instruments of the Research Council of Norway and Innovation Norway

- Coordinating across thematic areas and sectors in relevant instruments within Innovation Norway and the Research Council of Norway

- Ensuring that public support to research centres advance committing, sector-overarching and interdisciplinary cooperation between research institutions, suppliers and product developers

- Examining how different bioeconomy related councils are organised with a focus on cross-sectorial coordination, institutional efficiency and social dialogue

It also includes important aspects such as the provision of public procurement of climate friendly solutions, and more generally, the need for the public sector to be a role model and motivator for environmentally friendly building solutions.

A common action plan between three agencies (IN, SIVA, RCN) follows up on the implementation of the Strategy. The joined plan should include proposals for better structuring and coordination between relevant instruments within and across the agencies, (ii) ensure an appropriate balance in instruments for $R \& D$, demonstration, pilot and scale-up, market orientation and internationalisation, (iii) provide the basis for knowledge transfer and crosslearning, and (iv) provide a platform for effective implementation and joint dialogue with industry and research.

Several of the current instruments that are relevant to the bioeconomy are oriented towards the needs within individual industries and individual segments of the value chains. In line with the guidelines in this strategy, the overall instrument portfolio should as far as possible encourage synergies across established sectors, industries and disciplines, and have a holistic approach to different stages in the value chain.

Source: Government of Norway (2016)

\subsection{Policy coordination}

\subsubsection{The opportunities and challenges of the sector principle}

Norway's research and innovation system is characterised by a highly sectoral governance structure. The so-called "sector principle" gives no less than 15 individual Norwegian ministries a high degree of autonomy to formulate and execute STI policy measures in their respective fields. This principle is not unique but it is particularly strong in Norway. While it allows for stronger involvement of sectoral ministries in STI activities, it can also restrict holistic STI policy co-ordination around common priorities.

This governance structure has been proved advantageous in the past in promoting significant research initiatives in various fields throughout the policy spectrum since sectorial ministries have 
responsibilities to include $\mathrm{R} \& \mathrm{D}$ in their intervention portfolio. It is however detrimental to the capacity of Norway to tackle societal challenges as they call for policy co-ordination across silos. From a purely financial perspective, only a few ministries have significant STI budget and impactful interventions, principally the Ministry of Education and Research (MER), the Ministry of Trade, Industry and Fisheries (MTIF) and the Ministry of Health and Care Services (HOD). However, other sectoral ministries such as the Ministry of Agriculture or the Ministry of Petroleum and Energy (MPE) have important roles to play in a mission-oriented policy approach since key challenges to address fall under their remit (and therefore under their regulatory and procurement power).

As in many countries, the silos between the authorities respectively in charge of research and innovation policies - and those between these authorities and other sectoral authorities - represent a challenge to the adoption of a mission-oriented policy approach. Furthermore, while research policy and innovation policy are clearly under the aegis of respectively MER and MTIF, the support to research-based business innovation falls into the overlapping region between the two ministries (and by extension the two agencies RCN and Innovation Norway). A comprehensive review of innovation instruments called for a better division of labour between the different policy bodies (Deloitte, 2019).

\subsubsection{Interministerial co-ordination processes}

Although there is no high-level strategic council as can be found in many OECD countries and beyond ${ }^{11}$, some interministerial co-ordination processes "soften" the practice of the sector principle, mainly at the operational, rather than strategic, level. Weekly Cabinet meetings are used to ensure inter-ministerial co-ordination. In addition, other mechanisms are put in place such as interministerial negotiations in the course of the budgetary cycle, monthly meetings of the Interministerial Committee on Research Policy (departementenes forskningsutvalg or DFU) for dayto-day information exchange on research policy matters, cooperation of relevant ministries in the writing of White papers, strategies etc. that are related to research and innovation policy, as well as meetings of an informal network of STI contact points in different ministries.

The LTP process has also introduced a few additional processes and tools needed to achieve some holistic coordination. For instance, when the LTP is prepared (and revised every four years), highlevel co-ordination is required to agree on STI priorities. In its implementation, the LTP also influences interministerial negotiations in general, for instance, during annual budget conferences and the annual "high-level LTP workshops". Moreover, during its first four years, interdepartmental groups were formed within each thematic priorities to exchange information on different ministries' initiatives and monitor progress. Unfortunately, these groups have not met since the last revision of the LTP. As previously mentioned, the fact that the four-year investment plan within the LTP is now covering actions of several ministries - not only MER - can be seen as a positive evolution.

One of the most striking singularity of Norway's STI governance structure is the role played by agencies in interministerial coordination. Given its wide scope, its large number of principals and its role as government advisor on STI policy, RCN acts as a de facto co-ordination institution. The common governance system of RCN developed in close collaboration by all Ministries funding R\&D allows the agency to channel about $25 \%$ of all public R\&D funding (JRC, 2016). RCN receives each year about 15 'Letters of instructions', based on which it strives to build a funding portfolio of small and large programmes that is consistent and strategically-oriented, while still responding to the various specific demands of each 'principal'. MER is leading a common steering system of RCN, which aims to ease the alignment of instructions/priorities of the different sectoral Ministries. Due to this specific governance and funding arrangement of RCN, most of its programmes are crossministerial. For instance the ENERGIX programme for renewable energy is funded by 6 ministries: the Ministry of Petroleum and Energy, the Ministry of Climate and Environment, the Ministry of Transport and Communications, the Ministry of Agriculture and Food, the Ministry of Education and Research, and the Ministry of Trade, Industry and Fisheries. 


\subsubsection{Sectoral coordination}

Coordination between public and private actors in Norway - including stakeholders and citizen appears particularly effective in general due notably to a strong tradition of consultation and consensus-building, as well as a remarkable level of trust in Government. ${ }^{12}$ More specifically the previously mentioned "21-platforms" have not only contributed to strategic orientation but also eased coordination between public and private actors, as well as between industry and stakeholders (including trade unions) in some key thematic areas. Furthermore, in several areas not covered by "21-platforms", thematic strategies have been developed most often involving two or more ministries. These forums and other thematic strategic initiatives remain, however, strongly sectordriven and consensus-oriented processes, often lacking a broader and more visionary or forwardlooking perspective. Their thematic scope make them not always suited for coordinating the transformative societal changes that are likely to become more necessary prior to addressing the grand challenges Norway faces today. Furthermore, these platforms are in most cases set up in key sectors such as oil and gas and fish farming where the incumbents with strong lobbying power tend to favour protective and reactive strategies to reinforce the established status quo. These wellestablished consultative and advisory processes may even in some cases turn out to be detrimental to addressing societal challenges since some ministries tend to extensively rely on them in devising the policy actions to address societal challenges, hence excluding other ad hoc, more cross-sectoral, options.

21-platforms can however prove successful to support incremental changes or even redirections towards more sustainable industry options within their respective scope. This was for instance the case of the OG21 platform whose recommendation in 2016 led to the creation in 2017 of the national low-emission technology R\&D centre. More generally, 21-platform strategic reports and recommendations to the government have well recognised the need to tackle societal challenges. For instance, a 2019 OG21-study on hydrogen from natural gas with CCS explored the opportunity related to de-carbonising natural gas. Also, the Energy21 2018 Strategy's priorities were almost all related to low-emission / climate-friendly technologies. ${ }^{13}$

The fact remains that cross-fertilisation between platforms would be more conducive to new transition opportunities. Recently an initiative to map potential synergies between "21-Forums" and their potential collective contribution to tackling societal challenges has arisen in the energy area (Box 2). Although still in embryonic stage, this initiative and the idea of a possible "super 21 Forum" are a first step towards a challenge-oriented, cross-sectoral, public-private coordination body. Interestingly, such proposal originates mainly from the industry which increasingly calls for improved cross-ministerial and cross-sectoral coordination to address societal challenges. Interviewees highlighted that there are very few places where different industries can meet in Norway. 


\section{Box 2. Energi21 recommendations for a cross-sectoral coordination of 21-platforms}

In its latest strategy, the Energi21 Platform plead for a better cross-ministerial coordination with support from the Center of Government. Cooperation between the different 21-platforms that offer advises to several ministries could be instrumental to achieve this. The Energi 21 strategy pointed at a number of overlaps between the different platforms in energy-related issues, which call for proper coordinationto avoid redundancies and gap (see table below).

Map of coverage of energy issues by relevant 21 platforms.

\begin{tabular}{|c|c|c|c|c|c|c|c|c|}
\hline & $0 G 21$ & Digltal21 & Prosess21 & Maritlm21 & Hav21 & Skog22 & Bygg21 & Transport21 \\
\hline $\begin{array}{l}\text { Digitalised and integrated } \\
\text { energy systems }\end{array}$ & $x$ & $x$ & $x$ & & & $x$ & $x$ & $x$ \\
\hline $\begin{array}{l}\text { Climate-friendly and energy- } \\
\text { efficient industry, including CCS }\end{array}$ & $x$ & $\mathrm{x}$ & $\mathrm{x}$ & & & $x$ & & \\
\hline $\begin{array}{l}\text { Climate-friendly energy tech- } \\
\text { nologies for maritime transport }\end{array}$ & $x$ & $x$ & & $\mathrm{x}$ & $x$ & $x$ & & $x$ \\
\hline $\begin{array}{l}\text { Offshore wind power for } \\
\text { an international market }\end{array}$ & $x$ & $x$ & & $x$ & $x$ & & & \\
\hline $\begin{array}{l}\text { Solar power for an } \\
\text { international market }\end{array}$ & & $x$ & $x$ & & & & & \\
\hline
\end{tabular}

Hydropower as the backbone

of the norwegian energy supply

The Energi21 board therefore recommended to initiate cooperation between Energi21 and the OG21, Digital21, Prosess21, Maritim21, Hav21, Skog22, Bygg21 and Transport21 strategy processes in order to harmonise strategic key areas and exploit the synergies found in the overlapping areas in their scientific mandates. This cooperation would seek to facilitate integrated research strategies and development within the relevant thematic and technology areas.

Source: Energi21 (2018)

\subsection{Policy implementation}

\subsubsection{An innovative policy instrument toolbox for innovation}

Norwegian public authorities have used a variety of policy interventions and regulations to take advantage of natural opportunities (water, oil and gas, fish resources, etc.) and establish a virtuous circle between growth and innovation. In the oil and gas sector for instance, the government built upon the concession system from hydropower and implemented an adapted system for the oil and gas industry from the late 1960 s. This system together with other framework conditions such as taxation policy provided incentives for companies to develop endogenous technological capacity, leading to the creation of strong clusters of suppliers that now provide technical services around the globe.

Such practices are still in use today, for instance in the aquaculture area. In 2016, the Ministry of Trade, Industry and Fisheries (MTIF) launched a pilot initiative that consisted in granting free convertible development concessions for up to 15 years for projects promoting technology that can solve the main challenges facing the aquaculture sector, in particular environmental problems. The main novelty, with expected strong incentivisation effect on firms' investment in new costly and larger scale development, rely upon the convertibility of the concessions: provided the operation fulfils a set of fixed criteria - the development license could be converted into commercial license 
at a cost far below the normal price of such concession. ${ }^{14}$ Another difference from the previous practices is that the new licenses involved much larger and more specific technology-oriented projects.

Norway is also one of the few countries that apply levies on revenues in strong sectors to finance R\&D projects, which reinforces these sectors' competitiveness and, hence, revenues. Such a system was in place in $O \& G$ and is still operating in the agriculture, forestry and fisheries/aquaculture (see box 3$)$.

These schemes demonstrate the willingness and ability of the Norwegian public and private actors pertaining to a community to agree upon and design collective mechanisms to prepare for the future. Achieving a balance between consumption and investment of the rent, hence between current and future revenues, proves complicated in several resource-rich countries. Norway has systematically shown that its culture of dialogue helped the country achieve such balance.

Implementing a MOIP approach, especially when it comes to the 'transformer type' of MOIP, i.e. oriented towards solving societal challenges in the mid- to long-term, will call upon these feature of the Norwegian STI system. It requires the negotiation of common objectives based on a 'vision' for the future and a capacity to invest significant resources to achieve these objectives.

\section{Box 3. Levy-based research fund in key sectors}

The Norwegian Seafood Research Fund (FHF), created in 2001, is a state-owned limited company owned by the Ministry of Trade, industry and fisheries. It is financed by the industry through a $0.3 \%$ levy on exports of Norwegian Seafood. The goal is to jointly fund and organise industry-based R\&D in order to create added value to the seafood industry. The Ministry constitutes the general assembly and appoints the board of directors which is comprised of representatives of the industry. The industry anchoring is further strengthened through three industry advisory groups consisting of industry actors. The FHF priorities used to guide the competitive selection of projects are defined annually. FHF evaluates projects and activities continuously through the year but is also open to suggestions on specific issues to address through R\&D from industry and scientific communities. The fund is coordinated with RCN programmes, in particular Harvbruk. RCN and FHF have representatives seating in each other's Board. Furthermore, some RCN-FHF joint calls allow launching supporting more or larger projects.

The Foundation for Research Levy on Agricultural Products (FFL) was established in 1970. The Fund's capital is built up through a research fee on agricultural products, both imported and nationally produced. The fund finances research projects through annual open calls for proposals. A part of the fund is also set aside for basic funding of the research Institute Nofima. The board makes the priorities for the annual calls based on the needs experienced in the industry. The members of the board are: A representative appointed by The Ministry of Agriculture and Food, Norwegian Farmers' Union, Norwegian Farmers and Smallholders Union, Confederation of Norwegian Enterprise (NHO), Norwegian Agricultural Cooperatives (Norsk Landbrukssamvirke), Enterprise Federation of Norway (Virke) and Norwegian Food and Allied Workers Union (NNN). The Research Council participates as an observer. The Fund is on the National budget estimated on about NOK 170 million in 2020. However, recent years have shown that the actual revenues from the levy are much higher than the estimates due to increased consumption.

The Norwegian Agriculture Agency (NAA), the government agency in charge of implementing agricultural policies including payments, imports and property, is also in charge of various agricultural research and development funds. It has a coordinating role and functions as the secretariat for the board for the Fund for Research Fees of Agricultural Products (FFL) and the board of the Agricultural Agreement Research Funds (JA). The NAA is the link between the boards of the two funds that take decisions on which projects to finance, and the RCN that handles the application and evaluation process. 
Skogtiltaksfondet or Forest Owners' Joint Research Fund, established in collaboration with the Ministry of Agriculture and Food. The fund aims to increase R\&D involvement in the forest industry, and focus on R\&D tasks that are of importance to forest owners. Skogtiltaksfondet secures financing for research and development projects on Norwegian forestry through the deduction of NOK 1 per cubic meter of traded timber, an obligation regulated by law. In addition, the Fund counts with returns from the fund's accumulated capital. The Norwegian Forest Owners' Association is acting as the secretariat, and decisions are made by a board where forest owners are in majority.

Source: OECD (2020); FHF (2019)

\subsubsection{A relative disconnection between supply-push and demand-pull policy}

\section{instrument}

The OECD Innovation Policy Review performed in 2017 a check of the completeness of the Norwegian policy mix, concluding that it is comprehensive, and covers the various needs of the different communities of research and innovation actors, throughout all stages of the innovation process. A more recent study by Technopolis (Technopolis, 2019) based on a report by SOA (SØA, 2019) concurred with OECD, only identifying a gap in innovation "activation" instruments (innovation vouchers, technology audits, graduate/ $\mathrm{PhD}$ placement programmes, etc.), although these instruments might be less critical in the context of the Norwegian industrial structure.

Both studies point to two important and interrelated characteristics of the Norwegian STI policy instrument portfolio with important bearing on the country's ability to implement a MOIP approach: the lack of instruments nurturing and supporting the demand of innovative products; and the rise of neutral policy instruments.

As in many countries, one weak point lies in the lack of demand-side instruments, with only a few of them operated by Innovation Norway and sectoral agencies such as ENOVA in the energy area, and their disconnection from research support instruments. The review of business-related policy instrument highlighted that the sequential ('relay stick') division of labour between RCN and Innovation Norway does not allow commercialisation prospects to sufficiently guide knowledge generation (Deloitte, 2019). A noticeable exception is IN's Public-Private Innovation Partnership Programme (PPIP), a new demand-side (innovative procurement) instrument introduced in 2017 to tackle societal challenges via close collaboration partnerships between public institutions and private companies ( 


\section{Box 4. Innovation Norway's Public-Private Innovation Partnership Procurement programme (PPIP). Programme}

The Innovation Partnership Procurement programme aims to develop and implement new societal solutions using innovative public procurement in a cooperation framework. It is targeted towards solving complex and societal challenges across sectors, silos and governance levels. The goal is to accelerate the use of innovative public procurement as a tool for systemic innovation in the public sector, as well as market creation and closer cooperation between innovative companies and the public sector. The tool is jointly developed and delivered by Innovation Norway, The National Programme for Supplier Development and the Norwegian Digitalisation Agency. 3 ministries co-finance the PPIP budget. It benefits from the additional flexibility offered by the new European legal procurement procedure enacted in 2014.

The main steps of the PPIP are as follows (with a stage gate between phase 5 and 6):

1. Annual call for proposal: public sector entities (municipalities, regions, hospitals, state agencies and directorates) apply for funding to address specific societal challenges through innovative solutions

1. Needs analysis and problem identification: the selected public entities map user needs, the potential beneficiaries, the added value and costs.

2. Market dialogue : the selected public entities invite academia and companies to take part in workshops, info meetings, webinars etc. in order to develop a better understanding of the issue at hand and scan through the different potential solutions (and make sure that there is no solution currently available in the market).

3. PPIP Tender: a tender is launched using the European innovation procurement procedure Innovation Partnership. The object of the tender is the development of an innovative solution to the issue at stake.

4. R\&D and demonstration: the selected partners develop and test the solution.

5. Commercialisation: The public entities as well as any other public sector partner included in the process may - if the solution deemed attractive - trigger the procurement options (without additional tendering) and buy and implement the new solution.

Innovation Norway provides financial and technical support. During phase 4 for instance it coordinates different public actors to help launch joint procurements as much as possible. It allocates $10 \%$ of the project cost to the phase 2 and 3 . The remainder goes to the phase 5 .

14 Innovation Partnerships have been supported between 2016 and 2019 by the amount of NOK 136.5 million. They tackle challenges ranging from tunnel fire safety to high-tech self-help for cancer patients, energy efficient public buildings and the reduction of $\mathrm{Co} 2$ emissions when building railways/houses/roads. 5 to 8 new Innovation Partnerships will be selected and funded as part of the 2020 call for proposal. In 2019, the PPIP calls for proposal was coordinated with RCN's Pre-Commercial Procurement Programme.

So far one project started in 2016 reached the phase 6 . This project aims to develop tailor-made solutions for self-activation and self-empowerment of the elderly when returning from hospital.

The PPIP was positively evaluated in 2019. While most projects are still at an early stage, the assessment of the process and the survey showing a very high level of satisfaction among partners and participants indicate that the scheme is effective. Innovation Norway aims to develop this scheme in the future.

Source: Innoba (2019), Innovation Norway website; Information provided by Innovation Norway to OECD. 
). This challenge-oriented scheme brings together three ministries, two agencies and a national programme, mixes strategic and competitive processes as well as financial and technical support, all features that make it close to a MOIP initiative. Today, this scheme and Pilot-E (see chapter 4) appear as two of the few schemes that formally coordinate the support to the supply and demand for knowledge in a challenge-oriented framework. 


\section{Box 4. Innovation Norway's Public-Private Innovation Partnership Procurement programme (PPIP). Programme}

The Innovation Partnership Procurement programme aims to develop and implement new societal solutions using innovative public procurement in a cooperation framework. It is targeted towards solving complex and societal challenges across sectors, silos and governance levels. The goal is to accelerate the use of innovative public procurement as a tool for systemic innovation in the public sector, as well as market creation and closer cooperation between innovative companies and the public sector. The tool is jointly developed and delivered by Innovation Norway, The National Programme for Supplier Development and the Norwegian Digitalisation Agency. 3 ministries co-finance the PPIP budget. It benefits from the additional flexibility offered by the new European legal procurement procedure enacted in $2014 .^{15}$

The main steps of the PPIP are as follows (with a stage gate between phase 5 and 6):

2. Annual call for proposal: public sector entities (municipalities, regions, hospitals, state agencies and directorates) apply for funding to address specific societal challenges through innovative solutions

6. Needs analysis and problem identification: the selected public entities map user needs, the potential beneficiaries, the added value and costs.

7. Market dialogue : the selected public entities invite academia and companies to take part in workshops, info meetings, webinars etc. in order to develop a better understanding of the issue at hand and scan through the different potential solutions (and make sure that there is no solution currently available in the market).

8. PPIP Tender: a tender is launched using the European innovation procurement procedure Innovation Partnership. The object of the tender is the development of an innovative solution to the issue at stake.

9. R\&D and demonstration: the selected partners develop and test the solution.

10. Commercialisation: The public entities as well as any other public sector partner included in the process may - if the solution deemed attractive - trigger the procurement options (without additional tendering) and buy and implement the new solution.

Innovation Norway provides financial and technical support. During phase 4 for instance it coordinates different public actors to help launch joint procurements as much as possible. It allocates $10 \%$ of the project cost to the phase 2 and 3 . The remainder goes to the phase 5 .

14 Innovation Partnerships have been supported between 2016 and 2019 by the amount of NOK 136.5 million. They tackle challenges ranging from tunnel fire safety to high-tech self-help for cancer patients, energy efficient public buildings and the reduction of $\mathrm{Co} 2$ emissions when building railways/houses/roads. 5 to 8 new Innovation Partnerships will be selected and funded as part of the 2020 call for proposal. In 2019, the PPIP calls for proposal was coordinated with RCN's Pre-Commercial Procurement Programme.

So far one project started in 2016 reached the phase 6 . This project aims to develop tailor-made solutions for self-activation and self-empowerment of the elderly when returning from hospital.

The PPIP was positively evaluated in 2019. While most projects are still at an early stage, the assessment of the process and the survey showing a very high level of satisfaction among partners and participants indicate that the scheme is effective. Innovation Norway aims to develop this scheme in the future.

Source: Innoba (2019), Innovation Norway website; Information provided by Innovation Norway to OECD. 


\subsubsection{The increased use of "neutral" instruments}

According to SOA analysis, non-thematic instruments such as SkatteFUNN and the Programme for User-driven Research-based Innovation (BIA) ${ }^{16}$ account for an increasing share of the total public support to business R\&D (SØA, 2019). SkatteFUNN alone represented 55\% of the total public funding of business R\&D in 2017, up from 35\% in 2008 (OECD, 2019c]). While RCN notably implements a quantity of thematic R\&D programmes (including large-scale ones), their relative share in the total funding has decreased to such an extent that their synergies with neutral instruments are now put into question. While in the past neutral programmes complemented the thematic programmes both by mitigating thematic gaps, exploring new opportunities and strengthening the $\mathrm{R} \& \mathrm{D}$ capacity across the board, it seems that it is now thematic programmes that complement the neutral schemes. This shift "raises the question about the role of thematic programs should play in the future" (SØA, 2019).

This claim is backed by OECD data. The expansion of the tax credit scheme has been the main cause of the dramatic increase in government funding of R\&D since 2014 (Figure 9). 2014 was the year the ceiling of SkatteFUNN was doubled, followed by further rise in 2015, 2016 and 2017. Consequently the R\&D tax support increased from $0.04 \%$ of GDP in 2002 to $0.12 \%$ of GDP in 2018 (when it slightly decreased for the first time in 5 years). While it represented $35 \%$ of the total government support in 2008, it increased to 53\% in 2018 (Figure 10). Figure 10 also shows that despite this trend, Norway has still a significant amount of direct R\&D financing that can be mobilised to address specifically some selected challenges.

Figure 9. Direct government funding of business R\&D and tax incentives for R\&D, Norway, 2000-18 As a percentage of GDP

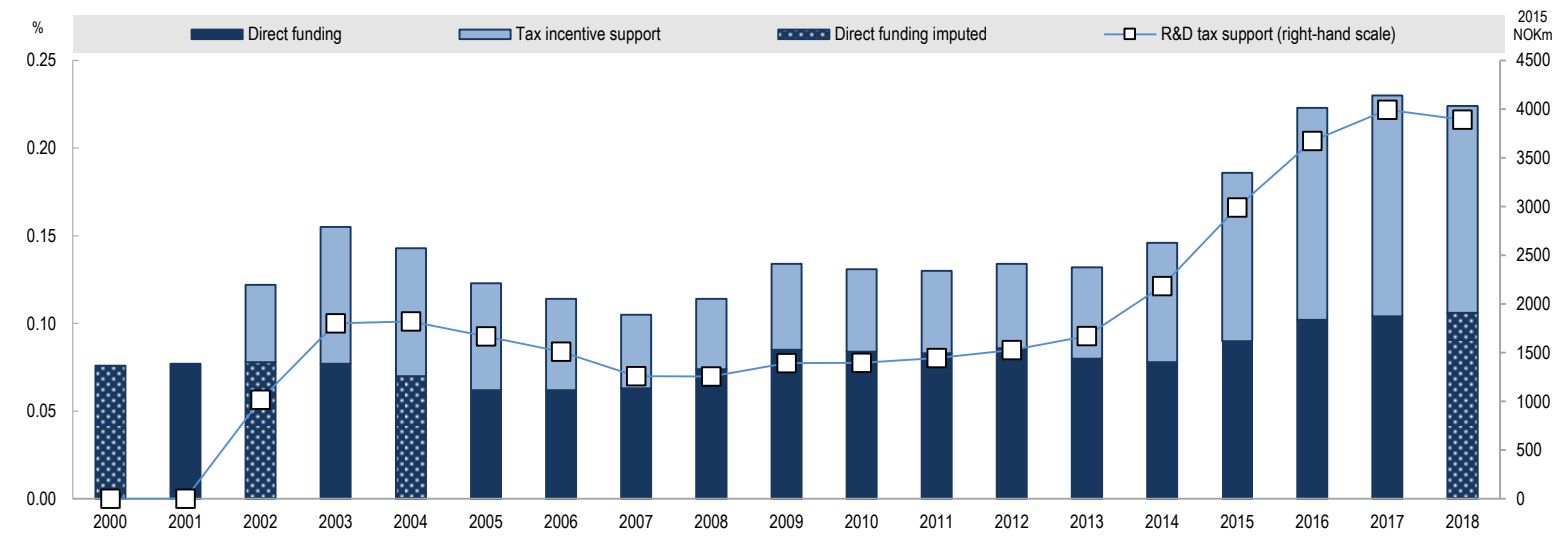

Source: OECD R\&D Tax Incentive Database, http://oe.cd/rdtax, December 2020.

Note: Right-hand scale: 2010 prices 
Figure 10. Direct and indirect government support to business R\&D, 2018 and 2006

\section{As a percentage of GDP}

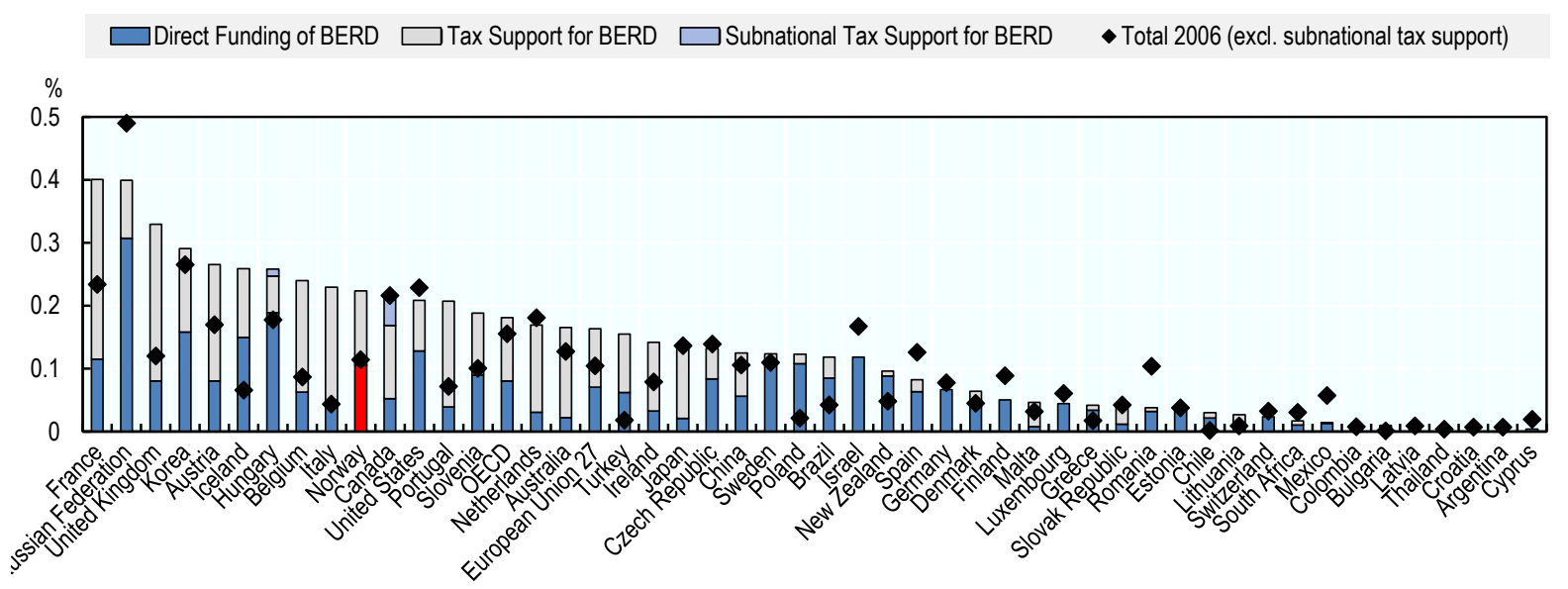

Source: OECD R\&D Tax Incentives Database, http://oe.cd/rdtax, December 2020.

Notes:

Note by Turkey: The information in this document with reference to "Cyprus" relates to the southern part of the Island. There is no single authority representing both Turkish and Greek Cypriot people on the Island. Turkey recognises the Turkish Republic of Northern Cyprus (TRNC). Until a lasting and equitable solution is found within the context of the United Nations, Turkey shall preserve its position concerning the "Cyprus issue".

Note by all the European Union Member States of the OECD and the European Union: The Republic of Cyprus is recognised by all members of the United Nations with the exception of Turkey. The information in this document relates to the area under the effective control of the Government of the Republic of Cyprus.

As regards the funding of public research, Figure 11 shows that Norway has a lower share of institutional (block) funding and a higher share of project (competitive) funding than comparator countries such as Denmark, France, Sweden and Austria (but lower project funding than the UK, US and Ireland). The two funding streams remain however balanced, which is appropriate for mission-oriented research which necessitates both institutional funding for building the long term research (and higher education) capacity and infrastructure, and project funding to steer strategically research towards national priorities. 
Figure 11. Percentages of institutional and project funding, year?

As a percentage of total GBARD

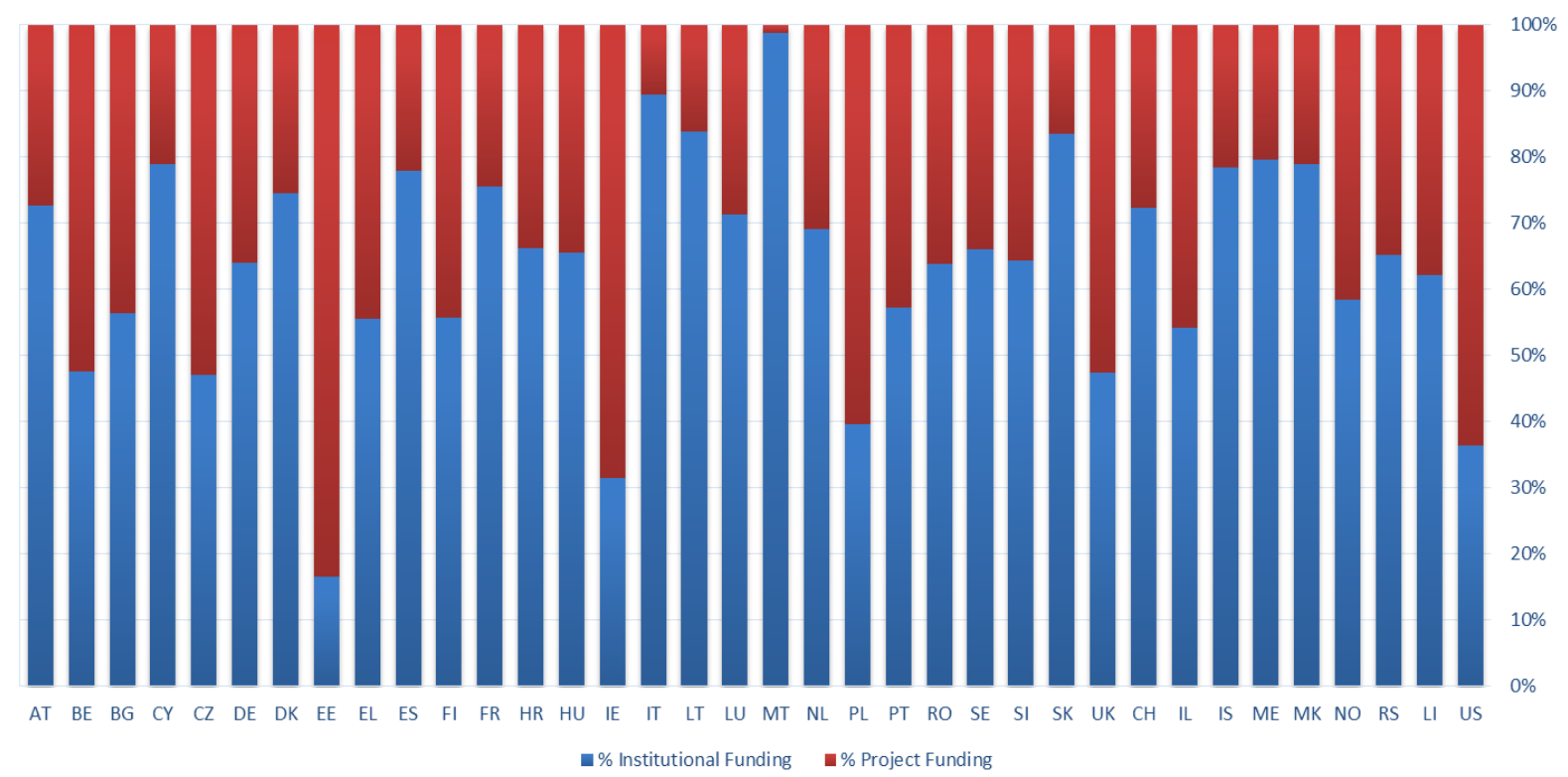

Source: Joint Research Center (2017)

Notes:

Note by Turkey: The information in this document with reference to "Cyprus" relates to the southern part of the Island. There is no single authority representing both Turkish and Greek Cypriot people on the Island. Turkey recognises the Turkish Republic of Northern Cyprus (TRNC). Until a lasting and equitable solution is found within the context of the United Nations, Turkey shall preserve its position concerning the "Cyprus issue".

Note by all the European Union Member States of the OECD and the European Union: The Republic of Cyprus is recognised by all members of the United Nations with the exception of Turkey. The information in this document relates to the area under the effective control of the Government of the Republic of Cyprus.

However, although they should not be overlooked, these trends do not preclude a mission-oriented approach:

- Norway has still sufficient financial resources and a national consensus that sustain strong investment to support research and innovation activities. The increase in indirect measures is not hollowing out the funds that could be dedicated to more oriented and voluntary schemes;

- MOIPs and more traditional policies are complementary not substitutes. First of all, MOIPs build upon (and often bundled together within a 'coordinated policy mix') other instruments, implemented by different policy bodies with complementary mandates. Second, there is still a need for open, non-thematic, policy instruments in order to, for instance, provide generic scientific knowledge and raise the general level of business R\&D investment across the board.

\subsubsection{Emerging trends toward mission-orientation}

Several of the funding and governance characteristics highlighted previously point to an STI system that is better suited to support well-established sectors rather than new areas for diversification. 
There are however some positive trends that bode well for the future with regards to the adoption of challenge-oriented, cross-sectoral and interdisciplinary policy approaches:

- There is an increasing number of initiatives that aim to promote cross-thematic collaboration. RCN for instance encourage knowledge transfer between research organisations pertaining to different areas through joint events and joint calls of thematic programmes in petroleum, renewable energy, fisheries and aquaculture. These efforts aim to develop new solutions in areas such as offshore engineering, construction of wind turbine foundations, maintenance of offshore installations, or use technology from the offshore industry to develop offshore farming. There have also been some interesting initiatives to stimulate cross-sectoral exchange in clusters. The two clusters GCE Subsea and NCE Seafood have jointly launched several cross-cluster initiatives to develop projects using competences and technology from the oil and gas industry to address challenges in aquaculture.

- Over the last 10-20 years, RCN has increasingly used Centres of Excellence and Centres of Excellent innovation to promote excellence in priority areas, in line with international trends. These hybrid forms of funding that mix competitive and institutional financial support have taken up a greater share of funding, in addition to the traditional programmatic activity. After being selected after a call for proposals, the centres receive 10-year funding. Much of them are in thematic areas of societal challenges or SDGs (for instance the dedicated centres of renewable energy, FMEs), and represent an attempt to create a more solid research and innovation landscape that combines high quality and international relevance.

- While RCN receives individual letters of instructions from the different ministries that finance its activities, it has in recent years been given more flexibility by some of its main principals to implement a portfolio approach, combining different demands, rather than responding to different ministries' requests by setting individual programmes or schemes. This materialises especially in shorter and less detailed letters of instructions. RCN has also modified its internal organisation to allow for such practices. Innovation Norway claims that it is also moving towards a portfolio approach, with better coordination and information exchange between its various programmes and schemes, including the supply-push and demand-side instruments. Another noticeable - although only emergent - evolution concerns the fact that Innovation Norway is increasingly supporting entire eco-systems instead of individual firms as it has done since its creation. This type of support is more suited to support strategic steering and collaboration, including in new 'transition' areas.

These trends leave more room for policy innovations, unconventional approaches and cross-cutting activities that are at the core of mission-oriented policies. The cooperation between RCN, ENOVA, and Innovation Norway as part of the Pilot-E mission-oriented initiative can be seen as resulting from such more holistic approaches to policy implementation (see Chapter 4).

\section{Mission-oriented policy initiatives in practice}

This section presents two MOIP initiatives in Norway: Pilot-E (environmentally friendly technologies for energy and transport); and CLIMIT (carbon capture and storage). The analysis of each case is performed along the three MOIP dimensions set out in the chapter 2. The full cases are presented in annex using the 'MOIP Design principles' (Larrue, 2021).

\subsection{Pilot-E}

Pilot-E is a cross-agency and challenge-oriented scheme that supports environmentally friendly technologies for energy and transport solutions from idea to market as a means of reducing emissions both in Norway and internationally. RCN defines PILOT-E as a "public mission-oriented instrument 
addressing societal challenges by combining financial schemes from different governmental bodies and tailoring them for targeted projects."

The PILOT-E scheme was launched in 2016 as a response to a general call by ministries to improve the coordination between the main Norwegian agencies, with a view to both initiate the necessary energy transition and develop new business activities. The Research Council, Innovation Norway and Enova organised a workshop to discuss different options, notably those revolving around the 'ARPA-E' model in the United States. The discussions being held at the level of implementation agencies, the more transformative options of mission-oriented policies were not considered as feasible and relevant to respond rapidly and effectively to the ministries' request. The 'acceleratortype' of MOIPs was therefore favoured from the beginning and received strong support from ministries as it was easier to explain and the expected results clearer than in the case of more systemic and transformative options.

The expected results of this joined-up approach are multiple:

- More rapid development via the fast tracking of projects through the toolbox of schemes of the different agencies

- Increased predictability of funding for project partners, hence more in-depth engagement on their side

- Seamless and continuous support to the same projects by the agencies from applied research to market deployment

- Initial selection of projects on the basis of a more comprehensive and better informed set of criteria, including the requirements at the various stages of the projects

Since its creation, several calls for proposals have been launched. Figure 12 provides a synthetic view of the Pilot-E scheme. 


\section{0 | MISSION-ORIENTED INNOVATION POLICY IN NORWAY}

Figure 12. Synthesis of the process, governance and MOIP features of Pilot-E
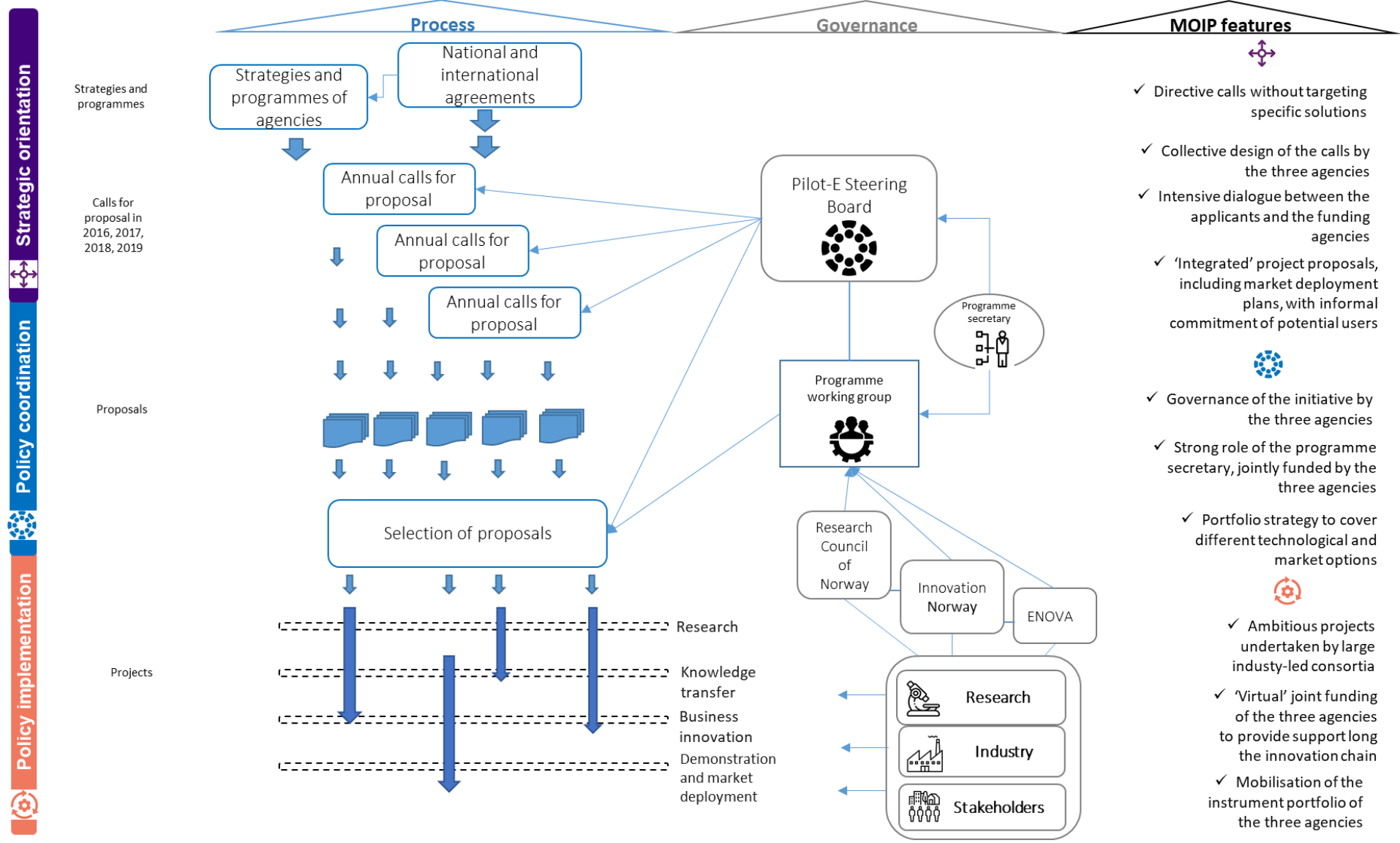

Source: MOIP online toolkit, https://stip.oecd.org/stip/moip 


\subsubsection{Strategic orientation}

The objective of Pilot-E is to develop, test and deploy new solutions for environmentally friendly energy and transport solutions in a given timeframe. This overall objective is embedded in several strategic frameworks, at the level of the agencies (e.g. RCN's Strategy for Sustainability 2017-2020) and at national level (e.g. Energy21, the annual national STI strategies in the energy area). It responds to these strategic frameworks by addressing challenges of national relevance, e.g. the significant problem of $\mathrm{CO} 2$ emissions and air pollution caused by freight ships as well as big cruise ships in Norwegian Fjords. The rationale underpinning the choice of the maritime sector as one theme is also economic since Norway has a strong maritime sector which covers most of the components of the value chain. Another criterium for focusing on this area was the importance of public authorities, notably on the demand side with municipalities.

Pilot-E provides concrete directions to potential beneficiaries by issuing targeted calls for proposal, with broad performance goals to be reached (for instance emission free land-based transportation) and no indication of any preferred technological options (for instance battery-powered or fuelled by hydrogen) $)^{2}$ :

- The 1st call in 2016: Emission free maritime transportation;

- 2nd call in 2017: Emission free land-based transportation; Digitalisation in the energy sector;

- 3rd call in 2018: Emission free maritime; transportation 2.0; Sustainable industrial processes for the future;

- 4th call in 2019: A zero-emissions hydrogen value chain; Zero-emissions construction and facilities.

- $5^{\text {th }}$ call in 2020: Zero-emission maritime transport; Climate neutral industry.

Based on these broad requirements, the applicants set the precise performance targets they aim to achieve in their projects with precise milestones. Applications must include a plan for a development pathway leading to market introduction and have measurable milestones that form the basis for a funding allocation.

Interestingly, although the scheme functions through competitive calls for proposals, the application process gives rise to many interactions between the agencies and the applicants. Given the level of ambition of the calls and the particular nature of the integrated scheme, the agencies perform some preparatory work to mobilise potential partners and explain the specificities of Pilot-E. Prior to some calls, the managers of the scheme even gather different companies to promote cooperation between them. These interactions avoid costly trial and error processes during the application stage and allow a greater strategic alignment between the agencies and the partners.

\subsubsection{Policy coordination}

Pilot-E is a joint initiative led by three Norwegian agencies, i.e. the Research Council of Norway, Innovation Norway and Enova. Although some of these agencies already had co-financed projects in the past and the managers of calls regularly met and exchanged in various occasions, this scheme is the first formal cooperation agreement including systematic co-decision and co-funding.

Although they operate under a general mandate of their principals which together cover most of the policy spectrum, the scheme is clearly led by the agencies. This is reflected in its lean governance structure composed of a Steering Board that gathers representatives of the three agencies and the Pilot-E project manager about three times a year. The latter, who also acts as the secretary of the Steering Group, is paid by the three partners. The Steering Board decides upon the overall plan for the scheme, the theme and content of the calls and receive the selected applicants. However, the power to decide on the selection and funding of the applicants lies at the upper-level programme to which Pilot-E pertains in each agency (e.g. Energix in the case of RCN). A 2-stages joint selection process that combines the selection criteria and process of the three partners has been specifically 
developed. A working group with advisers and theme specialists from inside and outside the agencies is in charge of developing one common recommendation for funding decision and of monitoring projects. They meet about 10 to 15 times per year.

The coordination is therefore deemed successful by the partners regarding the key decisions, i.e. developing the work programme and selecting the projects. On the operational side, the coordination is also considered beneficial as the three partners share the main operational tasks of running the scheme. RCN operates the call, Innovation Norway organises the applicants' interviews and ENOVA deals with the overall communication. However, some difficulties arose on detailed practical contingencies due to different rules and procedures between the agencies hindering the level of integration of the scheme. For instance, while RCN can fund consortia of firms, Innovation Norway can only fund individual firms, which create some contractual complications and add some bureaucracy for both applicants and the agencies. Hence, a consortium of three partners necessitates four contracts in total. On the reporting side, the same partners deliver only one joint progress report for the consortia, but three financial reports. There are also issues linked to EU RDI state aid rules, which set different funding rates according to the stages of the innovation process and the type of firms. One important implication is that there cannot be one unique contact point per project. The partners have to interact with representatives of the different agencies depending on the project phase. As can be expected from a pioneering initiative, Pilot-E is therefore not yet the one-stop-shop that partners had envisaged at the start.

Policy coordination between the three agencies also enables a more consistent and progressive portfolio approach in three ways:

1. In the context of the same call procedure, they tend to explore the technological landscape and fund different options, although in the end the partners intend to select the projects that best respond to the common criteria they have set. The first call funded for instance 15 consortia, including battery-powered ferries and hybrid hydrogen/battery ferries. They also deliberately cover different market segments from different types of passenger vessels (urban water vessels and others) to cargos and ferries of different sizes. The second call was purposively broad in order to cover various emission-free land-based transportation segments (light and heavy duty freight transport; Zero-emission construction machinery; Zero-emission public transportation);

2. from one call to the other, the level of ambition can be increased. While the first call for zero-emission maritime transportation did not specify other requirements than the absence of emission, the third call explicitly sought projects that commit to vehicles that can achieve higher performance in terms of for longer distances, at higher speed and/or for longer duration ('Emission-free maritime transportation 2.0');

3. finally, overall, despite its limited size, Pilot-E allows for a value-chain strategy. As part of the first call, Pilot-E funded not only projects of zero-emission boats but also zero-emission operation offshore wind power that could be used as charging stations for the vehicles. The third call also funded Zero-emission maritime transportation as well as infrastructure for zero-emission ships.

\subsubsection{Policy implementation}

Pilot-E aims to result in very concrete results, i.e. the deployment of new full-scale solutions in energy and transportation, such as various types of electric boats. The scheme is targeted towards consortia of two or more companies that have a complete plan from research to market deployment.

The Research Council of Norway, Innovation Norway and Enova combine multiple policy instruments and areas of expertise to provide a comprehensive support to selected project consortia all along the innovation cycle (Figure 13). RCN provides research grants for consortia's projects, Innovation Norway offer innovation subsidies, development grants, risk loans and equity for companies in the consortia and ENOVA risk loans and investment aids for demonstration and market deployment. ENOVA also act as a broker to help municipalities implement public procurements. The partners maintain also interactions with regulators as needed. These various instruments pertain 
to different schemes offered by each agency: RCN programmes (such as ENERGIX), Innovation Norway's Environmental Technology scheme, ENOVA's Market Change Support scheme, etc.

\section{Figure 13. Pilot-E as a fast-tracking scheme across sectors and stages of the innovation chain}

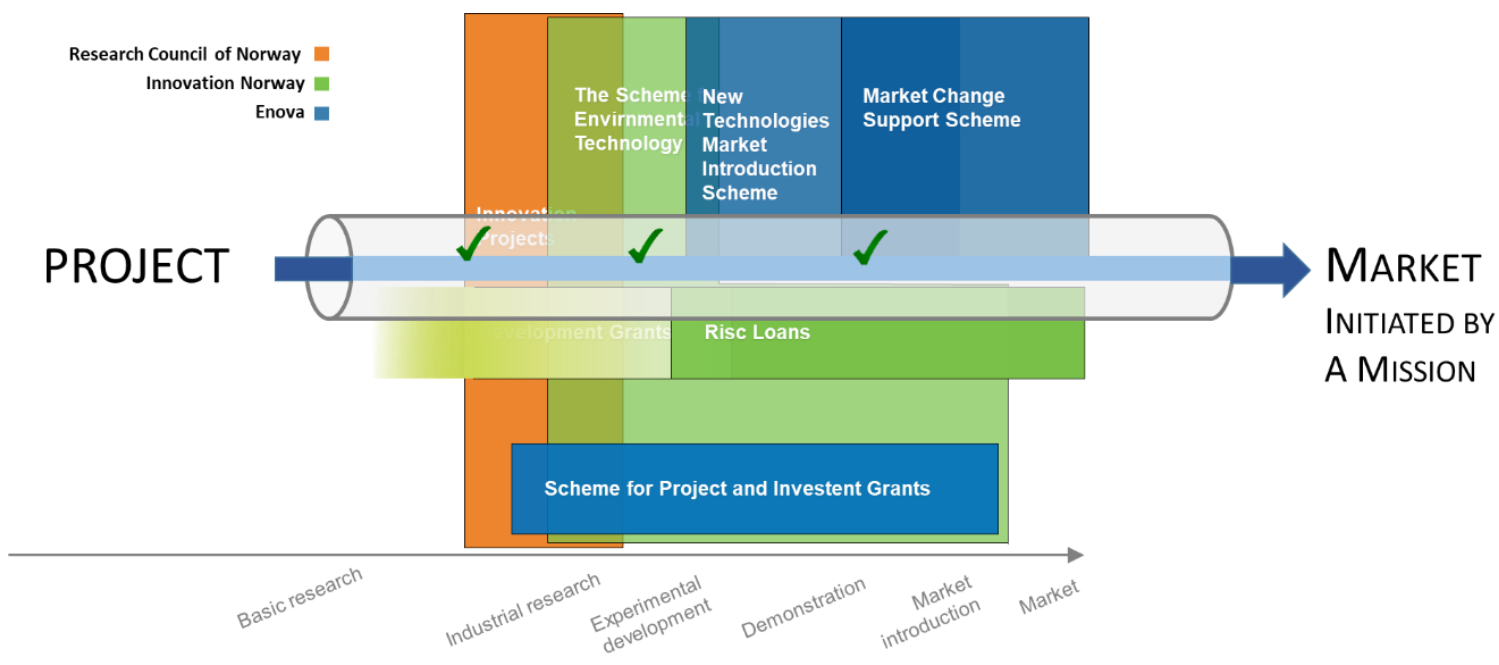

Source: Moengen T. (2019), PILOT-E - Fast track from concept to market, Presentation in Copenhagen, 26 June, RCN.

One of key expected novelties of Pilot-E lies in the articulation between the support to the supply and demand for innovation. The scheme requires that potential users of the solutions to be developed are on-board from the application phase and that the proposal includes market deployment plan. At this early stage, this plan is not binding and remains conditional to the success of the project in meeting its technological and cost targets. The agreement with the users at this stage is considered as a type of 'letter of intent' more than a formal contract. Likewise, the agencies do not commit to support the market deployment of the selected projects from the beginning, if only because the costs remain unknown until the last stage of the project. There is therefore a divide between the research and innovation stage and the market support stage. RCN and Innovation Norway offer a wellintegrated policy offer - although not yet as seamless as expected as previously mentioned- while ENOVA interventions only occur in a second phase and it is not formally included in the initial agreement. However, the integration of the whole process, from research to market deployment, is consolidated by trust relationships between the consortia partners and with the agency representatives.

Another issue, one that is not specific to MOIPs but that calls for significant communication and interactions with stakeholders and citizen, concerns the cost of innovative solutions. While the agencies claim that Pilot-E has succeeded in engaging the users of emission-free ferry technologies, i.e. ship-owners (partly owned by or subsidized by counties), the final users of the ferries themselves; i.e. citizen, have borne part of the burden of higher prices. This has led to protests during the winter 2020 .

\subsubsection{Strengths and margins for improvement}

Pilot-E is a voluntarist policy initiative that aims to guide/orientate early market creation, including through large-scale public procurement. It is in stark contrast with the mainstream policy rationale to merely correct market failures. By strengthening and systematising coordination between RCN, Innovation Norway and Enova, it integrates the financial means and intervention schemes of three of the main Norwegian agencies active in the STI system and can offer support along the entire pathway from research to market deployment. This joined up approach also allows for the funding 
for larger consortia that address more ambitious challenges, compared to the beneficiaries of each of the individual agencies.

The dense interactions between the applicants and the agencies during the proposal selection process allows for at the same time more directionality from public authorities and design of projects that are more suited to the real capacity of the project partners. The hands-on approach that characterises the role of public authorities in this initiative created a high level of trust among the various private and public actors, which has proved beneficial for increasing the intensity of their engagement and investment. The initiative managers claim for instance that they have secured the participation of traditionally risk-adverse ship suppliers in ambitious innovation projects, which has never been possible previously. The joint financing between the three agencies also increased the predictability of the funding, which also had a positive effect on the investment of private firms in the initiative.

The initiative has not yet become the one-stop-shop as it was expected to be. While it offers a seamless support from research to development, it does only imperfectly supress the divide between the supply-push and demand-side instruments.

Pilot-E is being progressively streamlined in other thematic areas, under the generic 'Pilot-X model'. Pilot-X schemes are launched in areas where major societal challenges are in urgent need of solutions and where it is necessary to establish cooperation between actors that do not normally work together. To date, this model is applied since 2019 in the area at the interface between transport and ICT technologies via the Pilot-T scheme. It builds upon a cooperative agreement between RCN and Innovation Norway (the latter under a mandate of the Ministry of Transport). It is also being considered in the health (Pilot-H), circular economy (Pilot-S), bio-economy or even ocean areas. As claimed by the partners, Pilot-E has now become a brand mark for interagency cooperation in Norway.

\subsection{CLIMIT}

CLIMIT is a programme for research, development and demonstration of carbon capture and storage technologies (CCS). Although RCN (programme Klimatek in 1997) and Norwegian O\&G companies have done research on CCS since the 1990s, lively political debates on CCS really started in the 2000s when Norway initiated discussions on the different options to make the extraction of natural gas more sustainable. Oil and gas extraction is, with transport, the main sources of emissions in Norway, mainly coming from the use of natural gas to drive turbines that supply the power on both offshore and onshore platforms. The committee appointed to advise the government on this matter concluded in 2002 that more R\&D on CCS was needed. The government established in 2005 a new agency under the Ministry of Petroleum and Energy - Gassnova - tasked with supporting R\&D and demonstration on CCS. The same year the programme CLIMIT was jointly initiated by Gassnova and RCN to support the development of CCS technology for natural gas power plants. The scheme was expanded in 2008 to include power generation based on all fossil fuels and in 2010 capture of industrial emissions were added to the work programme. It now supports CCS technologies in a range of key industrial sectors. The programme is in fact composed of two main components, CLIMIT R\&D and CLIMIT Demo, respectively led by the Research Council of Norway and Gassnova.

CLIMIT has supported development of CCS technology in Norway for more than ten years and is still one of the main CCS R\&D programmes globally. CCS is seen as one important way to achieve the Norwegian commitments as part of the Paris Agreement.

The Ministry of Petroleum and Energy (MPE) is the main funder of this programme, allocating about NOK 100 million per year to both Gassnova and RCN. Since the creation of CLIMIT, each of the two agencies have received more than NOK 1 billion from MPE. Figure 12 provides a synthetic view of the CLIMIT Programme. 
Figure 14. Synthesis of the process, governance and MOIP features of CLIMIT

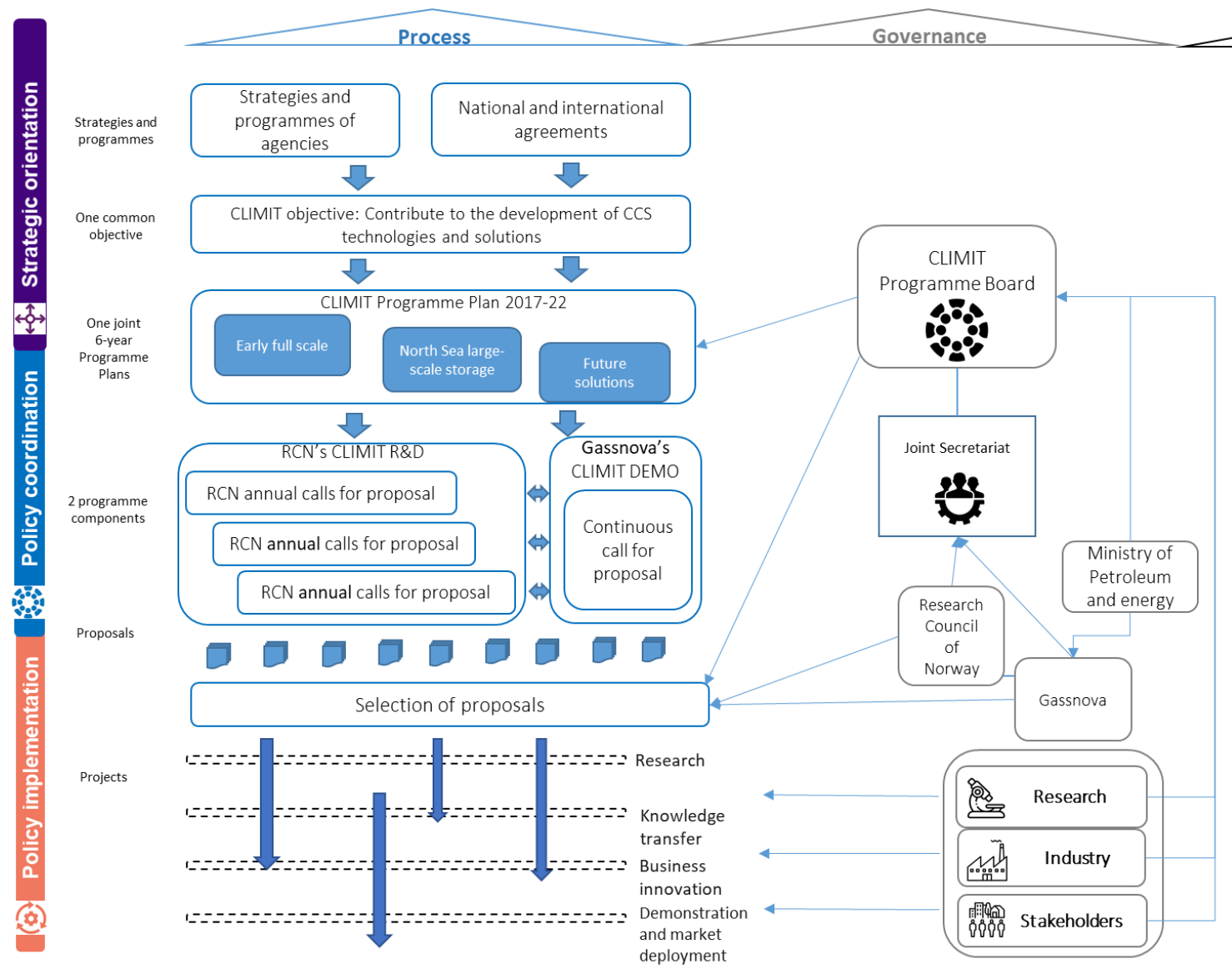
MOIP features

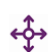
$\checkmark$ Build on a long history of R\&D on CCS technology in Norway, with this technological area
$\checkmark$ A 6-years programme plan jointly developed by the researchers, in the Programme Board, as well as representatives and experts of the two agencies
two different times horizons 8.
$\checkmark$ Joint initiative led by two agencies
$\checkmark$ Numerous interactions between the two agencies within a joint
secretariat
$\checkmark$ Lean governance structure
$\checkmark$ Implementation of a project portfolio approach (क)
$\checkmark$ Articulation between the support to R\&D and demonstration $\checkmark$ Different types of instruments mobilised by the two agencies to support the selected projects along the entire innovation chain $\checkmark$ Hands-on approach of the agencies, in particular Gassnova, dense interactions with project partners

Source: MOIP online toolkit, https://stip.oecd.org/stip/moip 


\subsubsection{Strategic orientation}

CLIMIT's primary objective, as stipulated in its mandate, is to contribute to the development of CCS technologies and solutions by providing financial support to projects that will:

- develop knowledge, expertise, technology and solutions that can contribute towards cost reductions and international deployment of CCS.

- leverage national advantages and develop new technology and service concepts with commercial and international potential.

The main orientations are presented in the CLIMIT 6-years Programme Plan. This document is developed by the Programme Board and advisers at RCN and Gassnova in consultation with other stakeholders and academics. The Programme Plan for 2017-2022 is focused on targeting future CCS activities and the opportunities that may be created through international application of this technology in order to drive CCS costs down through economies of scale and scope.

The programme has three focus areas with different timeline. Performance goals for the programme plan period have been established for each focus area Table 7.

\section{Table 7. Performance goals by focus area}

\begin{tabular}{|c|c|}
\hline Focus area & Performance goals \\
\hline $\begin{array}{l}\text { Early full-scale CCS value chain in } \\
\text { Europe (demonstration, until 2022) }\end{array}$ & $\begin{array}{l}\text { Contribute to making Norwegian technology and solutions available to the CCS value chains } \\
\text { being realised in Norway and Europe. } \\
\text { Contribute to using experience from the work on the first full-scale projects for further } \\
\text { expertise and technology development }\end{array}$ \\
\hline $\begin{array}{l}\text { Large-scale storage of } \mathrm{CO} 2 \text { on the } \\
\text { Norwegian shelf in the North Sea } \\
\text { (dissemination until 2025) }\end{array}$ & $\begin{array}{l}\text { Contribute to the acceleration and scale up of technology and solutions for large-scale } \\
\text { storage of } \mathrm{CO} 2 \text { on the Norwegian continental shelf in the North Sea. }\end{array}$ \\
\hline $\begin{array}{l}\text { Future solutions for CCS (until } 2035 \text { and } \\
\text { beyond }\end{array}$ & $\begin{array}{l}\text { Contribute to making CCS technology available to a wide range of industries at a competitive } \\
\text { cost. }\end{array}$ \\
\hline
\end{tabular}

Source: CLIMIT (2017)

The Programme Plan specifies concrete knowledge gaps but does not specify precise targets to be achieved. These are developed by the applicants themselves at the level of projects. These targets, which must be verifiable and, to the extent possible, quantifiable are established in a contract or funding letter signed by the project manager on the side of the beneficiary and one of the two agencies.

While RCN develops its own annual calls for proposal based on the Programme Plan, Gassnova implement continuous calls using directly the Programme Plan as the guide for potential applicants. Funding decisions are made by the Programme Board based on the ranking from the secretariat and the agencies' advisers. The Programme Board in most cases follow the recommendations of the secretariat, although some political issues can sometimes justify some changes.

While CCS is promoted by the Intergovernmental Panel on Climate Change (IPCC) and the International Energy Agency (IEA), this technology is still debated in Norway as in several countries. The effect of the failure of the first project of full-scale CCS plant in Mongstad has severely affected the legitimacy of this technology for some years. This high visibility project considered to be the equivalent of moon landing for Norway by the Prime Minister at the time - was launched in 2006. However, the full-scale CCS plant started in 2012 was abandoned as soon as 2013 for a combination of cost factors, technological uncertainty and political turmoil. This first national 'mission' in Norway was therefore considered a failure. Following this, the project was turned into a pilot plant known as the Technology Center Mongstad (TCM), still active today. Although it is not formally part of it, the TCM is managed by Gassnova and has numerous exchanges of knowledge and experience with the CLIMIT programme. More recently, the pressing challenge of climate 
mitigation has revived interest in CCS and strong advocates of this option are active, in the research, industrial and political communities.

Hence, the current efforts in CCS in Norway are three-fold: the CLIMIT-program, the National fullscale CCS project now named "Longship", and the Northern Lights project. The national full-scale CCS comprises the whole chain of CCS, namely capture of $\mathrm{CO} 2$ from a cement plant in Brevik in the south-east of Norway, a transport solution by ship to Øygarden on the west coast of Norway, and finally injection into a geological formation on the Norwegian Continental Shelf for permanent storage. The Longship project also includes support to a capture pilot at a waste incinerator in Oslo, but this support is given with the provision that the beneficiary acquires third party funding from the EU or elsewhere. The Northern Lights project concerns the transport and storage part of the Longship project. This represents an investment of NOK 17.1 billion (about Euro 1.6bn, the bulk being supported by public funds) It is conducted based on an agreement between Equinor, Shell and Total and includes transport by ship to a storage facility on the west-coast of Norway as well as drilling a well for final storage at the Norwegian continental shelf. The CLIMIT project will therefore serve these highly prioritised activities with research, innovation and demonstration activities.

\subsubsection{Policy coordination}

The CLIMIT programme is carried out in cooperation between the Research Council of Norway, which manages CLIMIT R\&D, and Gassnova which is in charge of CLIMIT Demo. Coordination is ensured by a joint secretariat composed of about four Gassnova employees and less than two employees at RCN. The programme manager is from Gassnova who takes also charge of most of the administrative work at overall programme level.

The main governance structure of CLIMIT is the Programme Board. Its 10 members originate from industry, universities and research institutes and are appointed by the MPE. A representative of the Norwegian Petroleum Directorate (under the MPE) is included among the members of the Programme Board. One representative from the MPE serves as an observer in the Programme Board. The joint secretariat prepares and attend the meetings of the Programme Board, about five times a year. The chair of the Programme Board reports to both the Executive Board of RCN and the Board of Gassnova.

MPE is the only ministry that funds the programme and is involved in its governance. The coordination across policy fields within CLIMIT relies therefore mainly on the joint secretariat involving the two agencies. Although the programme is far from an integrated one-stop-shop with its two programme components operating through distinct calls with different timelines, numerous interactions among the members of the secretariat allow exchanges of information between the R\&D and Demo parts. Applications can for instance be directed to the other components if considered relevant.

Taking advantages of synergies between its two components, one of the objectives of CLIMIT, as specified in its work programme, is also to accelerate the time from research to demonstration and to increase the chances that research progress are taken up by industry partners. To achieve this, the programme promotes the articulation between the upstream and downstream ends of the innovation chain: the applications to RCN CLIMIT R\&D calls must include a plan for demonstration; the applications to Gassnova CLIMIT Demo must include detailed information on past research activities. CLIMIT Demo also requires the project applicants to explain how the development work will be integrated in a commercialisation plan, including handling of intellectual property rights (CLIMIT, 2019). However, in reality not more than one out of ten projects funded under CLIMIT R\&D follow through to CLIMIT Demo as the engagement of companies in actual development and demonstration is difficult to secure.

CLIMIT also aims to adopt a portfolio approach to cover different CCS solutions, pertaining to:

- different generations of technology, at different scale, according to the different focus areas (see Figure 15); 
- different technological options, for instance to separate $\mathrm{CO}_{2}$ from other compounds emitted during an industrial process in order to allow for its capture;

- aspects of the CCS chain from industrial processes with integrated $\mathrm{CO}_{2}$ capture, to transport and storage of $\mathrm{CO}_{2}$. Projects regarding the use of $\mathrm{CO}_{2}$ are supported in CLIMIT only if the $\mathrm{CO}_{2}$ is not released into the atmosphere after being used;

- different sources of $\mathrm{CO}_{2}$, e.g. power generation or other industrial sources. The requirement for long-term storage means that the programme can also support development of technology that utilises $\mathrm{CO}_{2}$ to make new products, provided the $\mathrm{CO}_{2}$ is not released in the atmosphere when being used.

\section{Figure 15. CLIMIT and the exploration of different versions of the technology}

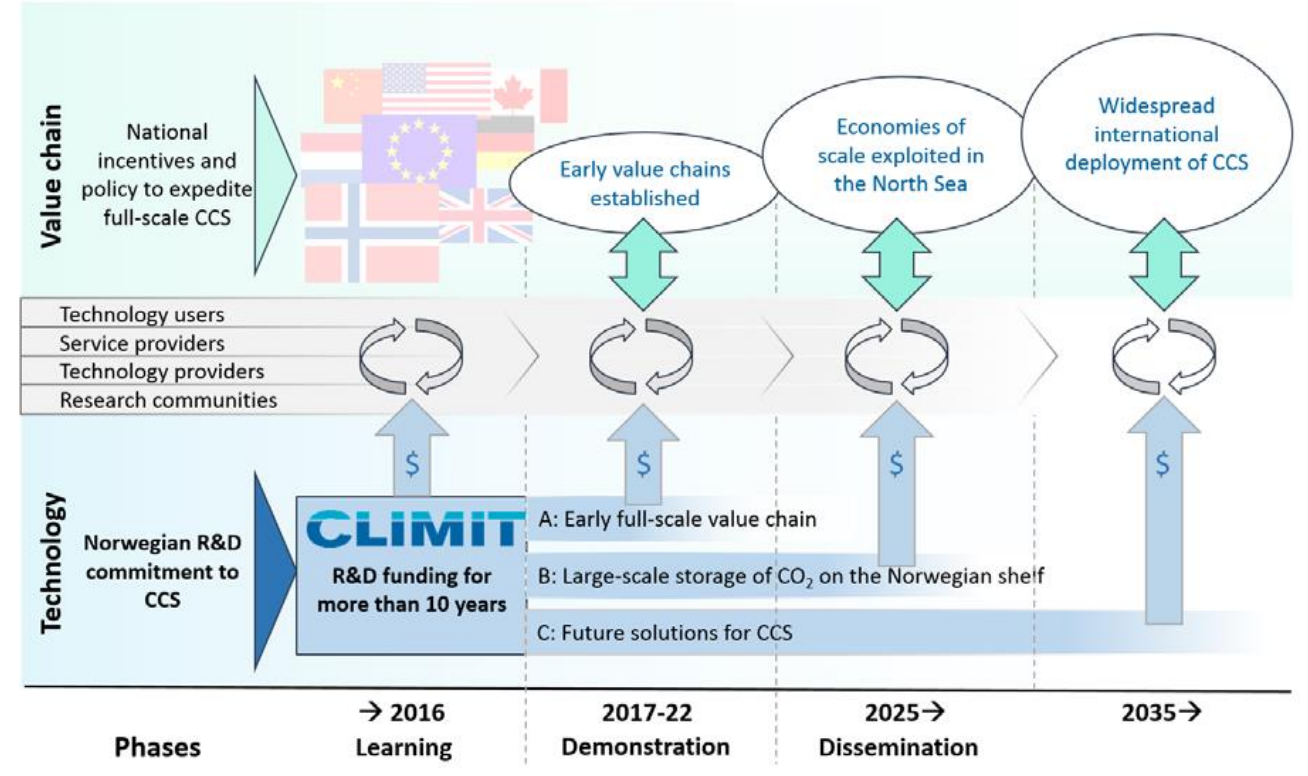

Source: CLIMIT (2017)

\subsubsection{Policy implementation}

The two agencies mobilise different types of in-house instruments to support the project. On CLIMIT R\&D side, RCN utilises different projects:

- Researcher Projects cover basic research that provides new knowledge which can be used to develop products and services;

- Knowledge-Building Projects for Industry contribute to industry-oriented researcher training and long-term competence development in the Norwegian research community within topics that are crucial to the development of business and industry in Norway;

- Innovation Projects for the Industrial Sector stimulate R\&D activity in trade and industry, particularly activities that promote innovation and sustainable value creation.

As for CLIMIT Demo, Gassnova also uses different types of projects:

- Industrial development Projects to apply research results to the development of new technologies or solutions or to substantially improve existing solutions;

- Pilot and Demonstration Projects are the final step before commercialisation of new products and services, and can comprise construction of facilities for testing of technology; 
- Other support can comprise of feasibility projects for development and pilot projects, support for international collaboration, or participation in strategically important international forums.

The two agencies voluntarily maintain some overlaps between RCN's Innovation Projects and Gassnova Industrial development Projects in order to let the companies at this pivotal stage choose the schemes that are most suited to their plans.

Since there is no market for $\mathrm{CO}_{2}$, the regulatory framework that applies to CCS is key to provide incentives for companies to engage in this technology. However, CLIMIT does not include activities to support and inform regulatory reforms. The MPE deals directly with regulators, for instance regarding the international transfer of $\mathrm{CO}_{2}$.

In order to increase their engagement in the programme, Gassnova also maintains intensive dialogue with companies to guide them during the project application and implementation stages.

\subsubsection{Strengths and margins for improvement}

The main added-value of this scheme consists in the joint action between the two agencies which allows for a greater coverage and better coordination under one programme of different technologies, stages of the innovation chain and components of the CCS value chain. The governance structure is lean and enables dense interactions and a high level of trust between the partners.

A hands-on approach of the agencies, in particular Gassnova, including during the competitive application stage is also instrumental in improving the engagement of private companies in a range of complex, costly and non-consensual technologies.

The articulation of the supply and demand for knowledge and innovation is also important in maintaining a pipeline from demonstration and deployment back to the research stage.

However, despite exchange of information and numerous interactions, the two programme components remain quite distinct and only a small portion of $R \& D$ projects continue to the demonstration stage. Although this is due in great part to the difficulty to mobilise industry partners, a greater integration may improve the 'hinge' between the two phases of the innovation process.

Strategic consistency might also be improved if a governance body could gather representatives of the ministry, the two agencies, and if possible other relevant ministries, to provide orientation to the programme. Currently, the Chair of the Programme Board reports individually to the RCN, Gassnova and MEP. In case of diverging views, the absence of direct interactions between the programme 'owners' can engender significant strategic problems.

\section{Conclusions and options for the future of the mission-oriented policy agenda in Norway}

\subsection{The Norwegian STI institutional setting is conducive to mission-orientation}

Norway is fully engaged in addressing societal challenges. Societal challenges are prominent in all overarching or thematic strategies, in particular the combat against climate change in order to fulfil commitments under the Paris Agreement to cut Carbon emissions by $40 \%$ by 2030 . Norway has also demonstrated strong interest in the adoption of better targeted and coordinated policies - be they labelled as mission-oriented policies or not - and have made significant strides in that direction by creating new pilot initiatives and modifying the objectives, design and governance of existing initiatives to make them more directional, better coordinated across policy fields and more effectively implemented.

While Norway has started only recently to implement purpose-built mission-oriented policies (see next chapter), its system of research and innovation - gradually built and improved over decades holds specific characteristics that offer a conducive ground for mission-orientation. Furthermore, 


\section{0}

mission-oriented policies could help solve some of the long-standing limitations of the Norwegian system. Notably, the system of innovation has evolved without a formal high level-agenda-setting body in the last decade. The launch and revision LTP mark a significant improvement in that matter, although the priorities remain broad and the interdepartmental monitoring groups have not met anymore after the three first years. Moreover, the so-called sector principle makes inter-ministerial coordination of research policy difficult but the small size of the country, some institutions (Cabinet meetings) and mechanisms (budgetary negotiations, integrated governance of RCN, DFU, etc.) and a tradition of consensus-building have mitigated the negative effect of a fragmented policy landscape. It has also been conducive to a stronger involvement in and ownership of STI policy by sectoral ministries in their own policy fields. This configuration has been effective for driving incremental patterns of improvement, but seems less adequate to support a more transformational 'triple transition' agenda.

Table 8 summarises the main institutional features that influence the capacity of the government to adopt a more mission-oriented policy approach in Norway. 
Table 8. Main challenges and opportunities of innovation systems in Norway for adopting missionoriented policies

\begin{tabular}{|c|c|c|c|}
\hline & & & (1) Policy implementation \\
\hline Opportunities & $\begin{array}{l}\text { - A widely acknowledged } \\
\text { need for a transition } \\
\text { beside O\&G, towards } \\
\text { societal challenges } \\
\text { Active role of STI policy } \\
\text { in Norway's past and } \\
\text { current development, } \\
\text { high level of } \\
\text { government support to } \\
\text { STI activities } \\
\text { The } 2014 \text { Long-Term } \\
\text { Plan as a first step } \\
\text { towards high level, } \\
\text { cross-ministerial STI } \\
\text { prioritisation, although } \\
\text { the priorities remain } \\
\text { broad and 'unsurprising' } \\
\text { "21-Strategies" are } \\
\text { sectoral platforms that } \\
\text { gather firms and } \\
\text { stakeholders to advise } \\
\text { the government on STI } \\
\text { priorities in their area }\end{array}$ & $\begin{array}{l}\text { The size of the country } \\
\text { favours exchange of } \\
\text { information and multiple } \\
\text { interactions even in } \\
\text { absence of formal } \\
\text { mechanisms } \\
\text { No high level strategic } \\
\text { council for holistic } \\
\text { coordination but several } \\
\text { mechanisms support } \\
\text { cross-ministerial and } \\
\text { cross-agency } \\
\text { coordination } \\
\text { Coordination of research } \\
\text { and research-based } \\
\text { innovation interventions } \\
\text { of different ministries by } \\
\text { using one single } \\
\text { research council (RCN), } \\
\text { with a common } \\
\text { governance system led } \\
\text { by MER } \\
\text { Many examples of } \\
\text { sectoral strategies } \\
\text { involving several } \\
\text { ministries } \\
\text { Several ministries } \\
\text { involved in research and } \\
\text { innovation; stronger } \\
\text { ownership of STI policy in } \\
\text { their own 'sector' }\end{array}$ & $\begin{array}{l}\text { - A comprehensive STI instrument } \\
\text { policy portfolio } \\
\text { - An increase of indirect } \\
\text { instruments but still significant } \\
\text { resources for 'oriented } \\
\text { instruments' - possibility to } \\
\text { leverage complementarities } \\
\text { between mission-oriented and } \\
\text { neutral instruments } \\
\text { Pilot MOIP initiatives at } \\
\text { programme/scheme levels on } \\
\text { which to learn and build } \\
\text { Significant efforts to implement a } \\
\text { strategic portfolio approach to } \\
\text { programme management at } \\
\text { RCN, based on stronger } \\
\text { autonomy given to the Agency } \\
\text { Numerous initiatives to promote } \\
\text { interdisciplinary and cross- } \\
\text { sectoral research and } \\
\text { innovation collaborations }\end{array}$ \\
\hline Challenges & $\begin{array}{l}\text { No strong agenda- } \\
\text { setting mechanism/ at } \\
\text { the highest level of the } \\
\text { STI system } \\
2018 \text { revision of the } \\
\text { Long-Term Plan was } \\
\text { not used to establish } \\
\text { more precise priorities } \\
\text { and targets } \\
\text { No cross-sectoral } \\
\text { platforms for joint action } \\
\text { to address societal } \\
\text { challenges (but some } \\
\text { voice in industry calls } \\
\text { for a 'super } 21-\text { Forum') }\end{array}$ & $\begin{array}{l}\text { - Highly sectoral } \\
\text { governance structure } \\
\text { ("sector principle") that } \\
\text { gives authorities to each } \\
\text { ministry to implement its } \\
\text { own STI interventions in } \\
\text { its area } \\
\text { Rather weak coordination } \\
\text { between ministries in } \\
\text { charge of research policy } \\
\text { and innovation policy }\end{array}$ & $\begin{array}{l}\text { - Still limited offer of demand-side } \\
\text { policy instruments and } \\
\text { disconnection from the supply } \\
\text { side instruments } \\
\text { Fragmented business innovation } \\
\text { policy support landscape as } \\
\text { shown by recent review of } \\
\text { business-related policy mix } \\
\text { Challenging for RCN to work } \\
\text { strategically due to both strong } \\
\text { interest groups and in practice } \\
\text { little room for maneuver. }\end{array}$ \\
\hline
\end{tabular}




\subsection{Several well-established MOIP initiatives help raise awareness and learning on mission-orientation}

Norway has already implemented several policies and programmes with strong mission-orientation features. Two of them are Pilot-E (carbon-free transportation) and CLIMIT (carbon capture and storage). More recently, the national response to the COVID-19 pandemic shows that Norway can propose unified and novel approaches when there is a shared political understanding of the challenge to be solved. Although not covered in this study as it is too recent, the Green Platform Initiative jointly run by the Research Council, Innovation Norway and Siva could represent a significant MOIP initiative to support green technology projects in a better targeted and coordinated way.

\section{Box 5. The Green Platform Initiative}

The Green Platform Initiative is a new scheme that aims to support large-scale R\&D and innovation projects that coordinate joint actions along the whole innovation chain from upstream research to business development, commercialisation and scaling of green transition processes, products and services. It was part of the Norwegian Government's third package of financial measures launched in May 2020 in response to the coronavirus pandemic. It has a budget of NOK 1 billion over a period of three years (2020-2022). Beyond this period, the Green platform is also meant to be a long-term vehicle for cooperation between the ministries and between the agencies. However, this longer term option has not yet been formalised, the actors involved are still in a learning phase.

The scheme has green transition of the industrial sector as a goal and does not focus on any sectors or technologies in particular to achieve this goal.

This initiative builds on the lessons learned from the Pilot-E and Pilot-T schemes. Five ministries participate in the Green Platform Initiative: The Ministry of Trade, Industry and Fisheries, Ministry of Research and Education, Ministry of Petroleum and Energy, Ministry of Climate and Environment, Ministry of Agriculture and Food and the Ministry of Transport and Communication.

It is a joint initiative where RCN, Innovation Norway and Siva complement each other and coordinate their funding instruments towards the common goals. Projects are funded in two steps to allow for a gradual approach: pre-project (up to three months and NOK 300,000), leading to large-scale projects ( 3 years and NOK 50 million per project). There is however no formal link between the pre-projects and the large-scale project applications. Actors can apply for the large projects without having applied for a pre-project.

Source: https://www.forskningsradet.no/en/apply-for-funding/the-green-platform-initiative/what-is-thegreen-platform-initiative/

The MOIP initiatives implemented in Norway are highly influenced by the specific national institutional setting in which they are embedded. Preference has been given in Norway to smallerscale initiatives led by agencies, aiming for 'accelerator' missions, rather than large and more disruptive/transformative national missions (Pilot-E and CLIMIT). When scanning through the MOIP landscape worldwide, one can indeed identify two main types of MOIPs: the 'National mission-oriented strategic frameworks' and the 'Moonshot challenge-based programmes' (Table 9). 
Table 9. Basic characteristics of the two core types of MOIPs

\begin{tabular}{|c|c|c|c|}
\hline Type & Leadership & Missions & Examples \\
\hline $\begin{array}{l}\text { National mission-oriented } \\
\text { strategic frameworks }\end{array}$ & $\begin{array}{l}\text { - Center of government } \\
\text { - High-level committee }\end{array}$ & $\begin{array}{l}\text { - Multiple missions or mission areas } \\
\text { - Pursuing ambitious challenges, } \\
\text { including transformative change } \\
\text { - Long-term horizon }\end{array}$ & $\begin{array}{l}\text { - Horizon Europe [EU] } \\
\text { - Mission-driven Top Sectors } \\
\text { policy [NL] } \\
\text { - High Tech Strategy } 2025 \text { [DE] }\end{array}$ \\
\hline $\begin{array}{l}\text { Moonshot challenge-based } \\
\text { programmes }\end{array}$ & $\begin{array}{l}\text { - Ministry } \\
\text { - Agency }\end{array}$ & $\begin{array}{l}\text { - Focused } \\
\text { - Seeking incremental or } \\
\text { breakthrough results } \\
\text { - Better fit for 'accelerator' missions } \\
\text { - Mid- to long-term horizon }\end{array}$ & $\begin{array}{ll}\text { - } & \text { Pilot-E [NO] } \\
\text { - } & \text { Moonshot R\&D Program [JP] } \\
\text { - } & \text { Industrial Strategy Challenge } \\
& \text { Fund [UK] }\end{array}$ \\
\hline
\end{tabular}

'National mission-oriented strategic frameworks' are broad initiatives set up at the highest level of policy making. They are characterised by concrete and ambitious targets that help coordinate actions among a wide array of public and private actors.

'Moonshot challenge-based programmes', such as Pilot-E and to a lesser extent CLIMIT, are focused on specific and ambitious problems to be solved and are implemented by dedicated agencies or programmes with strong leadership. To various degrees, these initiatives often borrow some of their characteristics from the US Defence Advanced Research Projects Agency (DARPA) programmes, in particular the competitive calls for proposal or other solicitation process based on clearly spelled-out challenges (giving them some flavour of a technology contest) and a strong delegation of authority to some of the key leaders (often under the title of 'project managers' or 'programme directors'). The challenges they pursue are often of technological or even scientific nature, in line with their focus and their narrow scope. These features often do not lend themselves well to tackling societal challenges that involve broader changes in individual and collective behaviours, formal and informal institutions and, not least, value systems.

The closest Norway ever got from top-down national missions was the already mentioned 'Norwegian moon-landing mission' on CCS and the famous electric vehicle policy. While the first one has been widely reported as a mission failure initially, ${ }^{1}$ the second one is considered a success. However, the extent to which the country can learn from this experience to implemented MOIPs is questionable. The JIIP study considered it as a mission-oriented policy initiative aiming for ambitious targets, ${ }^{2}$ but also highlighted that it remains very dependent on single policies, i.e. tax subsidies, without coordination with significant support for the supply side (European Commission, 2018). 
Table 10. Main features of selected MOIP initiatives in Norway

\begin{tabular}{|c|c|c|c|}
\hline & & $\begin{array}{l}868 \\
808 \\
808\end{array}$ & (4) Policy implementation \\
\hline Pilot-E & $\begin{array}{l}\text { - Targeted interventions towards } \\
\text { new solutions for environmentally } \\
\text { friendly technologies for energy } \\
\text { and transport in a given timeframe } \\
\text { - Significant potential impact on CO2 } \\
\text { emissions } \\
\text { - No picking of selected technologi- } \\
\text { cal solutions } \\
\text { - Applications include a market } \\
\text { introduction plan } \\
\text { - Dense interactions between the } \\
\text { agencies and the applicants during } \\
\text { the call for proposal process } \\
\text { - Hands-on approach of the } \\
\text { agencies }\end{array}$ & $\begin{array}{l}\text { - Joint initiative led by three of the } \\
\text { main Norwegian STI agencies, } \\
\text { under the aegis of three different } \\
\text { ministries } \\
\text { - Lean governance structure but } \\
\text { strong coordination between the } \\
\text { agencies } \\
\text { - Implementation of a project } \\
\text { portfolio approach that allows an } \\
\text { exploration of the technological } \\
\text { landscape and a greater coverage } \\
\text { of the different market segments } \\
\text { and components of the value chain }\end{array}$ & $\begin{array}{l}\text { - Combination of multiple policy } \\
\text { instruments and areas of expertise } \\
\text { to provide comprehensive support } \\
\text { across the innovation chain } \\
\text { - Articulation between the support to } \\
\text { the supply and demand for } \\
\text { innovation. } \\
\text { - Problem owners and users } \\
\text { participate in the projects from the } \\
\text { inception stage }\end{array}$ \\
\hline CLIMIT & $\begin{array}{l}\text { - Address a significant source of } \\
\text { emissions, in a key sector of the } \\
\text { Norwegian economy } \\
\text { - Build on a long history of R\&D on } \\
\text { CCS technology in Norway, with } \\
\text { opportunities to become leader in } \\
\text { this technological areas } \\
\text { - A 6-years programme plan jointly } \\
\text { developed by the researchers, } \\
\text { industry partners and stakeholders } \\
\text { in the Programme Board, as well } \\
\text { as representatives and experts of } \\
\text { the two agencies RCN and } \\
\text { GASSNOVA } \\
\text { - The Programme Plan covers the } \\
\text { entire innovation chain }\end{array}$ & $\begin{array}{l}\text { - Joint initiative led by two agencies, } \\
\text { each of them managing a } \\
\text { component of the programme } \\
\text { - Numerous interactions between the } \\
\text { two agencies within the joint } \\
\text { secretariat of the programme } \\
\text { - Lean governance structure } \\
\text { - Only one ministry funding and } \\
\text { engaging in the programme } \\
\text { - Implementation of a project port- } \\
\text { folio approach that allows an } \\
\text { exploration of the technological } \\
\text { landscape, different generations of } \\
\text { technologies and a greater } \\
\text { coverage of the different market } \\
\text { segments and components of the } \\
\text { CCS value chain }\end{array}$ & $\begin{array}{l}\text { - Articulation between the support to } \\
\text { R\&D and demonstration } \\
\text { - Different types of instruments } \\
\text { mobilised by the two agencies to } \\
\text { support the selected projects } \\
\text { - Hands-on approach of the agen- } \\
\text { cies, in particular Gassnova, dense } \\
\text { interactions with project partners }\end{array}$ \\
\hline
\end{tabular}

\subsection{Options for promoting a mission-oriented approach}

Norway has therefore some framework conditions that provide sound foundations for a missionoriented approach, and it has already moved forward along the policy learning curve thanks to early MOIP initiatives. Maybe as important is the fact that the concept and practice of MOIPs is now starting to spread in the political and policy arenas.

Yet, there is room for policy improvement and pushing forward a mission-oriented approach. More than a given state of mission-orientation, one should consider the potential for progress along the national 'MOIP trajectory', i.e. the evolutionary patterns of how a country can move towards more systemic policies under mounting pressure to address complex societal challenges. Norway is clearly following a more bottom-up and decentralised approach whereby agencies jointly play a key role in experimenting and implementing specific systemic policy initiatives. Understanding this policy trajectory leads to proposing some options for moving forward to the 'next stage' of missionorientation. Two options are proposed: scaling-up or elevating MOIPs. They are summarised in Table 11 and presented in more details in the following sections. 
Table 11. Two strategies for pushing further a MOIP approach in Norway

\begin{tabular}{|c|c|c|c|}
\hline Option for changes & Content & Opportunities & Challenges \\
\hline Scaling-up MOIPs & $\begin{array}{l}\text { - Enlarging the existing } \\
\text { MOIP schemes } \\
\text { And/or } \\
\text { - Replicating the existing } \\
\text { MOIP schemes in other } \\
\text { challenge areas }\end{array}$ & $\begin{array}{l}\text { - Rather consensual and low visibility } \\
\text { policy instrument, no political } \\
\text { opposition } \\
\text { - Does not require societal change } \\
\text { - Build upon initiatives that have } \\
\text { proved their effectiveness and } \\
\text { benefit from strong support from } \\
\text { industry }\end{array}$ & $\begin{array}{l}\text { - Enlarging the 'Pilot- } X \text { ' type of } \\
\text { scheme risk losing its } \\
\text { accelerator/intensifier effect } \\
\text { - The 'Pilot-X' type of scheme is not } \\
\text { universal, can only be implemented } \\
\text { in areas fulfilling certain conditions } \\
\text { - Less fit for 'transformer' missions }\end{array}$ \\
\hline Elevating MOIPs & $\begin{array}{l}\text { - Setting a process for } \\
\text { selecting and } \\
\text { implementing a few } \\
\text { national missions }\end{array}$ & $\begin{array}{l}\text { - Can aim for and support ambitious } \\
\text { and transformational change } \\
\text { (including for instance the transition } \\
\text { from O\&G) }\end{array}$ & $\begin{array}{l}\text { - Can raise strong political opposition } \\
\text { and resistance from interest groups } \\
\text { - Requires strong leadership from } \\
\text { high level decision makers not to } \\
\text { end with large/diluted missions } \\
\text { - Necessitates important financial } \\
\text { resources }\end{array}$ \\
\hline
\end{tabular}

International research collaboration being one of Norway's main priorities, it is important that the European dimension is clearly integrated in the choice and implementation of these options. The national mission-oriented policy initiatives should serve as a stepping-stone for Norwegian actors to participate in and contribute to the realisation of the Horizon Europe's missions.

\subsubsection{Scaling-up MOIP initiatives}

The scaling-up option consists in expanding the range and scope of current mission-oriented policies. This can be done in two main ways:

1. Enlarging the existing MOIP schemes, for instance towards new group of options in the area of emission-free transportation. However, one of the strengths of these schemes relies upon their focused and targeted scope to genuinely have an accelerator effect, based on dense 'qualitative' interactions and trust between the public and private partners, across sectors and policy fields. Any scaling up of these initiatives should not come at the expense of this advantage. On the contrary, a certain 'deepening' seems to be needed to improve the articulation between the supply and demand sides in Pilot-E and, even more, CLIMIT. The Energi21 Platform recommended the implementation of this option in its latest strategy launched in the 2018. It advised the government to further develop a unified framework of funding instruments along the entire innovation chain and strengthen the PILOT-E funding scheme for enhanced supplier development and value creation within selected technology areas. For this to be possible, it recommended significant increase of funding: from a total budget of NOK 100 million in 2018, the budget should increase to a total of 300 million for the period 2019-2022 (Energi21, 2018).

2. Building on these experiences, systematising the targeted inter-agency MOIP schemes. Agencies can replicate such schemes in other areas, under a clear joint mandate from their principals which would allow for greater and better portfolio approaches. This is already the case using RCN's Pilot-X schemes in the transport area and probably soon in the health (Pilot-H) or bio-economy (Pilot-B, focusing on aquaculture and timber) areas. The White Paper on Health 2018-2019 recommends that the government "study how a combination of research and innovation policy instruments can contribute to a more coherent process towards the implementation of new technology and new solutions in the health and care service" (MTIF, 2018) A key question relates to the domain of relevance of such schemes, i.e. in which challenge areas they could be useful and effective. They are most effective when the sector is well-established and already benefits from a strong competitive position, and that the country covers almost the whole value chain, including the users/buyers of the 
product or service. An inventory of MOIP initiative suggests that this type of 'accelerator' mission-oriented scheme works better in established fields, and certainly performs less well to establish new areas (European Commission, 2018 $\left.{ }_{[3]}\right)$. In any case Norway will need to identify clearly the areas where it is relevant to create such initiative; ii) the process by which the relevant community of actors can be mobilised (leveraging the 21- Platforms, the relevant agencies and regulators for instance). ${ }^{3}$

The Energi21 Platform recommended this option in its latest strategy launched in the 2018. It advised the government to further develop a unified framework of funding instruments along the entire innovation chain and strengthen the PILOT-E funding scheme for enhanced supplier development and value creation within selected technology areas. For this to be possible, it recommended significant increase of funding: from a total budget of NOK 100 million in 2018, the budget should increase to a total of 300 million for the period 2019-2022 (Energi21, 2018).

Recommendation for the MOIP scaling up option

The Norwegian government should give an informal 'mission' task force a mandate to identify the challenge areas where it would be relevant to create 'accelerator MOIPs' following to a greater or lesser extent the 'Pilot-X' model. This task force could be composed of RCN and other agencies' representatives involved in the support to research and innovation - IN, SIVA, ENOVA, Gassnova, etc. The mandate of this task force would include notably:

i) an analysis of the area-specific structural factors that are conducive to such approach (e.g. competitive position of Norway in the area; coverage of the value chain in Norway; prospect of technological/social change; cross-sectoral scope of the underpinning challenge; etc.)

ii) identification of potential challenge areas (as well as potential sub areas and related challenges);

iii) the challenge areas' specificities that would require adaptation to the 'Pilot-X' model;

iv) the process by which the relevant community of actors could be mobilised (e.g. leveraging the 21- Platforms, the relevant agencies and regulators, etc.).

v) the needed policy changes in the different identified challenge areas (e.g. providing the relevant agencies the needed mandate and flexibility to set up and implement joint schemes)

\subsubsection{Elevating MOIPS}

Public bodies can work to elevate the mission-oriented initiatives above the level of agencies, i.e. at the level of ministries and centre of government. This option is more challenging since it entails a strong direct involvement of higher-level public bodies in the strategic and coordination process. While in Norway some of the political leaders seem already sensitised to the concept of missionoriented policies thanks to agencies' initiatives, it proves more difficult to make this the case for larger and more 'transformer' missions than for the 'accelerator' type.

An active support from industry associations, employer associations, the powerful unions but also other stakeholder communities will also be key. This necessitates inspirational, i.e. not technocratic, missions resulting from a transparent and democratic process. Some international examples of broad and diluted missions (most of the time resembling more 'mission areas' than 'missions' per se) are available to recall that only the combination of a broad consultation to generate and discuss potential missions and a strong leadership to make a final choice, since no mission set can satisfy all interest groups, can result in relevant and powerful missions.

It also requires an identification of relevant framework and 'vehicle' to host a more top-down mission-oriented policy initiative. The next revision of the Long-Term Plan for Research and Higher Education which will start in 2021 could represent an important opportunity if the relevant policy ministries agree on structuring the plan around (or include within it) some clear and selective missions. MER, which leads the process, already indicated that it aims to make the next Plan more 
focused, better coordinated across the policy landscape and with societal challenges featuring more prominently. All these changes would be very conducive to a national mission-oriented approach. While it cannot be considered as a MOIP from what currently stands, the LTP could become one or at least supportive of such approach, paving the way towards its adoption. The German High Tech Strategy for instance evolved from a technology-based to a mission-oriented strategy. Although it still has some way to go before being considered a fully-fledged MOIP, it has made significant stride towards it, inserting the missions (or mission areas at this stage) at the heart of the German STI system and providing some holistic coordination mechanisms to monitor its implementation (Box $6)$.

\section{Box 6. The German High Tech Strategy: from a technology-based to a mission-oriented strategy}

The first HTS was launched in 2006 by the German government as a comprehensive national strategy that defines the objectives and milestones of the Federal Government's research and innovation (R\&I) policy. The German High-Tech Strategy 2025 is the fourth edition and was adopted in September 2018. It is a comprehensive, inter-ministerial strategy that aims to guide the German economy towards its objective of 3.5\% of GDP in R\&D in 2025 (3.13\% in 2018). This should be achieved by improved coordination of actors at the ministerial level, and improved dialogue between science, industry and society with a stronger focus on scientific communication and participation. The High Tech Strategy (HTS) 2025 is structured around three main 'fields of action': tackling the grand challenges; developing future competencies; establishing an open innovation and venture culture.

Regarding grand challenges, 6 focus areas and 12 mission areas aim to guide joint efforts of science, industry, civil society and policy makers across the various ministries around common objectives. Although they are still closer to mission areas than genuine missions (i.e. with clear target performance and deadlines), they are meant to be an essential tool for the implementation of the strategy. Examples of missions are 'Combating cancer', 'Substantially reducing plastic pollution of the environment' and 'Achieve substantial greenhouse gas neutrality in industry' (80-95 per cent less greenhouse gas emissions by 2050 than in 1990). Within each mission, the strategy expanded its concept of innovation to include not only technological innovation but also social innovation. Activities in the fields of science, research and innovation are now seen as enablers to contribute to solutions for global societal challenges.

The HTS is led by the Federal Ministry of Education and Research. As a comprehensive national strategy, it includes almost all federal ministries, and improves coordination of relevant actors at the ministerial level and in higher education and research institutions as well as the private sector. The strategy is coordinated through the so-called 'Round Table of State Secretaries on HTS $2025^{\prime}$. This is new intra-governmental coordination mechanism whose task is to define, steer and shape innovation policy agendas along the priorities of the HTS 2025. The Strategy also has a central advisory council, the High-Tech Forum. This body has no decision power, but it discusses with policy makers during its meetings and its deliberations are constantly passed on to the Round Table of State Secretaries. The Federal Government and the Fraunhofer-Gesellschaft share the chairmanship in order to ensure a close link between the Forum and policymakers. The strategy acts as the coordinative umbrella framework for Germany's federal government research and innovation (R\&I) policies, and has the primary function of a policy coordination tool.

The HTS 2025 document includes concrete research and innovation policy initiatives planned for the period 2018-2021 for several of the focus areas as well as horizontal goals (skills, support to SMEs etc.).

Source: OECD (2021), The design, governance and implementation of Mission-oriented policy to address societal challenges, final report, OECD Publishing, Forthcoming.

Building upon the positive experience of Pilot-E and CLIMIT, agencies which account for the bulk of the strategic analytical capabilities in the Norwegian STI policy system have a key role to play to 
propose a convincing framework to the centre of government and ministries. RCN has planned to launch a broad-based, inclusive, forward-looking process in 2020 to identify key Norwegian focus areas for the future. The results of this process will form the basis for the agency's input to the next revision of the Long-term Plan for Research and Higher Education. This could be the occasion to make the case for a transition from priority areas to mission areas and propose a cross-sectoral and cross-ministerial process to develop missions within these areas in the first year of the new term (RCN, 2020a). Last but not least, the LTP will have to include more prominently the industrial innovation dimension. Led by MER, the LTP remains to a great extent a higher education, research and research-based innovation plan (as its name suggests). A more active role of the Prime Minister office, and/or an ad hoc committee in charge of the monitoring of the Plan, ${ }^{4}$ could help make the Plan more holistic. Since these missions should have a concrete effect on the prioritisation of resources and might require some diversion from budgeted practices, the Ministry of finance will need also need to be on board.

With regards to the role of the centre-of-government and the implementation of a top-down missionoriented approach, Japan offers an interesting example to contrast with that of Norway. While such model would not be relevant to the Norwegian culture, institutional setting and political system, it is still valuable to consider in apprehending the range of MOIP trajectories and see whether Norway could, in its own way, start shifting toward a more coordinated and top-down model (Box 7).

\section{Box 7. Japan's gradual building of a Cabinet Office-led mission-oriented policy}

The review of the evolution of the Japanese STI system governance since the 1970s along the three dimensions of mission-orientation reveals that many of the essential features of missionorientation have been gradually developed and enhanced in particular in the last two decades. Some of these features were already present in MITI's goal-oriented model of industrial policy up until the end of the 1980s, however in very different forms. As Japan reached the technological frontier, the 1990s marked a transition with repeated calls for a new role of the State confined to the support to basic research and the setting of conducive framework conditions for innovation. However, as early as the mid-1990s, a new policy trajectory was initiated with the launch of the First Basic Plan. The successive Basic Plans have significantly evolved throughout the last 25 years, gradually adopting features that are consistent with a MOIP approach. Along these changes, the governance of the Japanese STI system has become more result-oriented, centrally designed and coordinated, as well more precise and 'hands-on':

- Basic Plans are increasingly geared towards specific goals (in particular those related to societal challenges) instead of being structured around disciplines or sectors;

- The Cabinet office, notably through its successive high-level STI councils, has become prominent to develop and implement the Basic Plans;

- The Basic Plans - which only provided the general strategic framework - are now accompanied and implemented through precise annual action plans.

STI policy has become more top-down, with strong directionality provided by the centre-ofgovernment bodies, in particular the Cabinet Office and the successive high level STI councils (the Council for Science and Technology Policy [CSTP] since 2001, the Council for Science, Technology and Innovation [CSTI] since 2014, complemented by the Integrated Innovation Strategy Promotion Council since 2018).

Besides providing stronger top-down strategic orientations, the role of this policy approach is to improve inter-ministerial coordination in the STI area. Reducing silos between MEXT (research and education) and METI (economy and industry) has been a long-standing priority in Japan in order to promote science and technology and innovation in an integrated manner. More recently, the scope of policy coordination extended to sectoral ministries as more emphasis was put on tackling societal challenges. Since some of the barriers to inter-ministerial coordination 
persisted, the reaction of successive governments was to strengthen the role of the high-level STI councils (CSTP, then CSTI). As it is the case for strategic orientation, CSTI was progressively granted more prerogatives for holistic coordination, for instance in the process of formation of ministries' budgets. These extended competencies and the creation of new central policy bodies in the Cabinet Office to support policy coordination in priority areas tend however to raise the complexity of the governance of the STI system.

The last stage of this evolution was the decision to provide CSTI with a large budget to operate its own STI programmes, rather than only trying to coordinate ministries' programmes. New topdown 'mission-oriented' strategic programmes led by the CSTI and supported by the Cabinet Office secretariat aim to increase universities and research institutes contribution to some selected national priorities, in close collaboration with industry. The Cross-ministerial Strategic Innovation Promotion Program (SIP) since 2014 and the Moonshot programme since 2019 represent two types of mission-oriented policies. The former aim to provide cross-ministerial support to accelerate innovation while the latter is a typical challenge-based programme that seek to produce technological breakthrough. Both have in common to focus on commonly established priorities and, inspired by the DARPA model of programme management, to grant extended power to selected programme directors in each theme or challenge. The ImPACT programme launched in 2014 to promote high-risk high-reward research also has some MOIP features.

Source: OECD (2021), Challenges and opportunities of mission-oriented innovation policy in Japan, STI Policy Paper, https://doi.org/10.1787/23074957.

$\mathrm{RCN}$ is engaged in promoting a national policy agenda addressing 'mission-oriented industrial challenges', as discussed with members of its International Advisory Board. ${ }^{5}$ It has for instance considered national missions in zero-emission maritime transportation (based on the Pilot-E experience) as well as in the offshore wind area, building notably on the technology and skills developed in the oil and gas sector. These proposed national missions were selected in great part on the basis of their broad coverage in terms of sectors, which allows to engage a wide range of actors and create multiple business opportunities (Figure 16).

\section{Figure 16. Example of national mission proposal by RCN: Zero-emission maritime transport}

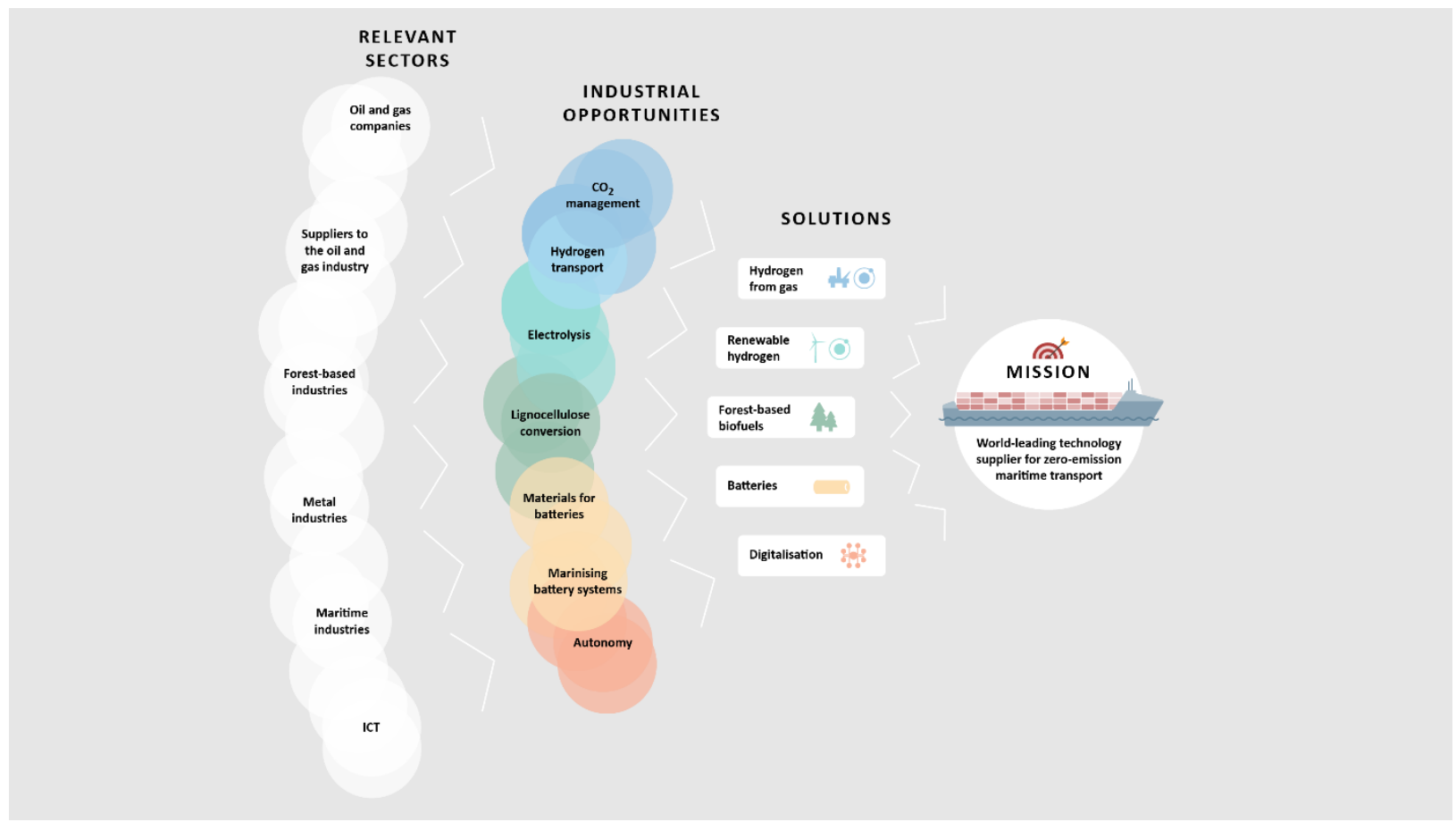


Source: Unander F.F. (2019), Accelerating technology development from laboratory to market - Norwegian experiences, Presentation at the IEA Energy Technology Perspectives workshop, 18 December 2019, Paris, RCN.

RCN also mobilised its International Advisory Board in 2019 and 2020 to receive recommendations as to how Norway could more thoroughly implement a MOIP approach and what could be the role to support the initiation and implementation of such approach (RCN, 2020b). The policy brief highlights the conducive framework conditions for MOIP:

- The overall capacity for social dialogue through tri-partite cooperation;

- The sector principle of R\&D policy implies that each sectorial ministry is responsible for $\mathrm{R} \& \mathrm{D}$ policy in their sectors or areas, creating coordination costs but also seeing R\&D as key to achieving their goals. Missions may provide incentives to stronger collaboration across policy areas;

- The 21-processes are multi-stakeholder commissions responsible for prioritization in key areas of Norwegian research and innovation policy, providing a bottom-up perspective on priorities to be chosen.

- Norway has a mixed economy in which the role of the state is relatively large. This may not have a direct bearing on the relevant capacities, but it illustrates that economic policy does not rely singularly on market failure corrections.

The resulting recommendations are very consistent with the conclusions and options of the present case study. The main recommendations are as follows:

1. Norway should more actively embrace mission-oriented policy to address manifest challenges;

2. Norway should reserve a mission-oriented policy for challenges for which direction-setting and momentum can help overcome inertia and barriers to change;

3. Selecting missions should be based on Norwegian challenges and explicit criteria to ensure robustness and legitimacy;

4. Leadership and governance should be acknowledged as key to implementation of missions;

5. The government should respond to urgency with a mission to address the climate crisis.

Building upon the sense of urgency related to the climate crisis, the "mission- 01 " called for by the last recommendation could be a pilot of the approach proposed in the 'elevating' option. This is also in line with a recommendation from CIVITA that calls for a "super project" aiming to support Norway's 'green-shift' using a mission-oriented approach (CIVITA, 2019). The need for coordination with Horizon Europe (2021-27), which Pillar 2 includes 5 mission areas, each of them including one or several missions, is also an opportunity for pushing further a national mission strategic framework in Norway.

However, as previously mentioned, the choice of the missions should be politically -riven and endorsed by the highest level of policy making, i.e. the Prime Minister Office and/or Cabinet and validated by the Storting. A dedicated cross-ministerial governance structure could lead and monitor this mission, possibly in relation with the coordination of the revised Long Term Plan. 
Recommendation for the 'elevating' option

The Norwegian government should take the opportunity of the future revision of the Long-term Plan for Research and Higher Education in 2021 to initiate a 'national mission-oriented approach', starting with a pilot mission to be programmed in the four-year investment plan of the next LTP (with dedicated multi-year funding). This pilot mission would coexist with and cut across the broader and more comprehensive LTP thematic priorities. The selection of the mission would involve proper high-visibility events and initiatives to ensure a strong involvement of stakeholders from different interest groups and the wider public. This process could build upon the interdepartmental groups that had been in function during the first four years of the Long Term Plan. It would be supported and, finally, endorsed, by the highest political and policy level. This could include: the Prime Minister office; the Cabinet, the Ministry of finance, the Storting. The academic and grey literature offers some valuable insights on the criteria and process for selecting missions. These should be considered when developing the 'Norwegian way to MOIPs' (see Box 8).

The progress of this pilot mission will be reviewed after the first four-year period. Decisions will be made to continue this mission and, if deemed relevant, add other missions as part of the fourth edition of the LTP. 


\section{Box 8. Criteria and process to select challenges and missions}

Mazzucato in her study commissioned by the European Commission proposes five criteria to select a challenge (European Commission, 2018 $\left.{ }_{[4]}\right)$ ). They should be:

- Bold, inspirational with wide societal relevance in order to engage the public at large;

- Targeted, measurable and time-bound to clearly frame the mission;

- Ambitious in terms of research and innovation actions but realistically feasible within the timeframe;

- Cross-disciplinary, cross-sectoral and cross-actor innovation;

- Open to multiple, bottom-up solutions.

A report commissioned in 2019 by RCN to Technopolis Group to support its reflections about how to improve Norwegian innovation policy, in the light of the recommendations of the 2017 OECD innovation system review of Norway, proposes the following steps for setting national missions (Technopolis, 2019):

- A broad consultation encompassing citizens, businesses, the state and the research community to identify a set of societal challenges that could be tackled and to ensure the social legitimacy of including them among possible candidates;

- A selection process reducing the number of challenges to be considered to, perhaps, half a dozen;

- A foresight exercise involving panels of informed citizens and stakeholders in creating desirable scenarios involving intervention, setting out the expected impacts and explicitly identifying the unique contributions Norway could make and the benefits to Norway (in business as well as social terms) of doing so. It is especially important that relevant ministries are involved, as they will play big roles in funding and implementing the interventions;

- A final selection process which assesses the proposed scenarios and selects perhaps three for implementation, based primarily on the amount of economic benefit thought likely to accrue to Norway. This is likely to be a good indicator of Norway's overall contribution to addressing the societal challenges;

- The government has to own the selection process and its results and devote considerable effort to communicating the results of its process back to the citizens, showing how this connects with the original consultation. 


\section{References}

Borowiecki, M. et C. Paunov (2018), "How is research policy across the OECD organised?: Insights from a new policy database", OECD Science, Technology and Industry Policy Papers, No. 55, OECD Publishing, Paris, https://doi.org/10.1787/235c9806-en.

CIVITA (2019), Innovasjonspolitikken trenger en tydeligere liberal retning (Innovation policy needs clearer directions), CIVITA Note, 29, https://www.civita.no/wp/?download=65657\&file=Notat 292019 Innovasjonspolitikken-trenger-entydeligere-liberal-retning.pdf

CLIMIT (2017), CLIMIT Programme Plan 2017-2022, CLIMIT HQ.

CLIMIT (2019), CLIMIT 2018 - Summary, CLIMIT HQ.

Deloitte (2019), Områdegjennomgang av det næringsrettede virkemiddelapparatet (Review of the businessoriented policy instruments), Report to the Ministry of Finance and the Ministry of Trade, Industry and Fisheries, https://www.regjeringen.no/no/dokumenter/vmg/id2677304/

Energi21 (2018), National strategy for research, development, demonstration and commercialisation of new, climate-friendly energy technology, Energi21, https://www.energi21.no/siteassets/energi21strategi20181r.pdf

European Commission (2018), Mission-oriented research and innovation: Inventory and characterisation of initiatives, Final Report, Study prepared for the European Commission, DG Research and Innovation, http://dx.doi.org/10.2777/697082.

FHF (2019), Research and development - By the industry - for the industry, Norwegian Seafood Research Fund, https://www.fhf.no/media/1371/fhf_engelsk_2019 21x21_emag_spreads.pdf

Government of Norway (2016), Familiar resources - undreamt of possibilities - The Government's Bioeconomy Strategy, https://www.regjeringen.no/contentassets/32160cf211df4d3c8f3ab794f885d5be/biookonomi-engkortversjon_uu.pdf

IEA (2020), The Oil and Gas Industry in Energy Transitions, IEA, Paris https://www.iea.org/reports/the-oil-andgas-industry-in-energy-transitions

Innoba (2019), Evaluation of Innovation Norway’s public-private Innovation Partnership Programme, Innoba.

Innovation Norway, 2019, Strategy 2020-2025, Innovation Norway.

JRC (2017), Analysis of national public research funding (PREF), Final Report, https://ec.europa.eu/jrc/en/publication/analysis-national-public-research-funding-pref-final-report

JRC (2016), RIO Country report 2015 - Norway, JRC Science for Policy Report, Joint Research Center, European Commission, https://rio.jrc.ec.europa.eu/country-analysis/Norway/country-report.

Kallerud E., Sarpebakken B. (2020), Realnedgang i bevilgningene til forskning i 2020, innfløkt prioriteringsbilde, Forkningspolitikk, https://www.fpol.no/realnedgang-i-bevilgningene-til-forskning-i-2020-innfloktprioriteringsbilde/. 
Kuhlmann, S., Rip, A. (2016), How the Norwegian research system could cope with grand societal and economic challenges: Report to the Research Council of Norway. Research Council of Norway,

https://doi.org/10.13140/RG.2.1.3052.8883

Larrue, P. (2021), "The design and implementation of mission-oriented innovation policies: A new systemic policy approach to address societal challenges", OECD Science, Technology and Industry Policy Papers, No. 100, OECD Publishing, Paris, https://doi.org/10.1787/3f6c76a4-en.

MER (2014), Long-term plan for research and higher education 2015-2024, Meld. St. 7

(2014-2015) Report to the Storting (white paper), Ministry of Education and Research, https://www.regjeringen.no/en/dokumenter/meld.-st.-7-2014-2015/id2005541.

MER (2018), Long-term plan for research and higher education 2019-2028 - Meld. St. 4 (2018-2019), Report to the Storting (white paper), Ministry of Education and Research,

https://www.regjeringen.no/contentassets/9aa4570407c34d4cb3744d7acd632654/en$\mathrm{gb} / \mathrm{pdfs} / \mathrm{stm} 201820190004000$ engpdfs.pdf

MTIF (2018), The health industry, Meld. St. 18 (2018-2019), Report to the Storting (white paper), Ministry of trade, Industry and Fisheries, https://www.regjeringen.no/en/dokumenter/meld.-st.-18-20182019/id2639253/ .

MTIF (2016), White paper on industrial policy - a greener, smarter and more innovative industry, Meld. St. 27 (2016-2017), Ministry of trade, Industry and Fisheries, https://www.regjeringen.no/contentassets/9edc18a1114d4ed18813f5e515e31b15/en$\mathrm{gb} / \mathrm{pdfs} / \mathrm{stm} 201620170027000$ engpdfs.pdf

Moengen T. (2018), Pilot E - Fast track from concept to market, Presentation in Copenhagen, 26th of June.

OECD (2021), Challenges and opportunities of mission-oriented innovation policy in Japan, STI Policy Paper, https://doi.org/10.1787/23074957.

OECD (2020), Innovation, Agricultural Productivity and Sustainability in Norway, OECD Forthcoming.

OECD (2019a), Measuring Distance to the SDG Targets 2019: An Assessment of Where OECD Countries Stand, OECD Publishing, Paris, https://doi.org/10.1787/a8caf3fa-en.

OECD (2019b), Government at a Glance 2019, OECD Publishing, Paris, https://dx.doi.org/10.1787/8ccf5c38-en.

OECD (2019c), RD tax incentives : Norway, 2019, http://www.oecd.org/sti/rd-tax-stats-norway.pdf.

OECD (2017a), OECD Reviews of Innovation Policy: Norway 2017, OECD Reviews of Innovation Policy, OECD Publishing, Paris, https://doi.org/10.1787/9789264277960-en.

OECD (2017b), "Business R\&D intensity adjusted for industrial structure, 2015: As a percentage of value added in industry", in OECD STI Scoreboard, OECD Publishing, Paris, https://doi.org/10.1787/sti scoreboard-2017graph141-en. Productivity Commission (2016), At a Turning Point: From a Resource-Based Economy to a Knowledge Economy, Official Norwegian Report (NOU) 2016: 3 5, https://produktivitetskommisjonen.no/files/2013/11/summary NOU2016 3.pdf 
RCN (2020a), Empowering ideas for a better world - Strategy for the Research Council of Norway 2020 - 2024, RCN, https://www.forskningsradet.no/contentassets/0b1 fe1ef42e 7435fa7d37e3a4d7dfdc6/strategi_20202024 en.pdf

RCN (2020b), Mission-oriented policy for Norway, Policy Brief from the RCN International Advisory Board.

RCN (2019a), Science \& Technology Indicators for Norway 2019, Research Council of Norway, https://www.forskningsradet.no/contentassets/c13c9822d47542108d768dfb4a8479c4/scienceand-technology-indicators-for-norway-2019 20.12.19 final.pdf

RCN (2019b), Pilot-E evaluation criteria (in Norwegian) : https://www.forskningsradet.no/contentassets/83e559cd624e492e9c1cd2b5ddb8b2f7/pilot-e2019-kriterier-og-evaluering.pdf

RCN (2018), Research for Sustainable Societal and Industrial Development - The Research Council of Norway's Strategy for Sustainability 2017-2020, https://www.forskningsradet.no/siteassets/publikasjoner/1254028329452.pdf

RCN (2015), Forskning for innovasjon og bar ekraft - strategi for norges Forskningsråd 2015-2020, Research Council of Norway, https://www.forskningsradet.no/siteassets/publikasjoner/1254011148537.pdf

Schwaag Serger, S., P. Larrue and C. Smith (2017), Research and innovation in health and care in Norway: Case study, OECD, https://www.oecd.org/norway/research-and-innovation-in-heath-and-care-in-norway.pdf.

SØA (2019), Norwegian industry-related RI policy agencies, measures and beneficiaries, SOA.

Technopolis (2019), Raising the Ambition Level in Norwegian Innovation Policy Final Report, Technopolis Group, https://www.forskningsradet.no/contentassets/9adfcaff0c4a48538c208024abd12b99/technopolisnaringsrettede-virkemidler.pdf.

Unander F.F. (2019), Accelerating technology development from laboratory to market - Norwegian experiences, Presentation at the IEA Energy Technology Perspectives workshop, 18 December 2019, Paris, RCN.

Volla R. (2019), Pilot E - Norwegian cross-agency scheme for transport and energy solutions, Presentation at the MOIP OECD workshop, 25/09, Vienna. 


\section{Annex A. List of interviews}

\section{List of Interviewees}

\begin{tabular}{|c|c|}
\hline Institution & Name and title \\
\hline $\begin{array}{l}\text { Ministry of Research and Higher } \\
\text { Education (MER) }\end{array}$ & $\begin{array}{l}\text { Ingvild Larsen Marheim, Director } \\
\text { Anne Karine Nymoen, Leader Strategy and Long term Plan }\end{array}$ \\
\hline $\begin{array}{l}\text { Ministry of Trade, Industry and } \\
\text { Fisheries (MTIF) }\end{array}$ & $\begin{array}{l}\text { Tone Evje, Deputy Director, Research and innovation Department } \\
\text { Carl Gjersem, Specialist director, Research and Innovation Analysis } \\
\text { Anne-Mari Voll, Senior Adviser }\end{array}$ \\
\hline Innovation Norway & $\begin{array}{l}\text { Eva Camerer, Head of Innovation policy } \\
\text { Åke Refsdal Moe, Strategy and Innovation policy }\end{array}$ \\
\hline $\begin{array}{l}\text { Ministry of Petroleum and Energy } \\
\text { (MED) }\end{array}$ & $\begin{array}{l}\text { Bjorn Haugstad, Director General, Climate, industry and Technology } \\
\text { department } \\
\text { Torgeir Knutsen, Deputy Director General, Climate, industry and } \\
\text { Technology department }\end{array}$ \\
\hline $\begin{array}{l}\text { Research Council of Norway } \\
(\mathrm{RCN})\end{array}$ & $\begin{array}{l}\text { Anne Kjersti Fahlvik, Executive Director } \\
\text { Randi Søgnen, Chief of Staff } \\
\text { Svend Otto Remøe, Special Adviser } \\
\text { John-Arne Røttingen, Chief Executive } \\
\text { Sven Olav Nås, , Special Adviser } \\
\text { Katrine Wyller, Special Adviser, Energix Programme } \\
\text { Trond Moengen, project leader of PILOT E scheme } \\
\text { Aage Stangeland, Special Adviser, CLIMIT Programme } \\
\text { Fritjof Fossum Unander, Executive Director } \\
\text { Rune Volla, Director of the Department for Energy } \\
\text { Kjell Emil Naas, Special Adviser, Havbruk programme } \\
\text { Marianne Haavardsholm Aandahl. Special Adviser, Higher Education } \\
\text { Philip Lorentzen Special adviser }\end{array}$ \\
\hline Gassnova & Ingrid Sørum Melaaen, Director of CLIMIT Programme \\
\hline Energi Norge & Eivind Heløe, Director \\
\hline $\begin{array}{l}\text { FFA (Association of Research } \\
\text { Institutes) }\end{array}$ & Agnes Landstad, Operating manager \\
\hline $\begin{array}{l}\text { Abelia (business association of } \\
\text { Norwegian knowledge and }\end{array}$ & Eline Oftedal, Head of innovation and business development \\
\hline
\end{tabular}


technology based enterprises)

Nordic Institute for Studies in Per Koch, Special Adviser and redactor

Innovation, Research and

Education (NIFU) $\quad$ Espen Solberg, Head of Research

Norwegian Institute of Public Camilla Stoltenberg, CEO, , Chair

Health (NIPH)

ENOVA (agency of the Ministry Anita Fossdal, Senior Adviser

of Climate and Environment) 


\section{Endnotes}

${ }^{1}$ Other MOIP national case studies are Austria, Japan and Korea.

2 The low R\&D intensity of Norway is at least partly related to the weight of resource-based industries in its economy. These industries have structurally low level of R\&D compared their value added, hence reducing the overall GERD. The effect can be significant: in 2015, the OECD calculated that the Business R\&D intensity adjusted for industrial structure was $2.7 \%$ of industry added value (while the 'official' non adjusted Business R\&D intensity was $1.7 \%$ ). This was above the OECD average (but still below countries like Finland, Denmark, Austria or France) (OECD, 2017b).

${ }^{3}$ In particular since the mid-2000s. Norway's government-financed GERD (normalised by the GDP) was only slightly above the OECD average in 2005 ( 0.65 for Norway, 0.63 for the OECD). Results are similar when considering Norway's government-financed GERD non normalised by the GDP (in 2018 , the Norwegian government funded about $48 \%$ of the GERD, to be compared with an OECD average of $25 \%$ ).

${ }^{4}$ However, direct funding represented only $45 \%$ of total government R\&D funding in 2017 , following a strong increase of indirect R\&D support (see infra 'policy implementation' section).

${ }^{5}$ ENOVA is a national agency that aims to contribute to environmentally sound and rational use and production of energy. It mainly relies on financial instruments and incentives to stimulate market actors and mechanisms to support the transformation to a low-emission society.

${ }^{6}$ Along with ground-breaking research and radical innovation and restructuring in the business and public sectors. Together these three objectives echo the three objectives of the LTP.

${ }^{7}$ The total national engagement on ocean related R\&D is close to 8000 mill NOK, which means that most of the national expenditures are funded outside RCN.

8 . It is worthwhile noticing that the number of projects on petroleum research has also increased from to 206 to 283 during the same period. https://prosjektbanken.forskningsradet.no/ consulted on August 4.

9 Based on data presented on the Innovation Norway website: https://www.innovasjonnorge.no/en/start-page/about/facts-and-numbers/.

${ }^{10}$ Notably MTIF and the Ministry of Agriculture and Food (Kallerud and Sarpebakken, 2020).

${ }^{11}$ They are in place in 31 of 35 (89\%) OECD countries and 15 were created since 2007 (Borowiecki and Paunov, 2018). 
${ }^{12}$ Norway is the third OECD country with the highest level of confidence in national government in 2018 (OECD, 2019b).

${ }^{13}$ See https://www.energi21.no/en/2018-strategy/

${ }^{14}$ https://www.norwayexports.no/new-development-licenses-spur-ocean-farming/.

https://salmonbusiness.com/ceo-of-the-norwegian-seafood-federation-calls-innovation-projectspossible-groudbreaking-for-norwegian-aquaculture-industry/

${ }^{15}$ This regulation seeks to ensure greater inclusion of common societal goals in the procurement process (environmental protection, social responsibility, innovation, combating climate change, employment, public health and other social and environmental considerations). The Article 31 stipulates that "where a contracting authority wishes to purchase goods or services, which are not currently available on the market, it may establish an innovation partnership with one or more partners. This allows for the research and development $(R \& D)$, piloting and subsequent purchase of a new product, service or work, by establishing a structured partnership".

See https://ec.europa.eu/environment/gpp/eu_public directives_en.htm

${ }^{16}$ This programme promotes the capacity and willingness of Norwegian trade and industry to innovate by providing support for R\&D projects based on companies' own strategies and challenges, independent of field or topic.

${ }^{1}$ The decision from the government in 2020 to invest massively in the implementation of CCS technologies relies at least partially on the progress accomplished in the follow up of the moonlanding mission.

${ }^{2} 100 \%$ of newly sold vehicles to be zero emission by 2025 for passenger and 2030 for light and heavy duty vehicles.

${ }^{3}$ During interviews, the development of a hydrogen economy (as an energy carrier and/or for final use) was also mentioned as a potential area for a Pilot-X scheme for Norway.

${ }^{4}$ Whether the current Cabinet and other current cross-ministerial mechanisms like the DFU are sufficient is still an option question. It is likely that the Cabinet would need to be reinforced to play a more active role, ahead and after the Cabinet meetings.

${ }^{5}$ RCN's International Advisory Board is an independent standing committee of international experts, appointed by its Chief Executive to provide advice on research and innovation policy. The Board meets twice a year. Mission-oriented policies have been on the agenda of the three last meetings of the IAB. A policy brief on mission-oriented policy for Norway has been prepared. It contains recommendations for next steps for both RCN and the Norwegian government. 